\title{
Abdominal hernias and adhesions
}

Citation for published version (APA):

van den Hil, L. C. L. (2021). Abdominal hernias and adhesions: foundations for research and prevention. [Doctoral Thesis, Maastricht University]. Maastricht University. https://doi.org/10.26481/dis.20210604lc

Document status and date:

Published: 01/01/2021

DOI:

10.26481/dis.20210604lc

Document Version:

Publisher's PDF, also known as Version of record

\section{Please check the document version of this publication:}

- A submitted manuscript is the version of the article upon submission and before peer-review. There can be important differences between the submitted version and the official published version of record.

People interested in the research are advised to contact the author for the final version of the publication, or visit the DOI to the publisher's website.

- The final author version and the galley proof are versions of the publication after peer review.

- The final published version features the final layout of the paper including the volume, issue and page numbers.

Link to publication

\footnotetext{
General rights rights.

- You may freely distribute the URL identifying the publication in the public portal. please follow below link for the End User Agreement:

www.umlib.nl/taverne-license

Take down policy

If you believe that this document breaches copyright please contact us at:

repository@maastrichtuniversity.nl

providing details and we will investigate your claim.
}

Copyright and moral rights for the publications made accessible in the public portal are retained by the authors and/or other copyright owners and it is a condition of accessing publications that users recognise and abide by the legal requirements associated with these

- Users may download and print one copy of any publication from the public portal for the purpose of private study or research.

- You may not further distribute the material or use it for any profit-making activity or commercial gain

If the publication is distributed under the terms of Article $25 \mathrm{fa}$ of the Dutch Copyright Act, indicated by the "Taverne" license above, 
Abdominal hernias and adhesions

Foundations for research and prevention 
Copyright (c) Leontine Charlotte Louise Clabbers-van den Hil, 2021

All rights reserved. No part of this thesis may be reproduced or distributed in any form or by any means, without the prior written permission of the author or the publisher.

Cover: P. Jansen

Layout: Tiny Wouters

Printing: Multicopy

ISBN: 9789090346618

Publication of this thesis was financially supported by Maastricht University and the department of surgery of the Maastricht University Medical Centre.

The work presented in this thesis was performed within NUTRIM School of Nutrition and Translational Research in Metabolism. 


\title{
Abdominal hernias and adhesions Foundations for research and prevention
}

\author{
PROEFSCHRIFT
}

ter verkrijging van

de graad van doctor aan de Universiteit Maastricht, op gezag van de Rector Magnificus, Prof. dr. Rianne M. Letschert, volgens het besluit van het College van Decanen,

in het openbaar te verdedigen

op vrijdag 4 juni 2021 om 16.00 uur

door

Leontine Charlotte Louise Clabbers-van den Hil

Geboren op 26 februari 1989

te 's-Gravendeel 


\section{Promotor}

Prof. dr. N.D. Bouvy

Copromotor

Dr. M.H.F. Schreinemacher (Hasselt)

\section{Beoordelingscommissie}

Prof. dr. L.P.S. Stassen (voorzitter)

Prof. dr. A.A.M. Masclee

Prof. dr. R.R.W.J. van der Hulst

Prof. dr. J.F. Lange (Erasmus Medisch Centrum)

Dr. M.S. Ibelings (Elisabeth-Tweesteden Ziekenhuis) 


\section{Contents}

$\begin{array}{lll}\text { Chapter } 1 & \text { General Introduction and outline of the Thesis. } & 7\end{array}$

$\begin{array}{lll}\text { Part I } & \text { Awareness of adhesions and scoring systems }\end{array}$

Chapter 2 Adhesion awareness in 2016: An update of the national 21 survey of surgeons.

Chapter 3 META score: an international consensus scoring system on mesh-tissue adhesions.

Part II Abdominal wall closure and hernia repair; experimental findings

Chapter 4 Prevention of incisional hernia using different suture materials for closing the abdominal wall; a comparison of PDS ${ }^{\circledR}$, Vicry $^{\circledR}$ and Prolene ${ }^{\circledR}$ in a rat model.

Chapter 5 Analysis of adhesion formation of a new elastic thermoplastic polyurethane (TPU) mesh in comparison to polypropylene (PP) meshes in IPOM position.

Chapter 6 MRI Evaluation of an Elastic TPU Mesh under Pneumoperitoneum in IPOM Position in a Porcine Model.

Part III A human model for adhesion assessment and hernia prevention

Chapter 7 Comparability of histological outcomes in rats and humans in a hernia model

Chapter 8 Prophylactic mesh placement to avoid incisional hernias after stoma reversal: a systematic review and meta-analysis.

Part IV Discussion

Chapter 9 General discussion and future perspectives

Part V Appendices

Nederlandse samenvatting (summary, in Dutch)

Valorisation

Dankwoord (Acknowledgements, in Dutch)

Curriculum Vitae 



\section{Chapter 1}

General introduction and outline of the Thesis 
The word surgery originates from the Greek words cheiros and ergon, which means as much as hand work. One of the first operations described is the so-called trephination of the skull. Ever since, surgery developed tremendously, especially with the introduction of general anesthesia and antiseptics. This modern surgery exists for only one and a half century and created the opportunity for intra-abdominal surgery. ${ }^{1}$ During this period, surgical techniques have undergone major developments, leading to improved outcomes.

However, post-operative complications still occur frequently. Late occurring complications after intra-abdominal surgery, include incisional hernias and intraabdominal adhesions, which may subsequently lead to bowel obstruction or abdominal pain. 2,3

This thesis investigates placement of intra-abdominal meshes for incisional hernia repair and prevention of incisional hernias, as well as formation of intra-abdominal adhesions to meshes.

\section{Abdominal wall hernia}

The abdominal wall consists of multiple layers, including the skin. Abdominal wall muscles and their associated fasciae are the main layers accounting for the strength of the abdominal wall. Weakness of these layers can cause hernias. ${ }^{4}$

An abdominal wall hernia is defined as an abnormal protrusion of intra-abdominal content through a defect or weakened region of the abdominal wall. ${ }^{5}$ Hernias can be congenital, develop spontaneously or are acquired. Congenital and spontaneously developed hernias are primary abdominal wall hernias and are named after the region in the abdominal wall in which they occur. ${ }^{6,7}$ The majority of acquired hernias develop after abdominal surgery and are called incisional hernias.

\section{Incisional hernia}

To enter the abdominal cavity, incisions can be made at several sites of the abdominal wall. An often chosen incision is the midline incision, which involves an incision through the linea alba. This procedure is fast, with minimal damage to muscles, nerves and blood vessels. $^{8}$

After closing a midline incision, healing will start following the general principals of tissue healing. This consists of four phases, starting with hemostasis, followed by the inflammatory, proliferative and maturation phase. The duration of the maturation phase differs between tissue types and in the case of aponeurotic healing this phase can continue for over one year. Although after one year the healed midline incision regained $60-90 \%$ of its original strength, it will never regain $100 \%$ of its strength. ${ }^{8,9}$

Taking this into account, it is comprehensible that the majority of hernias develop in the first two years postoperatively, but they can even develop after ten years. ${ }^{10}$ 
Incidences of incisional hernias up to $20 \%$ are reported after midline incisions. ${ }^{10,11}$ Risk factors for incisional hernias can be divided in patient and procedure related risks. Patient related factors are high body mass index (BMI), smoking and collagen diseases. ${ }^{10,12,13}$ Procedure related factors include the location of incision and closure technique. ${ }^{14,15}$ Also postoperative wound complications, such as wound infections and seroma formation, increase the risk on hernia development. ${ }^{10}$

\section{Stoma related hernia}

Next to incisional hernias after midline laparotomy, also stoma related hernias occur frequently.

During surgery, an ostomy is created by making a fascia defect, through which the stoma is led. If another intestinal loop also passes this fascia defect, a parastomal hernia has developed. Reported incidences for parastomal hernias vary between $4-48 \%$ and will lead to surgical repair in 1 out of 4 patients. ${ }^{16,17}$

Another stoma related hernia is het incisional hernia that develops at the former stoma site, in case of temporary stomata. In this type of hernia, the average reported incidence is $7 \%$ and $44 \%$ of the clinical relevant hernia needs surgical repair. ${ }^{18}$

\section{Hernia repair}

Surgical repair of incisional hernias is required in one out of three patients, due to pain, cosmetic complaints, strangulation or incarceration. ${ }^{19,20}$ While in the past primary suture repair was performed frequently to repair incisional hernias, nowadays primary suture hernia repair becomes more and more obsolete, due to the high recurrences rates, with reported incidences up to $63 \%$ after 10 years. ${ }^{11}$ Currently, almost all incisional and ventral hernias are repaired using meshes. Mesh repair decreases the risk on recurrence, although still recurrence rates up to $13 \%$ are reported. ${ }^{21}$

Yet, hernias smaller than $2 \mathrm{~cm}$ are often repaired with primary suture repair, despite the results of recent literature, which have shown a decrease in recurrences after mesh repair compared to suture repair, even in hernias measuring only $1.5 \mathrm{~cm} .{ }^{22}$

\section{Mesh positioning}

The abdominal wall consists of multiple layers, and therefore several options for mesh positioning during hernia repair are described. ${ }^{5}$ The retromuscular position is often used in open hernia repair, since it is associated with less surgical site infections and recurrences. ${ }^{23,24}$ During retromuscular mesh repair, a plain between the musculus rectus abdominis and the retromuscular fascia is created and the mesh is placed in this plain. Using this technique meshes do not have to be fixed and the mesh does not stay in contact with the viscera. ${ }^{25}$ 
Next, intraperitoneal mesh placement is often performed, when hernia repair using laparoscopy takes place. Laparoscopy is associated with a shorter hospital stay and multiple hernias can be detected more easily. ${ }^{26}$ On the other hand, the mesh is placed intra-abdominal, where it makes contact with the viscera. This can lead to complications, such as adhesions and fistula formation. ${ }^{27}$

\section{Mesh types}

Surgical meshes for hernia repair can be divided into synthetic and biological meshes. It is believed that biological meshes can be used more safely in contaminated areas, although evidence is lacking. ${ }^{28}$

Several mesh types are available, each mesh with its own properties. The most important property is that meshes are biocompatible. Pore size plays an important role in this. Meshes with a pore size more than $75 \mu \mathrm{m}$ allow better infiltration of inflammatory cells and blood vessels. Smaller pore size is associated with an increased risk on granuloma formation and eventually formation of scar plates. ${ }^{29}$

Related to pore size is the weight of the mesh. Low weight meshes are thought to cause less post-operative pain, but may give an increased risk on hernia recurrence compared to heavy-weight meshes. Next, tensile strength is an important mesh property. $^{29}$

\section{Postoperative adhesion formation}

Development of adhesions is associated with peritoneal damage due to surgery. During postoperative tissue healing, there is a disbalance between the coagulation and fibrinolytic system, eventually leading to adhesion formation. ${ }^{30}$

Adhesion formation occur in up to $93 \%$ of patients who underwent laparotomy. ${ }^{31}$ After laparoscopy this incidence decreases, although still $40 \%$ of the patients will develop adhesions. ${ }^{32}$ Adhesions can lead to chronic abdominal pain, bowel obstruction and female infertility. ${ }^{33}$ This leads to readmissions of one out of three patients within 10 years after the index-operation. ${ }^{2}$ Unfortunately, surgical treatment of adhesions and adhesion related complications subsequently leads to new adhesion formation. Therefore, the treatment of adhesions should be searched in the prevention of adhesions.

\section{Adhesion formation in presence of meshes}

To minimize the risk on hernia recurrence, it is important that meshes for hernia repair show an excellent ingrowth in the abdominal wall. The foreign body reaction that appears in presence of a mesh is one of the factors that is involved in mesh ingrowth. ${ }^{34}$ On the other hand, when the mesh is placed within the abdominal cavity and thus in direct contact with the viscera, the activation of the inflammatory cascade triggers 
adhesions to form between meshes and viscera. This may lead to several serious complications, like fistula formation between intestines and the mesh. ${ }^{35}$

In order to prevent mesh tissue adhesions, many experimental and clinical studies with different meshes have been performed. Since the 1960s polypropylene meshes have been used, due to its strength and excellent ingrowth capacity. ${ }^{36}$ However, intraabdominal placed polypropylene meshes are also associated with extensive adhesion formation. ${ }^{37}$ To prevent adhesion formation, several mesh materials and coatings, that serve as an mechanical barrier between the mesh and viscera, have been developed. ${ }^{38,39}$ Although this has led to a reduction in adhesion formation, the perfect mesh does still not exist.

\section{Scoring systems}

To investigate the reduction of adhesions after placement of an adhesion barrier, many studies have been performed during the last decades, using several scoring systems.

Diamond et al. were one of the firsts who described an adhesion score. ${ }^{40}$ This score is developed to measure post-operative adhesion formation. To measure adhesions to a mesh, modified Diamond scores have been developed. Another wellknown adhesion score, is the score of Zühlke et al., but many more scores are used. ${ }^{41}$ Most scoring systems include the extent, type and tenacity of adhesions. Furthermore, number of adhesions and organ involvement are part of adhesion scores. ${ }^{42,43}$

With the use of so many scoring systems, it is impossible to compare studies accurately. Therefore, standards for hernia research and scoring systems are warranted. $^{44}$

\section{Outline of the thesis}

This thesis is divided into three parts. The first part explores awareness of surgeons regarding adhesions, combined with the proposal of a new adhesion scoring system. Part two contains a set of experimental studies on abdominal wall closure to prevent hernias and on adhesion reduction with a new mesh for hernia repair. The third part focuses on translation of experimental results to the human situation, together with hernia prevention.

\section{Part I - Awareness of adhesions and scoring systems}

Post-operative adhesions and adhesions to intra-abdominal meshes are a major problem, with high readmission rates. Next, reinterventions are complicated with an increased risk on inadvertent injuries to the intestines. To minimize the risks, full attention regarding this topic is required from surgeons. In 2010, a study was published, which showed that knowledge and awareness of adhesions is limited among 
Dutch surgeons. ${ }^{45}$ To discover improvements regarding this topic, a new national survey was performed six years later. Results are presented in chapter 2.

To measure adhesions to intra-abdominal meshes, several adhesion scores have been developed, which decreases the comparability between studies significantly. Next, different scoring systems between experimental and clinical studies have been used. This makes it nearly impossible to compare studies regarding mesh-tissue adhesions and to draw correct conclusions from these studies. To improve study comparability, one uniform scoring system is warranted. In chapter $\mathbf{3}$, we present the outcomes of an international consensus study that focuses on the development of a widely supported adhesion scoring system in presence of a mesh.

\section{Part II - Abdominal wall closure and hernia repair; experimental findings}

With an incidence of $20 \%$, incisional hernias are a frequent complication of abdominal surgery. ${ }^{10,11}$ To decrease this risk, the small bites technique has been introduced, with promising results. ${ }^{8,14}$ Next, the ideal suture for abdominal wall closure have been investigated in clinical studies, but with inconclusive results. ${ }^{20,46}$ In chapter 4 , different types of sutures were compared in an animal study, to investigate the effect on abdominal wall healing.

When an incisional hernia needs surgical repair, a mesh is placed for reinforcement of the abdominal wall. Important mesh characteristics are pore size and tensile strength, to prevent scar plate formation and to minimize the risk on hernia recurrence. ${ }^{29} \mathrm{~A}$ new, elastic mesh has been compared with commercially available meshes in chapter $\mathbf{5}$ and $\mathbf{6}$ on the short and long-term. Adhesion formation to these meshes was investigated, as well as the elastic properties of the meshes and the foreign body reaction to these meshes.

\section{Part III - A human model for adhesion assessment and hernia prevention}

Part two of this thesis shows promising result, but translation to the clinical setting is difficult. A recent overview of animal studies in hernia research has shown a wide variation in animals used, which could also be seen in part two of thesis. To make animal studies more valuable, a good correlation with the human setting is necessary. In chapter 7, histological outcomes in rats and humans were compared in a hernia model to assess if rats should be used in incisional hernia research.

In the end, prevention of incisional hernias is desired. Recent studies have shown promising results with the use of a prophylactic mesh to prevent midline incisional hernias and parastomal hernias. ${ }^{47,48}$ In chapter $\mathbf{8}$, it was investigated if the same results could be seen when a prophylactic mesh is placed to prevent incisional hernias after stoma reversal. 
In chapter 9, the results of this thesis are discussed and future perspectives regarding abdominal wall hernia repair with meshes and prevention of incisional hernias are presented. 


\section{References}

1. Bishop WJ. The early history of surgery. London: R. Hale; 1960. 192 p. p.

2. Ellis H, Moran BJ, Thompson JN, Parker MC, Wilson MS, Menzies D, et al. Adhesion-related hospital readmissions after abdominal and pelvic surgery: a retrospective cohort study. Lancet. 1999; 353(9163):1476-80.

3. Fink C, Baumann P, Wente MN, Knebel P, Bruckner T, Ulrich A, et al. Incisional hernia rate 3 years after midline laparotomy. Br J Surg. 2014;101(2):51-4.

4. Jelinek LA, Patel AR, Ferguson T. Anatomy, Abdomen and Pelvis, Anterolateral Abdominal Wall Fascia. StatPearls. Treasure Island (FL)2019.

5. Muysoms F, Campanelli G, Champault GG, DeBeaux AC, Dietz UA, Jeekel J, et al. EuraHS: the development of an international online platform for registration and outcome measurement of ventral abdominal wall hernia repair. Hernia. 2012;16(3):239-50.

6. Smith J, Parmely JD. Ventral Hernia. StatPearls. Treasure Island (FL)2019.

7. Muysoms FE, Miserez M, Berrevoet F, Campanelli G, Champault GG, Chelala E, et al. Classification of primary and incisional abdominal wall hernias. Hernia. 2009;13(4):407-14.

8. Israelsson LA, Millbourn D. Prevention of incisional hernias: how to close a midline incision. Surg Clin North Am. 2013;93(5):1027-40.

9. Rath AMC, J.P. The healing of laparotomies: review of the literature. Hernia. 1998;2(3):145-9.

10. Hoer J, Lawong G, Klinge U, Schumpelick V. [Factors influencing the development of incisional hernia. A retrospective study of 2,983 laparotomy patients over a period of 10 years]. Chirurg. 2002;73(5): 474-80.

11. Burger JW, Luijendijk RW, Hop WC, Halm JA, Verdaasdonk EG, Jeekel J. Long-term follow-up of a randomized controlled trial of suture versus mesh repair of incisional hernia. Ann Surg. 2004;240(4):578-83; discussion 83-5.

12. Sorensen LT, Hemmingsen UB, Kirkeby LT, Kallehave F, Jorgensen LN. Smoking is a risk factor for incisional hernia. Arch Surg. 2005;140(2):119-23.

13. Antoniou GA, Georgiadis GS, Antoniou SA, Granderath FA, Giannoukas AD, Lazarides MK. Abdominal aortic aneurysm and abdominal wall hernia as manifestations of a connective tissue disorder. J Vasc Surg. 2011;54(4):1175-81.

14. Deerenberg EB, Harlaar JJ, Steyerberg EW, Lont HE, van Doorn HC, Heisterkamp J, et al. Small bites versus large bites for closure of abdominal midline incisions (STITCH): a double-blind, multicentre, randomised controlled trial. Lancet. 2015;386(10000):1254-60.

15. Bickenbach KA, Karanicolas PJ, Ammori JB, Jayaraman S, Winter JM, Fields RC, et al. Up and down or side to side? A systematic review and meta-analysis examining the impact of incision on outcomes after abdominal surgery. Am J Surg. 2013;206(3):400-9.

16. Carne PW, Robertson GM, Frizelle FA. Parastomal hernia. Br J Surg. 2003;90(7):784-93.

17. Martin L, Foster G. Parastomal hernia. Ann R Coll Surg Engl. 1996;78(2):81-4.

18. Bhangu A, Nepogodiev D, Futaba K, West Midlands Research C. Systematic review and meta-analysis of the incidence of incisional hernia at the site of stoma closure. World J Surg. 2012;36(5):973-83.

19. van Ramshorst GH, Eker HH, Hop WC, Jeekel J, Lange JF. Impact of incisional hernia on health-related quality of life and body image: a prospective cohort study. Am J Surg. 2012;204(2):144-50.

20. Bosanquet DC, Ansell J, Abdelrahman T, Cornish J, Harries R, Stimpson A, et al. Systematic Review and Meta-Regression of Factors Affecting Midline Incisional Hernia Rates: Analysis of 14,618 Patients. PLoS One. 2015;10(9):e0138745.

21. Kokotovic D, Bisgaard T, Helgstrand F. Long-term Recurrence and Complications Associated With Elective Incisional Hernia Repair. JAMA. 2016;316(15):1575-82.

22. Kaufmann R, Halm JA, Eker HH, Klitsie PJ, Nieuwenhuizen J, van Geldere D, et al. Mesh versus suture repair of umbilical hernia in adults: a randomised, double-blind, controlled, multicentre trial. Lancet. 2018;391(10123):860-9.

23. Timmermans L, de Goede B, van Dijk SM, Kleinrensink GJ, Jeekel J, Lange JF. Meta-analysis of sublay versus onlay mesh repair in incisional hernia surgery. Am J Surg. 2014;207(6):980-8.

24. Holihan JL, Nguyen DH, Nguyen MT, Mo J, Kao LS, Liang MK. Mesh Location in Open Ventral Hernia Repair: A Systematic Review and Network Meta-analysis. World J Surg. 2016;40(1):89-99. 
25. Schumpelick V, Klinge U, Junge K, Stumpf M. Incisional abdominal hernia: the open mesh repair. Langenbecks Arch Surg. 2004;389(1):1-5.

26. Lavanchy JL, Buff SE, Kohler A, Candinas D, Beldi G. Long-term results of laparoscopic versus open intraperitoneal onlay mesh incisional hernia repair: a propensity score-matched analysis. Surg Endosc. 2019;33(1):225-33.

27. Awaiz A, Rahman F, Hossain MB, Yunus RM, Khan S, Memon B, et al. Meta-analysis and systematic review of laparoscopic versus open mesh repair for elective incisional hernia. Hernia. 2015;19(3): 449-63.

28. Kockerling F, Alam NN, Antoniou SA, Daniels IR, Famiglietti F, Fortelny RH, et al. What is the evidence for the use of biologic or biosynthetic meshes in abdominal wall reconstruction? Hernia. 2018;22(2): 249-69.

29. Brown CN, Finch JG. Which mesh for hernia repair? Ann Roy Coll Surg. 2010;92(4):272-8.

30. Arung $W$, Meurisse M, Detry O. Pathophysiology and prevention of postoperative peritoneal adhesions. World J Gastroenterol. 2011;17(41):4545-53.

31. Menzies D, Ellis H. Intestinal obstruction from adhesions--how big is the problem? Ann R Coll Surg Engl. 1990;72(1):60-3.

32. Stommel MWJ, Ten Broek RPG, Strik C, Slooter GD, Verhoef C, Grunhagen DJ, et al. Multicenter Observational Study of Adhesion Formation After Open-and Laparoscopic Surgery for Colorectal Cancer. Ann Surg. 2018;267(4):743-8.

33. ten Broek RP, Issa Y, van Santbrink EJ, Bouvy ND, Kruitwagen RF, Jeekel J, et al. Burden of adhesions in abdominal and pelvic surgery: systematic review and met-analysis. BMJ. 2013;347:f5588.

34. Klinge U, Dietz U, Fet N, Klosterhalfen B. Characterisation of the cellular infiltrate in the foreign body granuloma of textile meshes with its impact on collagen deposition. Hernia. 2014;18(4):571-8.

35. Leber GE, Garb JL, Alexander Al, Reed WP. Long-term complications associated with prosthetic repair of incisional hernias. Arch Surg. 1998;133(4):378-82.

36. Read RC. Milestones in the history of hernia surgery: prosthetic repair. Hernia. 2004;8(1):8-14.

37. Matthews BD, Pratt BL, Pollinger HS, Backus CL, Kercher KW, Sing RF, et al. Assessment of adhesion formation to intra-abdominal polypropylene mesh and polytetrafluoroethylene mesh. J Surg Res. 2003;114(2):126-32.

38. Lak KL, Goldblatt MI. Mesh Selection in Abdominal Wall Reconstruction. Plast Reconstr Surg. 2018;142(3):99s-106s.

39. Schreinemacher MH, van Barneveld KW, Dikmans RE, Gijbels MJ, Greve JW, Bouvy ND. Coated meshes for hernia repair provide comparable intraperitoneal adhesion prevention. Surg Endosc. 2013;27(11): 4202-9.

40. Diamond MP, Linsky CB, Cunningham T, Constantine B, diZerega GS, DeCherney AH. A model for sidewall adhesions in the rabbit: reduction by an absorbable barrier. Microsurgery. 1987;8(4):197-200.

41. Zuhlke HV, Lorenz EM, Straub EM, Savvas V. [Pathophysiology and classification of adhesions]. Langenbecks Arch Chir Suppl II Verh Dtsch Ges Chir. 1990:1009-16.

42. de Oliveira N, Paschoa AF, Crespo CC, Massumoto CM, Adam C. [Use of the combination of a nitrofurazone derivative with polyethylene glycols in the prevention of the formation of peritoneal adhesions - experimental study]. Arq Gastroenterol. 1981;18(2):54-9.

43. Garrard CL, Clements RH, Nanney L, Davidson JM, Richards WO. Adhesion formation is reduced after laparoscopic surgery. Surg Endosc. 1999;13(1):10-3.

44. Schreinemacher $M$, Henatsch D, van Barneveld K, Bouvy N. The need for standardised animal models and scoring systems in assessing mesh biocompatibility. Hernia. 2010;14(3):335-6.

45. Schreinemacher MH, ten Broek RP, Bakkum EA, van Goor H, Bouvy ND. Adhesion awareness: a national survey of surgeons. World J Surg. 2010;34(12):2805-12.

46. Diener MK, Voss S, Jensen K, Buchler MW, Seiler CM. Elective midline laparotomy closure: the INLINE systematic review and meta-analysis. Ann Surg. 2010;251(5):843-56.

47. Jairam AP, Timmermans L, Eker HH, Pierik R, van Klaveren D, Steyerberg EW, et al. Prevention of incisional hernia with prophylactic onlay and sublay mesh reinforcement versus primary suture only in midline laparotomies (PRIMA): 2-year follow-up of a multicentre, double-blind, randomised controlled trial. Lancet. 2017;390(10094):567-76.

48. Cross AJ, Buchwald PL, Frizelle FA, Eglinton TW. Meta-analysis of prophylactic mesh to prevent parastomal hernia. Br J Surg. 2017;104(3):179-86. 


\section{PART I}

Awareness of adhesions and scoring systems 



\title{
Chapter 2
}

Adhesion awareness in 2016: An update of the national survey of surgeons

\author{
S. van Steensel \\ L.C.L. van den Hil \\ M.H.F. Schreinemacher \\ R.P.G. ten Broek \\ H. van Goor \\ N.D. Bouvy
}




\section{Abstract}

\section{Background and aims}

Adhesions, that form in $60-80 \%$ of all abdominal operations, can cause complications such as chronic abdominal pain, small-bowel obstruction, female infertility, and the need for adhesiolysis in future surgeries. Our 2010 Adhesion Awareness survey demonstrated that despite the huge clinical impact of adhesions; adhesion-related complications were seldom mentioned in the informed consent. Six years later, a follow-up survey was conducted to assess the progress on awareness of adhesionrelated complications in the Netherlands.

\section{Material and methods}

The 2010 Adhesion Awareness survey was repeated after a literature update. The knowledge regarding adhesions, the use of anti-adhesive agents and involvement in the informed consent process were assessed. Surgeons and surgical trainees were contacted by e-mail. The data was analyzed using a Chi-square or Mann-Whitney U test and corrected for multiple testing.

\section{Results}

The response rate was 32.6\%, similar to the survey in 2010 (34.4\%). 88.1\% agreed with the clinical relevance of adhesions, comparable to 2010 (89.8\%). The score on the knowledge test was $38.8 \%$ (2010: $37.2 \%)$. Involvement of adhesion-related complications in the informed consent process increased, although $32.5 \%$ almost never mentions adhesions. In 2016, 42.4\% reported a correct occurrence of bowel lesions during adhesiolysis: higher than in 2010 ( $p<0.001)$.

\section{Conclusions}

The adhesion awareness did not increase in six years, despite the efforts made. However, an increased awareness regarding adhesiolysis related complications was detected.

Improvement of knowledge and behavior is essential to narrowing the gap between the impact of adhesions as a major complication of abdominal surgery and the limited adhesion awareness. 


\section{Introduction}

Abdominal surgery leads to intraperitoneal adhesion formation in almost all patients $(60-80 \%)$, often giving rise to complications in the short, but also in the medium and long-term. ${ }^{1,2}$ Adhesion related complications comprise of chronic abdominal pain, small-bowel obstruction and female infertility. ${ }^{3}$ Adhesions are responsible for $56 \%$ of postoperative small-bowel obstructions, are the most likely cause of chronic abdominal pain after a former laparotomy in $57 \%$ of the patients and effects $23 \%$ of the female patients who require fertility treatment after abdominal surgery. ${ }^{3}$ Additional to the direct complications of adhesions, there is also an increased risk of adverse events during future surgery because of the need for adhesiolysis accompanied with increased risk of bowel injury. ${ }^{3}$

The direct link between abdominal surgery and adhesion-related complications is often overlooked because of the long period between the occurrence of complications and the initial surgery. ${ }^{3}$ However, the clinical burden is extensive considering that up to a third of patients that have undergone abdominal surgery will be readmitted for adhesion-related complications in the next 10 years. Moreover, a mean readmission rate of 2.2 per patient has previously been reported. ${ }^{4,5}$ Thus, adhesions must be regarded as one of the most important complications after abdominal surgery.

However, there is a discrepancy between the clinical impact of adhesion related morbidity and the provided information regarding this topic during the informed consent process preoperatively. ${ }^{6}$ Therefore, it was hypothesized that surgeons lack sufficient awareness of this common complication and its possible impact. To investigate this, a survey among surgeons was performed in 2010 in the Netherlands. ${ }^{7}$ This survey showed that two out of three Dutch surgeons recognized adhesions as a serious problem, but the readmission rates and the incidence of small-bowel obstructions caused by adhesions were grossly underestimated. In response, a number of high quality reviews and meta-analyses demonstrating the impact of adhesions were published. ${ }^{3,8,9}$ Results of these studies were presented during symposia and at national surgical meetings in order to raise awareness and educate about the problem and its possible prevention.

Six years after conducting the National Adhesions Awareness Survey we reevaluated the adhesion awareness among surgeons in the Netherlands. A second National survey was conducted recently using the same questionnaire, with an update of the knowledge test using recent literature.

\section{Material and methods}

The original survey in 2010 was conceived by the Dutch Adhesion Group, a steering group of 11 general and gynecologic surgeons with affiliation to adhesion related morbidity. In order to provide comparable data, the survey of 2010 was used after a 
minor update. The answers of the knowledge test were adjusted to the most recent literature and some additional questions were added to evaluate the progression of adhesion awareness over time. ${ }^{7}$ Only an online version was available, which was in Dutch and consisted of 62 multiple choice and five open questions with a total word count of 827 words. The complete translated survey can be found in the appendix (See Appendix 2.1). The surveys were filled out anonymously.

\section{Knowledge test}

Ten multiple choice questions regarding prevalence and morbidity of adhesions were formulated to obtain information on the average know-how of participating surgeons. The following statements were considered correct:

- $56 \%$ of the small bowel-obstructions are caused by postoperative adhesions. ${ }^{3}$

- The 5-years readmission rate after laparotomy directly related to postoperative adhesions is approximately $5 \% .{ }^{10}$

- The 10-years readmission rate after laparotomy probably related to postoperative adhesions is approximately $30 \%{ }^{4}$

- latrogenic bowel injury occurs in $40 \%$ of the operations, needing adhesiolysis of approximately one hour. ${ }^{3}$

- The highest risk for adhesion formation is caused by a total colectomy in comparison to a partial small-bowel resection, resection of the rectum, appendectomy or cholecystectomy. ${ }^{10}$

- Of the women that have a history of abdominal surgery, $23 \%$ will be treated for infertility. 3,11

- An age over 60 years is associated with fewer adhesion formation compared to younger patients. A history of abdominal surgery is associated with more adhesion formation compared to patients with no prior abdominal surgery and Crohn's disease has no effect on adhesion formation. ${ }^{10}$

\section{Survey distribution}

The questionnaire was distributed among 1582 surgeons and trainees using an online survey service (SurveyMonkey Inc, Palo Alto, California, USA; www.surveymonkey.com). All e-mail addresses were collected using the website of the Dutch Association for Surgery. The survey has been sent to all surgeons and trainees on a Tuesday (7:00am) and four reminders were sent afterwards, respectively one, two and three weeks after the initial e-mail, alternating at 7:00pm and at 7:00am. The last reminder was sent four weeks after the first invitation at 7.00am. One week after the last reminder the online survey was closed. 


\section{Data analysis}

Data was exported from the online survey service into IBM SPSS statistics, version 23.0 (SPSS, Inc., Chicago, Illinois, USA) for further analysis. Only surveys that were more than $80 \%$ completed were included for analysis. Results were compared to the 2010 survey. In case of normal distribution tested using the Shapiro-Wilk test, proportions were compared using the Pearson Chi-square test and for the comparison of means an independent student t-test was used. The Mann-Whitney $U$ test was used when the data was not normally distributed. To take multiple testing into account, a Bonferroni corrected $p$-value of $<0.0017(0.05 / 29)$ was considered as statistically significant.

\section{Results}

Of the 1582 surgeons and trainees contacted, a total response rate of $n=514(32.5 \%)$ was generated, which was comparable with 2010 (34.4\%). From the respondents, $25.7 \%$ also responded to the 2010 survey. Ninety three participants explicitly refused to participate and 41 surveys were excluded because they were incomplete. A total of 380 surveys $(90.3 \%)$ was available for analysis. The group of respondents was divided in trainees (20.8\%), general and gastro-intestinal surgeons combined (49.5\%) and others (29.7\%). Further demographic details are shown in Table 2.1.

Table 2.1 Baseline characteristics participants.

\begin{tabular}{lccc}
\hline & $\mathbf{2 0 1 0}$ & $\mathbf{2 0 1 6}$ & $\boldsymbol{p}_{\text {-value }} \mathbf{a}^{\mathbf{a}^{\mathbf{2}}}$ \\
\hline Male (\%) & - & 80.0 & - \\
Trainees (\%) & 26.1 & 20.8 & 0.10 \\
General/GI surgeon (\%) & 49.1 & 49.5 & 0.10 \\
Other type of surgeon (\%) & 24.8 & 29.7 & 0.10 \\
Working experience (mean in years) & 10.8 & 12.7 & 0.01 \\
Non-academic hospital (\%) & 72.1 & 71.3 & 0.79 \\
Fulltime (\%) & 89.1 & 83.7 & 0.02 \\
\hline
\end{tabular}

Baseline characteristics are expressed in percentages and means. ${ }^{a} p$-values $<0.05$ were considered significant.

\section{Opinion on adhesions}

Of all respondents, $88.1 \%$ agreed to the clinical relevance of adhesions, which is comparable to the $89.8 \%$ of the respondents agreeing to this statement in the survey of 2010 ( $p=0.41$ ). All outcomes are presented in Table 2.2. No significant differences were detected between trainees, gastrointestinal and general surgeons or other surgeons. Of the respondents, $70.8 \%$ agreed that adhesiolysis for diffuse abdominal complaints is an obsolete intervention. Regarding focal abdominal complaints only $27.2 \%$ agreed that adhesiolysis is senseless. 
Table 2.2 Overview of the outcomes of the Adhesion Awareness survey. Outcomes of 2010 compared with the outcomes of 2016.

\begin{tabular}{|c|c|c|c|}
\hline Topic & $2010(n=501)$ & $2016(n=380)$ & $p$-value ${ }^{a}$ \\
\hline Adhesions are not of clinical interest & & & 0.41 \\
\hline Disagree & $89.8 \%$ & $88.1 \%$ & \\
\hline Neutral & $4.4 \%$ & $5.5 \%$ & \\
\hline Agree & $5.8 \%$ & $6.3 \%$ & \\
\hline Adhesions have more beneficial than detrimental effects & & & 0.005 \\
\hline Disagree & $72.3 \%$ & $63.4 \%$ & \\
\hline Neutral & $20.4 \%$ & $27.1 \%$ & \\
\hline Agree & $7.2 \%$ & $9.5 \%$ & \\
\hline Adhesiolysis for diffuse abdominal pain complaints is not effective & & & - \\
\hline Disagree & - & $11.6 \%$ & \\
\hline Neutral & - & $17.6 \%$ & \\
\hline Agree & - & $70.8 \%$ & \\
\hline Adhesiolysis for focal abdominal pain complaints is not effective & & & - \\
\hline Disagree & - & $47.5 \%$ & \\
\hline Neutral & - & $25.3 \%$ & \\
\hline Agree & - & $27.2 \%$ & \\
\hline $\begin{array}{l}\text { Adhesiolysis should preferably be performed by specialized } \\
\text { gastrointestinal surgeons }\end{array}$ & & & - \\
\hline Disagree & - & $30 \%$ & \\
\hline Neutral & - & $15.8 \%$ & \\
\hline Agree & - & $54.2 \%$ & \\
\hline $\begin{array}{l}\text { Which proportion of small bowel obstruction is caused by } \\
\text { postoperative adhesions? }\end{array}$ & & & 0.002 \\
\hline Correct answer (\%) & $32.1 \%$ & $42.4 \%$ & \\
\hline $\begin{array}{l}\text { Which percentage of patients will be readmitted within } 5 \text { years } \\
\text { after laparotomy, due to morbidity directly related to adhesions? }\end{array}$ & & & 0.40 \\
\hline Correct answer (\%) & $42.8 \%$ & $40 \%$ & \\
\hline $\begin{array}{l}\text { Which percentage of patients will be readmitted within } 10 \text { years } \\
\text { after laparotomy, due to morbidity probably related to adhesions? }\end{array}$ & & & 0.01 \\
\hline Correct answer (\%) & $6.9 \%$ & $11.8 \%$ & \\
\hline $\begin{array}{l}\text { What is the percentage of occurrence of inadvertent bowel lesions } \\
\text { caused by adhesiolysis? }\end{array}$ & & & $<0.001^{*}$ \\
\hline Correct answer (\%) & $23.9 \%$ & $42.4 \%$ & \\
\hline $\begin{array}{l}\text { Which procedure carries the highest risk for adhesion-related } \\
\text { morbidity? }\end{array}$ & & & - \\
\hline Correct answer (\%) & - & $70.8 \%$ & \\
\hline $\begin{array}{l}\text { Which percentage of the women with a history of abdominal } \\
\text { surgery has to be treated for infertility? }\end{array}$ & & & - \\
\hline Correct answer (\%) & - & $6.1 \%$ & \\
\hline What is the influence of age $>60$ years on adhesion formation & & & 0.50 \\
\hline Correct answer $(\%)$ & $31.8 \%$ & $33.9 \%$ & \\
\hline $\begin{array}{l}\text { What is the influence of a history of abdominal surgery on } \\
\text { adhesion formation? }\end{array}$ & & & 0.97 \\
\hline Correct answer (\%) & $87.6 \%$ & $87.6 \%$ & \\
\hline What is the influence of Crohn's disease on adhesion formation? & & & 0.39 \\
\hline Correct answer (\%) & $16.1 \%$ & $13.9 \%$ & \\
\hline
\end{tabular}


Table 2.2 (continued)

\begin{tabular}{|c|c|c|c|}
\hline Topic & $2010(n=501)$ & $2016(n=380)$ & $p$-value ${ }^{a}$ \\
\hline $\begin{array}{l}\text { How many patients do you inform about adhesion-related } \\
\text { morbidity as a possible complication after laparotomy? }\end{array}$ & & & 0.003 \\
\hline Virtually none & $41.1 \%$ & $32.5 \%$ & \\
\hline$<5 \%$ & $15.2 \%$ & $17.3 \%$ & \\
\hline $5-10 \%$ & $11.2 \%$ & $10.1 \%$ & \\
\hline $10-25 \%$ & $7.6 \%$ & $6.4 \%$ & \\
\hline $25-50 \%$ & $6.4 \%$ & $6.7 \%$ & \\
\hline $50-75 \%$ & $3.0 \%$ & $5.6 \%$ & \\
\hline Virtually all & $15.4 \%$ & $21.3 \%$ & \\
\hline $\begin{array}{l}\text { How many patients do you inform about adhesion-related } \\
\text { morbidity as a possible complication after laparoscopy? }\end{array}$ & & & 0.60 \\
\hline Virtually none & $64.3 \%$ & $65.9 \%$ & \\
\hline$<5 \%$ & $11.6 \%$ & $10.4 \%$ & \\
\hline $5-10 \%$ & $7.0 \%$ & $6.9 \%$ & \\
\hline $10-25 \%$ & $3.0 \%$ & $2.9 \%$ & \\
\hline $25-50 \%$ & $2.8 \%$ & $4.8 \%$ & \\
\hline $50-75 \%$ & $1.0 \%$ & $2.7 \%$ & \\
\hline Virtually all & $10.2 \%$ & $6.4 \%$ & \\
\hline You do not believe in adhesion prevention & & & 0.743 \\
\hline Disagree & $39.1 \%$ & $34.4 \%$ & \\
\hline Neutral & $38.5 \%$ & $35.8 \%$ & \\
\hline Agree & $22.4 \%$ & $29.8 \%$ & \\
\hline $\begin{array}{l}\text { You would like to apply adhesion prevention in all abdominal } \\
\text { operations }\end{array}$ & & & $<0.001^{*}$ \\
\hline Disagree & $19.2 \%$ & $17.5 \%$ & \\
\hline Neutral & $27.7 \%$ & $26.9 \%$ & \\
\hline Agree & $53.1 \%$ & $55.7 \%$ & \\
\hline $\begin{array}{l}\text { You would like to apply adhesion prevention only in certain } \\
\text { indications }\end{array}$ & & & 0.86 \\
\hline Disagree & $19.2 \%$ & $17.5 \%$ & \\
\hline Neutral & $27.7 \%$ & $26.9 \%$ & \\
\hline Agree & $53.1 \%$ & $55.7 \%$ & \\
\hline Laparoscopic surgery causes fewer adhesions than open surgery & & & $<0.001^{*}$ \\
\hline Disagree & $23.4 \%$ & $4.9 \%$ & \\
\hline Neutral & $0 \%$ & $9.5 \%$ & \\
\hline Agree & $76.6 \%$ & $85.6 \%$ & \\
\hline Meticulous surgical technique reduces adhesions & & & $<0.001^{*}$ \\
\hline Disagree & $21.2 \%$ & $8.2 \%$ & \\
\hline Neutral & $0 \%$ & $16.3 \%$ & \\
\hline Agree & $78.8 \%$ & $75.5 \%$ & \\
\hline $\begin{array}{l}\text { Extraperitoneal mesh position causes fewer adhesions than } \\
\text { intraperitoneal mesh position }\end{array}$ & & & 0.95 \\
\hline Disagree & $4.6 \%$ & $3.5 \%$ & \\
\hline Neutral & $8.8 \%$ & $7.6 \%$ & \\
\hline Agree & $86.6 \%$ & $88.8 \%$ & \\
\hline A coated mesh causes fewer adhesions than an uncoated mesh & & & 0.40 \\
\hline Disagree & $5.2 \%$ & $7.0 \%$ & \\
\hline Neutral & $26.4 \%$ & $24.9 \%$ & \\
\hline Agree & $68.4 \%$ & $68.0 \%$ & \\
\hline Electrocautery causes fewer adhesions & & & - \\
\hline Disagree & - & $32.8 \%$ & \\
\hline Neutral & - & $56.1 \%$ & \\
\hline Agree & - & $11.1 \%$ & \\
\hline
\end{tabular}


Table 2.2 (continued)

\begin{tabular}{|c|c|c|c|}
\hline Topic & $2010(n=501)$ & $2016(n=380)$ & $p$-value ${ }^{a}$ \\
\hline Less intraperitoneal suture material reduces adhesions & & & 0.32 \\
\hline Disagree & $13.1 \%$ & $9.8 \%$ & \\
\hline Neutral & $39.6 \%$ & $33.2 \%$ & \\
\hline Agree & $47.3 \%$ & $57.1 \%$ & \\
\hline You do not believe in antiadhesive agents & & & 0.92 \\
\hline Disagree & $26.5 \%$ & $24.2 \%$ & \\
\hline Neutral & $44.3 \%$ & $42.0 \%$ & \\
\hline Agree & $29.1 \%$ & $33.8 \%$ & \\
\hline $\begin{array}{l}\text { You experience a lack of clarity about when to use an antiadhesive } \\
\text { agents }\end{array}$ & & & 0.005 \\
\hline Disagree & $11.0 \%$ & $6.3 \%$ & \\
\hline Neutral & $22.3 \%$ & $28.6 \%$ & \\
\hline Agree & $66.7 \%$ & $65.1 \%$ & \\
\hline $\begin{array}{l}\text { You prefer using a locally acting antiadhesive agent over an agent } \\
\text { that acts throughout the whole abdomen }\end{array}$ & & & 0.06 \\
\hline Disagree & $31.3 \%$ & $24.5 \%$ & \\
\hline Neutral & $50.3 \%$ & $55.2 \%$ & \\
\hline Agree & $18.4 \%$ & $20.3 \%$ & \\
\hline $\begin{array}{l}\text { You think the costs do not outweigh the possible benefits of } \\
\text { antiadhesive agents }\end{array}$ & & & 0.58 \\
\hline Disagree & $9.2 \%$ & $8.2 \%$ & \\
\hline Neutral & $57.4 \%$ & $59.1 \%$ & \\
\hline Agree & $33.3 \%$ & $32.7 \%$ & \\
\hline
\end{tabular}

\section{Prevalence and morbidity of adhesions}

The mean percentage of correct answers of the correspondents on the knowledge test was $38.8 \%$ (SD 13.0), not significantly different from the score in 2010 (37.2\%, SD 15.2) $(p=0.92)$.

In 2016, 42.4\% reported a correct occurrence of iatrogenic bowel lesions during adhesiolysis, this was only $23.9 \%$ in 2010 ( $p<0.001)$. The relation between the 5 -years readmission rate after laparotomy and postoperative adhesions was reported correctly by $40.0 \%$, whereas 10 -years readmission rates were only reported correctly by $11.8 \%$ of the respondents. In both cases, no significant difference from the 2010 survey was detected. Of all participants, $70.8 \%$ reported correctly a total colectomy as surgery with the highest risk on adhesion formation. In contrast, $93.4 \%$ underestimated the necessity of fertility treatment in women that have a history of abdominal surgery. Furthermore, $33.9 \%, 87.6 \%$ and $13.9 \%$ indicated correctly the association between adhesions and age over 60 years, history of abdominal surgery and a history of Crohn's disease respectively. 


\section{Informed consent}

Regarding laparotomy, $32.5 \%$ of the respondents reported that they almost never mention adhesions and related morbidity during the informed consent procedure, while $21.3 \%$ always report this complication risk (Figure 2.1). In the past six years this has increased, in the 2010 survey $41.1 \%$ never mentioned and $15.4 \%$ always mentioned adhesions and its morbidity preoperatively. This difference was not significant after correcting for multiple testing. Furthermore, 65.9\% did not inform patients about the risk on adhesions before a laparoscopic procedure, which was comparable with the response from the 2010 survey. No differences between the subgroups were detected.

Figure 2.1 Informed consent. Percentage of patients informed regarding adhesion related complications after laparoscopy and laparotomy in 2010 and 2016.

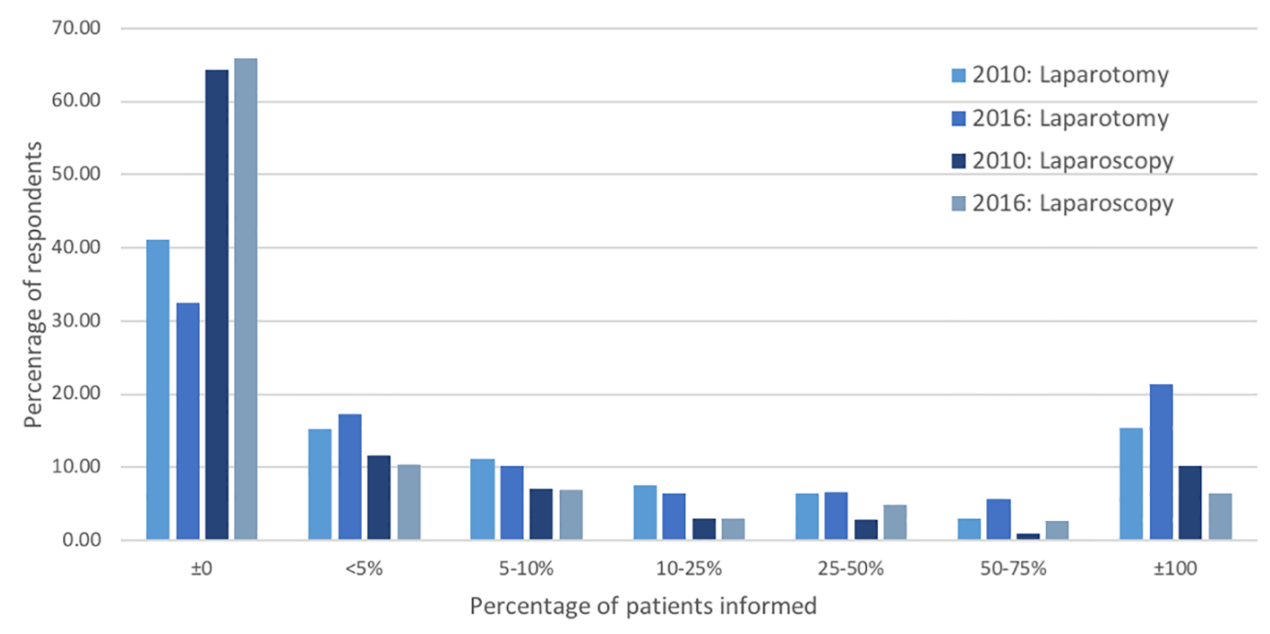

\section{Adhesion prevention and anti-adhesive barriers}

Adhesion prevention for specific indications is believed to be more effective than adhesion prevention for all abdominal surgery $(p<0.001)$. Furthermore, gastrointestinal and general surgeons believed more strongly in the effectiveness of using meticulous surgical techniques than other groups $(83.8 \%, \mathrm{p}<0.001)$. Residents believed the least in adhesion reduction by the use of such surgical techniques (residents $62.8 \%$ vs. other $82 \% ; p<0.001$ ). Furthermore, in the most recent survey more surgeons believe that laparoscopic surgery and the use of meticulous surgical techniques reduce adhesion formation ( $p<0.001$ for both outcomes).

Of the respondents, $29.8 \%$ stated not to believe in anti-adhesive products with no differences between types of surgeons or residents. But interestingly, significantly more respondents indicated to like to apply adhesion prevention in all abdominal operation in 2016 compared to 2010 ( $45.8 \%$ vs. $33.6 \%$ respectively, $p=0.001$ ). 


\section{Discussion}

Although adhesions have a significant impact on patients' quality of life and health care costs $^{4,12}$, Dutch surgeons still underestimate the problem and there appears to be no improvement compared to the results of the similar survey conducted in 2010 . The two most striking underestimations are the long-term morbidity and the need for fertility treatment as a consequence of intra-abdominal adhesions.

Even though almost $90 \%$ of Dutch surgeons consider adhesions to be a clinical problem, only a quarter of all respondents inform patients regularly about the risk of adhesion related morbidity after laparotomy: in case of laparoscopic interventions, this is even less. A striking discrepancy that was also concluded in the 2010 survey and also shows a meager improvement over a six-year time-period.

The apparent underestimations and poor involvement in the informed consent process could be related due to the fact that surgeons are not directly confronted with adhesions as a complication of operations performed by themselves.

The overall knowledge score of respondents in 2016 was approximately the same as in 2010, leading to the conclusion that adhesion awareness has not significantly changed over these years.

This survey showed that the awareness and knowledge of Dutch surgeons concerning complications related to adhesiolysis increased between 2010 and 2016. A bowel defect is seen in $40 \%$ of the surgical procedures, when adhesiolysis takes over an hour. ${ }^{3}$ This is an important morbidity of intra-abdominal adhesions.

Unfortunately, adhesion formation can affect patients lifelong, considering the $30 \%$ readmission rate within 10 years postoperatively. ${ }^{4}$ Although discussion regarding the true readmission rate is ongoing. A population based study, published after the conduction of the survey, showed a slightly lower readmission rate after 5 years $(4.5 \%)$ after open surgery. ${ }^{13}$ Others report a readmission rate of $6 \%$ within 4 years, but more interestingly is the readmission rate after laparoscopic surgery, which is higher than expected (3.0\%). ${ }^{13}$ So, the positive effect of laparoscopic surgery in comparison to open surgery on adhesion formation seems to be overestimated.

Intra-abdominal adhesion research has been held back by the absence of a sound non-invasive diagnostic. Laparoscopy, the only definitive diagnostic, is invasive, causes more adhesions and exposes the patient to the risk of iatrogenic bowel injury. The visceral slide, which is the normal longitudinal movement of the intra-abdominal viscera caused by respiratory excursion of the diaphragm, can be used for non-invasive diagnostic purposes. Transabdominal ultrasonography (TAU) and cine magnetic resonance (cine MRI) can detect abnormalities of the visceral slide that might be caused by intra-abdominal adhesions with an accuracy of $70 \%$ to $95 \%$. TAU is limited in some patients due to intestinal gas or obesity and requires an extensive examination, which obstacles are overcome by cine MRI. However, prospective trials involving these non-invasive techniques are awaited. ${ }^{14}$ 
Next, adhesions often cause abdominal pain and are associated with female infertility. ${ }^{3}$ Taking this all into account, adhesions have a major impact on patient's quality of life and moreover, that they have a significant effect on health care costs. The use of anti-adhesive agents are shown to be cost-effective. ${ }^{12}$ Surprisingly, the opinion of respondents regarding the effect of anti-adhesive agents did not change over the past six years. Although there is sufficient evidence that hyaluronate carboxymethylcellulose and regenerated cellulose reduce adhesion formation, the indication is a point of discussion. Heterogeneity, lack of long-term follow-up and a high variability in the quality of studies are reasons for reserved conclusions and thus more research is needed focusing on patient outcomes. ${ }^{15}$ The lack of consensus is persistent in the last six years and no guidelines were drafted to aid the surgeon in clinical practice, in contrast to the gynecologists who published the 2012 European field guideline. ${ }^{16}$

In the period between 2010 and 2016 an extensive review on the burden of adhesions and a meta-analysis regarding anti-adhesive products were published in high impact journals among others. Multiple conferences and meetings were organized to address the issue, but overall adhesion awareness did not increase. The factors responsible are subject to speculation, but the underestimation is most profound regarding problems involving adhesions that do not immediately return to the outpatient department of the surgeon. Female infertility is treated by the gynecologist, chronic abdominal complaints by the gastro-enterologist and complications occurring ten years from now are maybe considered not to be of the highest priority. Hopefully, with the development of new non-invasive diagnostic tools, such as the cine MRI, cause and effect will be linked more directly. The discrepancy between the effort in raising awareness and the actual effect on adhesion awareness is alarming. It shows that providing scientific information is not enough to change clinical practice and it calls for consensus in the form of guidelines, which are broadly carried by clinicians in the field.

Among the limitations of this study is the response rate, although it is comparable with the survey conducted in $2010 .^{7,17}$ A risk of selection bias is present. Surgeons with affinity for the burden of adhesions are more likely to respond, thus the results of this survey can be an underestimation of the problem. This survey was only distributed among Dutch surgeons, but worldwide extrapolation seems permissible.

Lastly, the surveys in 2010 and 2016 were filled in anonymously and for the statistical analysis they were considered as two independent samples of the same population, instead of pairing the surveys of participants.

In conclusion, adhesion awareness in the Netherlands did not increase between 2010 and 2016 despite all the efforts that were made during symposia, congresses, published meta-analysis and even newspaper articles. The awareness among surgeons regarding adhesiolysis related complications, as a significant morbidity caused by adhesions, has increased between 2010 and 2016. The disappointing effect on the adhesion awareness calls for a different approach. Courses should be developed and organized on a regular base. Furthermore, guidelines for preventing and treating adhesions are urgently needed. 


\section{References}

1. Menzies D, Ellis H. Intestinal obstruction from adhesions--how big is the problem? Ann R Coll Surg Engl 1990;72(1):60-3.

2. Stommel MWJ, Ten Broek RPG, Strik C, Slooter GD, Verhoef C, Grunhagen DJ, et al. Multicenter Observational Study of Adhesion Formation After Open-and Laparoscopic Surgery for Colorectal Cancer. Ann Surg. 2018;267(4):743-8.

3. ten Broek RP, Strik C, Issa Y, Bleichrodt RP, van Goor H. Adhesiolysis-related morbidity in abdominal surgery. Ann Surg. 2013;258(1):98-106.

4. Ellis H, Moran BJ, Thompson JN, Parker MC, Wilson MS, Menzies D, et al. Adhesion-related hospital readmissions after abdominal and pelvic surgery: a retrospective cohort study. Lancet. 1999;353(9163):1476-80.

5. Parker MC, Ellis H, Moran BJ, Thompson JN, Wilson MS, Menzies D, et al. Postoperative adhesions: tenyear follow-up of 12,584 patients undergoing lower abdominal surgery. Dis Colon Rectum. 2001; 44(6):822-29; discussion 9-30.

6. Rajab TK, Wallwiener M, Talukdar S, Kraemer B. Adhesion-related complications are common, but rarely discussed in preoperative consent: a multicenter study. World J Surg. 2009;33(4):748-50.

7. Schreinemacher MH, ten Broek RP, Bakkum EA, van Goor H, Bouvy ND. Adhesion awareness: a national survey of surgeons. World J Surg. 2010;34(12):2805-12.

8. ten Broek RP, Stommel MW, Strik C, van Laarhoven CJ, Keus F, van Goor H. Benefits and harms of adhesion barriers for abdominal surgery: a systematic review and meta-analysis. Lancet. 2014;383(9911):48-59.

9. Vogels RRM, Kaufmann R, van den Hil LCL, van Steensel S, Schreinemacher MHF, Lange JF, et al. Critical overview of all available animal models for abdominal wall hernia research. Hernia. 2017;21(5):667-75.

10. Parker MC, Wilson MS, Menzies D, Sunderland G, Clark DN, Knight AD, et al. The SCAR-3 study: 5-year adhesion-related readmission risk following lower abdominal surgical procedures. Colorectal Dis. 2005; $7(6): 551-8$.

11. Johnson P, Richard C, Ravid A, Spencer L, Pinto E, Hanna M, et al. Female infertility after ileal pouchanal anastomosis for ulcerative colitis. Dis Colon Rectum. 2004;47(7):1119-26.

12. ten Broek RP, Bakkum EA, Laarhoven CJ, van Goor H. Epidemiology and Prevention of Postsurgical Adhesions Revisited. Ann Surg. 2016;263(1):12-9.

13. Andersen $P$, Jensen KK, Erichsen R, Froslev T, Krarup PM, Madsen MR, et al. Nationwide populationbased cohort study to assess risk of surgery for adhesive small bowel obstruction following open or laparoscopic rectal cancer resection. BJS Open. 2017;1(2):30-8.

14. Zinther NB, Fedder J, Friis-Andersen H. Noninvasive detection and mapping of intraabdominal adhesions: a review of the current literature. Surg Endosc. 2010;24(11):2681-6.

15. Robb WB, Mariette C. Strategies in the prevention of the formation of postoperative adhesions in digestive surgery: a systematic review of the literature. Dis Colon Rectum. 2014;57(10):1228-40.

16. De Wilde RL, Brolmann H, Koninckx PR, Lundorff P, Lower AM, Wattiez A, et al. Prevention of adhesions in gynaecological surgery: the 2012 European field guideline. Gynecol Surg. 2012;9(4):365-8.

17. Meuleman T, Schreinemacher MH, van Goor H, Bakkum EA, Dorr PJ. Adhesion awareness: a nationwide survey of gynaecologists. Eur J Obstet Gynecol Reprod Biol. 2013;169(2):353-9. 


\section{Appendix 2.1}

\section{The National Adhesion Awareness Survey}

1. I participated in the Adhesion awareness survey 5 years ago: Yes / No.

2. You are... (multiple options possible): In training to become a surgeon / General surgeon / Oncologic surgeon / Vascular surgeon / Gastrointestinal surgeon / Paediatric surgeon / Trauma surgeon.

3. How many years of work experience do you have as a surgeon or surgeon in training?

4. You currently work at a: Non-academic hospital / Academic hospital.

5. You currently work: Full-time / Part-time.

6. You are: Male / Female.

7. What is your opinion regarding intra-abdominal adhesions?

a. Adhesions are clinically irrelevant: I strongly disagree / I disagree / I am Neutral / I agree / I strongly agree.

b. Adhesions have more positive effects than negative: I strongly disagree / I disagree / I am Neutral / I agree / I strongly agree.

8. What is your opinion regarding adhesiolysis?

a. Adhesiolysis because of diffuse abdominal complaints is pointless: I strongly disagree / I disagree / I am Neutral / I agree / I strongly agree.

b. Adhesiolysis because of focal abdominal complaints is pointless: I strongly disagree / I disagree / I am Neutral / I agree / I strongly agree.

c. Preferably, only specialised gastrointestinal surgeons should perform adhesiolysis: I strongly disagree / I disagree / I am Neutral / I agree / I strongly agree.

9. In how many patients with a small bowel obstruction are postoperative adhesions the cause?

This percentage is closest to: $<25 \% / 25-50 \% / 50-75 \% />75 \%$

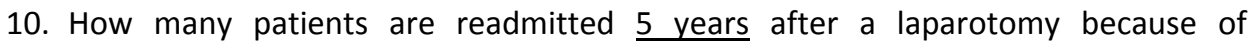
morbidity directly related to adhesions? This percentage is closest to: $2 \%$ / $5 \%$ / $10 \% / 20 \%$ 
11. How many patients are readmitted 10 years after a laparotomy because of morbidity probably related to adhesions? This percentage is closest to: $5 \%$ / 10\% / $20 \% / 30 \%$

12. The complexity of an operation is measured by the time needed for adhesiolysis, because there is a relation with the risk of iatrogenic bowel injury. In how many operations, after one hour of adhesiolysis, is an iatrogenic bowel injury caused? This percentage is closest to: $<25 \% / 25-50 \%$ / $50-75 \% />75 \%$

13. The risk of adhesion formation is the highest in which surgical procedure? Partial small bowel resection / Appendectomy / Total (procto)colectomy / Rectum resection / Cholecystectomy.

14. How many women undergo fertility treatment after abdominal surgery? This percentage is closest to: $<10 \% / 10-20 \% / 20-30 \% />30 \%$

15. It is proven that some patient specific factors influence the formation of adhesions.
a. age $>60$ year causes: Less adhesions / No effect / More adhesions.
b. Previous operations causes: Less adhesions / No effect / More adhesions.
c. Morbus Crohn causes: Less adhesions / No effect / More adhesions
d. The use of prednisone causes: Less adhesions / No effect / More adhesions.

16. How many patients do you inform regarding adhesions or adhesion related complaints as a possible complication of a laparotomy? Almost none / $<5 \%$ / 5 $10 \% / 10-25 \%$ / $25-50 \%$ / $50-75 \%$ / Almost every patient.

17. How many patients do you inform regarding adhesions or adhesion related complaints as a possible complication of a laparoscopic procedure? Almost none / $<5 \%$ / $5-10 \% / 10-25 \%$ / $25-50 \%$ / $50-75 \%$ / Almost every patient.

18. What is your opinion regarding adhesion prevention?

a. You do not believe in adhesion prevention: I strongly disagree / I disagree / I am Neutral / I agree / I strongly agree / N/A.

b. You would like to apply adhesion prevention in all abdominal surgery: I strongly disagree / I disagree / I am Neutral / I agree / I strongly agree / N/A.

c. You would like to apply adhesion prevention only with specific indications: I strongly disagree / I disagree / I am Neutral / I agree / I strongly agree / N/A.

d. You are inclined to apply more adhesion prevention than five years ago: I strongly disagree / I disagree / I am Neutral / I agree / I strongly agree / N/A. 
19. What has influenced your opinion regarding adhesion prevention most in the past five years? Tuition and conference / Publication in a medical journal / Interaction with colleagues / Your own experience with adhesions / N/A.

20. What is your opinion regarding the following statements?

a. Laparoscopic surgery causes less adhesions than open surgery: I strongly disagree / I disagree / I am Neutral / I agree / I strongly agree.

b.... and you apply it as much as possible for that reason: I strongly disagree / I disagree / I am Neutral / I agree / I strongly agree.

c. A meticulous surgical technique (tissue handling, avoiding the use of gauzes in the abdomen, etc.) causes less adhesions: I strongly disagree / I disagree / I am Neutral / I agree / I strongly agree.

d.... and you apply it as much as possible for that reason: I strongly disagree / I disagree / I am Neutral / I agree / I strongly agree.

e. Extraperitoneal placement of a mesh causes less adhesions than intraperitoneal mesh placement: I strongly disagree / I disagree / I am Neutral / I agree / I strongly agree.

f. ... and you apply it as much as possible for that reason: I strongly disagree / I disagree / I am Neutral / I agree / I strongly agree.

g. A coated mesh causes less adhesions than a mesh without coating when its placed intraperitoneal: I strongly disagree / I disagree / I am Neutral / I agree / I strongly agree.

h.... and you apply it as much as possible for that reason: I strongly disagree / I disagree / I am Neutral / I agree / I strongly agree.

i. The use of electrosurgery causes less adhesions / I strongly disagree / I disagree / I am Neutral / I agree / I strongly agree.

j. ... and you apply it as much as possible for that reason: I strongly disagree / I disagree / I am Neutral / I agree / I strongly agree.

k. Reducing the intraperitoneal use of suture material results in less adhesions: I strongly disagree / I disagree / I am Neutral / I agree / I strongly agree.

I. ... and you apply it as much as possible for that reason: I strongly disagree / I disagree / I am Neutral / I agree / I strongly agree.

21. What is your opinion regarding products for adhesion prevention?

a. You do not believe in products for adhesion prevention: I strongly disagree / I disagree / I am Neutral / I agree / I strongly agree.

b. It is unclear when to use products for adhesion prevention: I strongly disagree / I disagree / I am Neutral / I agree / I strongly agree.

c. You rather use products for adhesions prevention that act locally than a product with effect throughout the whole abdomen: I strongly disagree / I disagree / I am Neutral / I agree / I strongly agree. 
d. You think that the cost of products for adhesion prevention are disproportional in comparison to the possible advantages: I strongly disagree / I disagree / I am Neutral / I agree / I strongly agree.

22. What factors are contributory to your trust in products for adhesion prevention?

23. What factors are contributory to your distrust in products for adhesion prevention?

24. The following products for adhesion prevention you have...

a. Interceed: never used it / never used it but would like to / used it in the last year / used it once.

b. Seprafilm: never used it / never used it but would like to / used it in the last year / used it once.

c. Adept: never used it / never used it but would like to / used it in the last year / used it once.

d. Spraygel: never used it / never used it but would like to / used it in the last year / used it once.

e. Hyalobarrier: never used it / never used it but would like to / used it in the last year / used it once.

f. Ringers lactate: never used it / never used it but would like to / used it in the last year / used it once.

g. Intercoat: never used it / never used it but would like to / used it in the last year / used it once.

25. For what indications have you used products for adhesion prevention?

a. Relaparotomy because of adhesion related problems: Never / Rarely / Regularly / Often / Very often.

b. Pancreas- and duodenum surgery: Never / Rarely / Regularly / Often / Very often.

c. Partial small bowel resection: Never / Rarely / Regularly / Often / Very often.

d. Creating an ileostomy: Never / Rarely / Regularly / Often / Very often.

e. Appendectomy: Never / Rarely / Regularly / Often / Very often.

f. Subtotal colectomy: Never / Rarely / Regularly / Often / Very often.

g. Panproctocolectomy: Never / Rarely / Regularly / Often / Very often.

h. Laparoscopic colon surgery: Never / Rarely / Regularly / Often / Very often.

i. Rectum procedure: Never / Rarely / Regularly / Often / Very often.

j. Abdominal wall surgery: Never / Rarely / Regularly / Often / Very often.

k. Aortic bifurcation prostheses: Never / Rarely / Regularly / Often / Very often.

26. How many times are products for adhesion prevention used by you and your colleagues in your hospital? \% of all laparotomies and \% of all laparoscopic procedures: 
27. Do you think that this percentage has increased over the last five years? Yes / No. Can you explain your answer?

28. Do you have a last remark regarding adhesions?

29. Your email-address: 



\title{
Chapter 3
}

\section{META score: an international consensus scoring system on mesh-tissue adhesions}

\author{
L.C.L. van den Hil \\ E.H.H. Mommers \\ J.W.A.M Bosmans \\ S. Morales-Conde \\ V. Gómez-Gil \\ K. LeBlanc \\ A. Vanlander \\ E. Reynvoet \\ F. Berrevoet \\ S. Gruber-Blum \\ E. Altinli \\ C.R. Deeken \\ R.H. Fortelny \\ J.W. Greve \\ K. Chiers \\ R. Kaufmann \\ J.F. Lange \\ U. Klinge \\ M. Miserez \\ A.H. Petter-Puchner \\ M.H.F. Schreinemacher \\ N.D. Bouvy
}

World Journal of Surgery 2020;44(9):2935-2943 


\section{Abstract}

\section{Background}

Currently, the lack of consensus on postoperative mesh tissue adhesion scoring leads to incomparable scientific results. The aim of this study was to develop an adhesion score recognised by experts in the field of hernia surgery.

\section{Material and methods}

Authors of three or more previously published articles on both mesh tissue adhesion scores and postoperative adhesions were marked as experts. They were queried on seven items using a modified Delphi method. The items concerned the utility of adhesion scoring models, the appropriateness of macroscopic and microscopic variables, the range and use of composite scores or sub scores, adhesion-related complications and follow-up length. This study comprised two questionnaire-based rounds and one consensus meeting.

\section{Results}

The first round was completed by 23 experts (82\%), the second round by 18 experts (64\%). Of those 18 experts, 10 were able to participate in the final consensus meeting and all approved the final proposal. From a total of 158 items, consensus was reached on 90 items. The amount of mesh surface covered with adhesions, tenacity and thickness of adhesions and organ involvement were concluded to be a minimal set of variables to be communicated separately in each future study on mesh adhesions.

\section{Conclusions}

The MEsh Tissue Adhesion (META) scoring system is the first consensus-based scoring system with a wide backing of renowned experts and can be used to assess meshrelated adhesions. By including this minimal set of variables in future research interstudy comparability and objectivity can be increased and eventually linked to clinically relevant outcomes. 


\section{Introduction}

Intra-abdominal mesh placement for incisional hernia repair is a well-known inducer of adhesions between intestines and mesh. ${ }^{1}$ Intra-abdominal adhesions are a known cause for serious postoperative complications such as bowel obstruction and abdominal pain. ${ }^{2,3}$ To prevent such complications, many meshes for intra-abdominal application have been designed using either anti-adhesive coatings or different materials such as PTFE to prevent adhesion formation.

Important factors influencing adhesion formation are mesh material, pore size and the presence of antiadhesive coatings. ${ }^{4}$ These factors may influence the number of adhesions, though complete adhesion prevention is currently not possible. ${ }^{4,5}$ Ideally, new designs and concepts could be tested in vitro, but with a lack of understanding and combining of so many variables involved in adhesion formation, testing of new surgical meshes still depends heavily on animal testing. ${ }^{6,7}$ Unfortunately, comparing the efficacy of anti-adhesive devices, both clinically and in animal research, has become increasingly difficult due to the abundance of various adhesion scores. Currently, there are over twenty different experimental and clinical adhesion scores available. ${ }^{8-10}$ Clearly, there is a lack of consensus on the ideal adhesion scoring method, and interstudy comparability is decreasing due to the increasing diversity in adhesion scores. ${ }^{8,10-12}$ Subsequently, this could lead to redundant tests with less reduction of animals-experiments and increased costs.

The goal of this study was to achieve consensus on an adhesion scoring method focusing on mesh-related adhesions using a modified Delphi method amongst an international panel of experts in an attempt to increase consistent outcome reporting in the field of intra-abdominal mesh-related adhesions. ${ }^{13}$ Consistent outcome reporting provides us information on similarities and differences in both experimental and clinical settings and eventually allows for a correlation with clinically relevant outcomes.

\section{Material and methods}

The Delphi method is a technique to evaluate a topic and to try to reach consensus on this topic. It comprises of multiple rounds of questionnaires, which are completed individually by an expert panel. The Delphi method is characterised by anonymity, controlled feedback to the expert panel, and statistical analysis of the results. ${ }^{14}$ This study used the RAND-UCLA Appropriateness Method (RAM), which is a modified Delphi score specifically aimed at the medical field. ${ }^{15}$

\section{Systematic review and panel formation}

PubMed, MEDLINE and EMBASE were searched to identify all publications on adhesion scoring models following the same methodology as recently published. ${ }^{16}$ Search criteria 
included abdominal 'hernia/herniation/wall defect', 'surgical mesh/meshes' and 'surgical adhesion/tissue adhesion'. The search was limited to articles published between January 1, 1990 and December 31, 2015. English, Dutch and German were used as language restriction. Studies were included if they reported about the presence of a mesh, mesh-tissue adhesions and the use of an adhesion score. In vitro studies, literature reviews and letters to the editor were excluded.

The potential experts were identified as having published at least three full-text publications on adhesion scoring systems or complications due to mesh-related adhesions. After a first invitation by e-mail, two personalized reminders were sent after one and two weeks. In case authors did not respond to the reminders, they were considered unreachable and were not included in the expert panel.

\section{Questionnaires}

Questionnaires were designed and distributed online (SurveyMonkey Inc, Palo Alto, CA). The questionnaires addressed multiple choice questions regarding seven main topics: 1) Utility of adhesion scoring models, 2) appropriateness of macroscopic variables, 3) appropriateness of microscopic variables, 4) composite scores versus sub scores, 5) the range of scoring scales, 6) adhesion-related complications, and 7) followup length.

Panel members were able to rate the questions on a nine-point Likert scale, ranging from very inappropriate (score 1) to very appropriate (score 9). Participants were encouraged to provide additional remarks in a free text field, such as other important variables or feedback on their answers.

At the end of each round, the results were statistically analysed and presented during the follow-up round.

In follow-up rounds, items without consensus were repeated and adjusted if required, according to comments received in the previous round. Supplementary questions were developed and added to the follow-up rounds in order to establish concrete variables for a new adhesion score.

\section{Final consensus meeting}

The last round of the Delphi method was a face-to-face meeting held during the $38^{\text {th }}$ International Congress of the European Hernia Society (EHS) in Rotterdam, The Netherlands. During this meeting, all remaining items without consensus were discussed. All experts who finished two questionnaire rounds were invited to participate in the meeting. After the meeting, a summary of the discussion was sent to the entire panel, followed by two suggestions for a new adhesion scoring model. The final adhesion score was selected based on the expert panel preference. 


\section{Statistical analysis}

All data were analysed using MS Excel 2015 (Microsoft Corporation, Redmond WA, USA). Consensus was reached if the panel rated a topic unanimously as either inappropriate (panel median 1-3) or appropriate (panel median 7-9), without disagreement. Disagreement was tested to identify considerable dispersion between ratings of panel members, using the inter-percentile range adjusted for symmetry, according to the RAND-UCLA Appropriateness Method Manual and as used by Moossdorff et al. ${ }^{15,17}$

\section{Results}

Fifty-seven international experts in the field of adhesion research were invited to participate and 28 experts accepted the invitation to participate in this Delphi. Panel characteristics are shown in Table 3.1.

Table 3.1 Characteristics of expert panel.

\begin{tabular}{lc}
\hline Characteristics of expert panel & \\
\hline Gender & 13 \\
Male & 5 \\
Female & \\
Function & 5 \\
M.D./Resident/Surgeon & 2 \\
Postdoctoral Researcher & 11 \\
Professor & \\
Country & 3 \\
Austria & 5 \\
Belgium & 1 \\
Germany & 2 \\
Spain & 4 \\
The Netherlands & 1 \\
Turkey & 2 \\
USA & \\
\hline
\end{tabular}

The first questionnaire was completed by 23 experts (82\%); 18 experts (64\%) completed the follow-up questionnaire. Ten of the 18 experts that finished the second round were also able to participate in the final face-to-face meeting. All 18 experts approved the last proposal of the new adhesion score. Figure 3.1 and Table 3.2 show a summary of the study outcomes and of the outcomes of the questionnaires and the face-to-face meeting. 
Figure 3.1 Flow of information through the Delphi analysis. The Delphi analysis consisted of three rounds and resulted in a consensus on $57 \%$ of the topics discussed. The figure provides a flowchart of information throughout the Delphi analysis, combined with the most important consensus reached in each round.

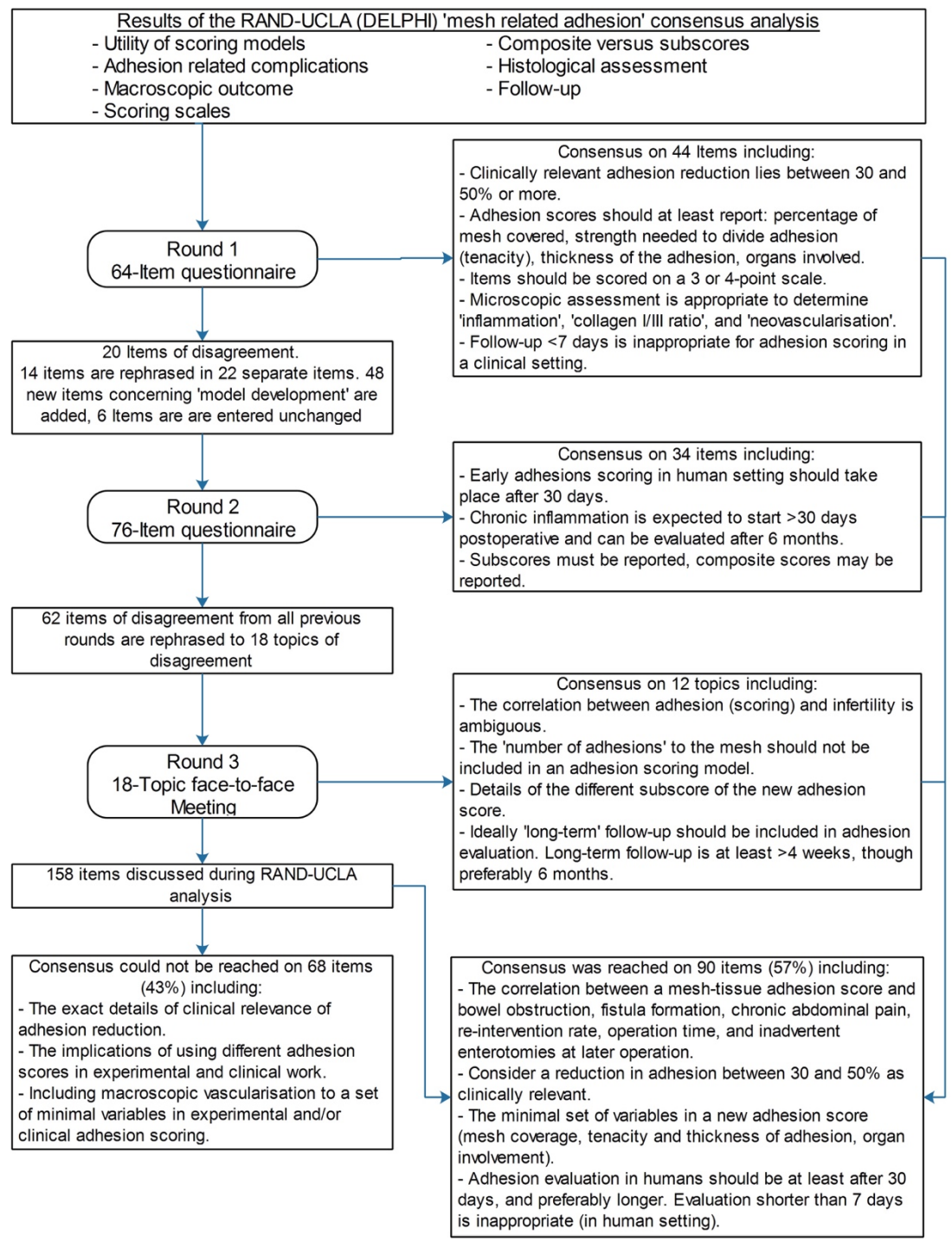


Table 3.2 Summary of outcomes of questionnaires and face-to-face meeting.

\begin{tabular}{lcr}
\hline & Number of Questions, $\mathbf{n}$ & Consensus, $\mathbf{n}(\%)$ \\
\hline Utility of adhesion scoring models & 10 & $7(70 \%)$ \\
Appropriateness of macroscopic variables & 42 & $19(45 \%)$ \\
Appropriateness of microscopic variables & 19 & $13(68 \%)$ \\
Composite scores versus sub scores & 4 & $2(50 \%)$ \\
Range of scoring scales & 33 & $21(64 \%)$ \\
Adhesion-related complications & 9 & $7(78 \%)$ \\
Follow-up length & 41 & $24(59 \%)$ \\
\hline
\end{tabular}

\section{Questionnaires}

The first questionnaire consisted of 64 items distributed over seven categories. After the first round, consensus was reached on 44 out of 64 items (69\%) of the presented items. Disagreement existed on the remaining 20 items. Fourteen of these 20 items were rephrased into 22 separate items. Six items remained unchanged.

The second questionnaire consisted of the 28 items extracted from the first questionnaire, combined with 48 new items, leading to a total of 76 items. The 48 new items were added to address the formulation of a new adhesion score. At the end of the second round, consensus was reached on another 34 out of 76 items (45\%) of the presented items. Consensus was achieved on one out of six of the remaining, unchanged items and on eight out of 22 of the adjusted items from the first round (32\%). Regarding the new items, consensus was achieved on 25 out of 48 items (52\%).

\section{Final face-to-face meeting}

The main goal of the meeting was to formulate the final variables that had to be included in a new adhesion scoring model. Furthermore, the most appropriate scoring scales and follow-up times had to be selected. Feedback on the first two rounds was provided to the participants before the final meeting. During the meeting, items on which no consensus was reached (summarized in 18 topics) were discussed. On 12 out of $18(66.7 \%)$ topics consensus was reached.

Next, a foundation for the scoring system was created and the scoring system was largely outlined. However, it was not possible to develop the scoring system to the smallest detail. Therefore, a subgroup of six authors drafted two detailed META scoring system, based on the gathered information. These two proposals for the MEsh Tissue Adhesion (META) scoring system were developed and sent to the 18 experts from round two to review the newly developed scores and to express the preferred score. Consensus for one score was reached, although disagreement persisted. After adjusting the score, a final version was sent to all the participants and approved. 


\section{Consensus based Adhesion Scoring Model}

All experts consented that mesh-tissue adhesions should be scored systematically in both human and experimental settings and that a uniform consensus-based scoring method should be used to increase interstudy comparability. According to the experts, mesh-related adhesion scores had to exist primarily of macroscopic variables. Variables included in the META scoring system are 1) percentage of mesh surface covered with adhesions, 2) strength needed to divide adhesions (tenacity), 3) thickness of adhesions, and 4) organ involvement (see Table 3.3).

Any new scoring system for intra-abdominal mesh-tissue adhesions is preferably based on a four- or five-point scale to allow adequate variation in responses and statistical analyses. Follow-up times in experimental research should be at least four weeks after mesh-implantation to evaluate chronic inflammation. Follow-up of clinical studies on mesh-related adhesions should include a minimum follow-up of 6 months.

Table 3.3 META scoring system with each item scored and reported separately.

\begin{tabular}{ll}
\hline Item & Score \\
\hline Percentage of mesh surface covered with adhesions & 0 \\
$0 \%$ & 1 \\
$1-25 \%$ & 2 \\
$26-50 \%$ & 3 \\
$51-75 \%$ & 4 \\
$76-100 \%$ & 0 \\
Tenacity & 1 \\
No adhesions & 2 \\
Loose adhesions easily released by traction only & 3 \\
Adhesions require sharp dissection, no organ/serosal damage & 0 \\
Adhesions require sharp dissection, with unavoidable organ/serosal damage & 1 \\
Thickness of adhesions & 2 \\
No adhesions & 3 \\
Single thin, filmy adhesion & 4 \\
Multiple thin, filmy adhesions & \\
Single dense adhesion with or without filmy adhesions & \\
Multiple dense adhesions with or without filmy adhesions & 0 \\
Organ involvement & 1 \\
No adhesions & 2 \\
Adhesions between mesh and omentum or a solid organ & 3 \\
Adhesions between mesh and part(s) of the intestinal tract & \\
Adhesions between mesh and part(s) of the intestinal tract with enteric fistulas or bowel erosion 3
\end{tabular}

The META-consensus score consist of four main items. 1) 'Percentage of mesh surface covered with adhesion' can either be scored by automated computer analysis of pictures taken during surgery, or be estimated by the surgeon. 2) 'Tenacity' depends on the tools needed for adhesiolysis and relates to the strength of the adhesions. 3) 'Thickness of adhesions' is divided in four categories of adhesions. Macroscopically, two types of adhesions can be scored (filmy or dense) the categories are based on either single or multiple adhesions of both types. 4) 'Organ involvement' scores the adhered structures and increases in severity with increased adherence to the intestinal tract. The most severe category describes adhesions to the intestinal tract combined with macroscopic damage or interference with an organ such as fistula formation or bowel erosion. When reporting the META-consensus score, all items must be scored and reported individually in order to increase comparability between publications. An overall score can be calculated by adding all individual categories, though the relevance of this sum is unclear. Follow-up times in experimental research have to be a minimum of four weeks after mesh-implantation. In clinical studies the minimal follow-up time should be 6 months. 


\section{Discussion}

This paper describes the establishment of a consensus based scoring system for mesh related adhesions. The authors of this article hope that this score will be able to serve as a reporting standard for future research.

As such, the described score should be reported whenever adhesions with meshes in an experimental or human setting are studied. By doing so, we will be able to improve comparability between studies, reduce unnecessary experiments, and hopefully correlate scores with clinical outcomes. Based on such research further refinement and validation of the scoring system will also be possible.

To validate the META scoring system, a small group of researchers, preferably from different research groups, should be formed. This group should score adhesions using the META scoring system and subsequently the outcomes should be compared. Ideally, adhesions are scored by researchers anonymously in an experimental setting. However, it might be hard to schedule an experiment at one timepoint with researchers from different international research groups and therefore a first step could be to score adhesions based on photographs. Next, the scores should be compared and differences in outcomes should be discussed. If it turns out that a description of one or more variables is unclear, the description will be adjusted. Subsequently, the research group should score the adhesions again, using this new description. Eventually, a meeting with the researchers should be scheduled to confirm the first outcomes in an experimental setting. Next, to validate the META scoring system, another group of researchers should approve the findings by performing the same experiment as described above.

It may seem unusual that yet another scoring system had to be determined, while over 20 adhesion scores already exist. However, a general disadvantage of these scores is that none of them have ever been validated, nor consistently used or reported by other research groups. Furthermore, variables in the adhesion scores have often been ill-defined, making it difficult to replicate and interpret the scores correctly and therefore lead to a moderate reproducibility. ${ }^{18}$ Even if the variables are clearly stated, the risk on limited reproducibility persists. ${ }^{9,19}$ In order to create more uniformity and to increase reproducibility, the META scoring system has been developed based on the opinion of eighteen leading experts in the field of adhesion research, using a modified Delphi analysis. This analysis has proven to be of benefit, because it is developed for the medical field as a tool to combine the best available evidence and experts opinion, when randomized clinical trials regarding a specific topic are absent. ${ }^{15}$ Although the included variables do not differ much from the currently existing scores, the usage of the score and how researchers can assign a score to each variable have been extensively described.

It is recommended to report all variables separately to compare results between studies accurately and to enable future analyses of each variable. In such way, it might lead to the conclusion that some variables closely correlate with one another and thus 
do not bring additional information, but even more so a correlation of one or more variables with clinically relevant outcomes could be examined more closely. The META scoring system score can be interpreted as a minimal set of outcome criteria that can be used as a standalone scoring system or be supplemented with other outcome variables, if desired.

The most important difference with other adhesion scores is that all authors realize that this scoring system is probably just a first step in order to create uniformity, hopefully leading to better understanding of mesh tissue formation and important involved variables. With this information it could be that the current META scoring system requires adjustments. This awareness in combination with the desire to understand tissue adhesions and create uniformity in mesh tissue adhesion research is the main strength of the META scoring system and hopefully contributes to the development of an ideal adhesion score, based on the data gathered using the META scoring system.

Another strength is that questionnaires were filled out anonymously, making experts' status influencing the outcomes impossible, thus leading to objective opinions. Unfortunately, not all invited researchers responded to our invitation to participate in this search for consensus. Authors who did become a panel member are convinced that a uniform scoring method is needed.

Next, some limitations must be addressed. The major weakness of the META scoring system and all other adhesion scores, is that the correlation between included variables and clinical outcomes is not clear yet. Ideally, higher scores correlate perfectly with impaired clinical outcomes. However, it is difficult to assess clinical outcomes, such as functional impairment, especially in experimental research and therefore the currently included variables have been chosen as objectively measurable proxies. In the end, it may eventually appear that different scores for experimental and clinical setting should be used.

Next, ambiguity exists about topics as difference in tenacity and thickness of adhesions or follow-up time, as can be explained by a lack of objective criteria and definitions. Since full consensus was not to be expected, the current consensus has attempted to describe these variables as simple and clear as possible. Nevertheless, interobserver differences can still occur and further assessment of the intra- and interobserver variability, also among different labs, is warranted.

Furthermore, consensus was reached on only $59 \%$ of topics. Regarding the first main topic 'utility of adhesion scoring models', it remained unclear whether the same adhesion score can be used in experimental and clinical research, since it is unclear what the relevance is of the presence of adhesions, even more so in different species or at different follow-up lengths. However, by using a uniform mesh adhesion scoring system, data from both experimental and clinical studies can be collected in order to compare these data.

Interestingly, the expert panel concluded that only a reduction in an adhesion score of at least $50 \%$ should be considered relevant. No consensus was reached on a 
reduction in adhesion scores of $20-30 \%$, even though $20-30 \%$ reduction has often been considered to be a good result in experimental research. However, during a gynaecology consensus meeting regarding postoperative adhesion prevention, it was suggested that also a single adhesion can cause severe complications. ${ }^{20}$ This could lead to the conclusion that only the presence of adhesions is of interest. However, experts feel that a higher adhesion score indicates a higher probability that clinical events may arrive. Next, a higher adhesion score is associated with an increased risk of enterotomies. ${ }^{21}$ Yet, only describing the presence of adhesions is too limited to compare future studies and relate the outcomes with clinical outcomes.

The experts in our panel agreed that chronic abdominal pain, bowel obstruction, fistula formation, re-intervention rate, operation time and inadvertent enterotomies at later operations are associated with adhesions which are findings from large observational studies. ${ }^{3,21,22}$ Interestingly, a recently published meta-analysis shows that the relation between adhesions and chronic abdominal pain is debatable. Although, it is shown that adhesiolysis reduced chronic abdominal pain on the short-term, it remains unclear whether adhesiolysis is effective on the long-term. Considering the short-term results, there seems to be a relation between the presence of adhesions and chronic abdominal pain. ${ }^{23}$ Regarding infertility, the expert panel agreed that they found it inappropriate to correlate adhesions and infertility, because too many factors are involved in infertility.

Recommended follow-up times are at least four weeks in experimental animal studies and six months in clinical studies to first evaluate chronic inflammation. After four weeks of follow-up in experimental research, it is believed that the chronic inflammatory phase starts and significant changes in adhesion morphology are unlikely to happen hereafter. ${ }^{5,24}$ Since the appropriate time point for long-term follow-up depends partly on the size of the animal, no recommendations regarding long-term follow-up are formulated. For practical reasons, it is considered appropriate in a clinical setting to score mesh-tissue adhesions during eventual future re-operations, thus usually on the long-term.

Next to macroscopic variables, also microscopic variables are of interest in meshtissue adhesion research. According to this Delphi analysis, the presence of inflammatory cells, collagen and neovascularization are important variables and can provide further information regarding biocompatibility of meshes. ${ }^{25,26}$ However, the expert panel preferred separate scores for macroscopic and microscopic variables and chose not to include the microscopic items in the current adhesion scoring system.

An important factor for the META scoring system to succeed, is an adequate distribution of the score. Therefore, the META scoring system will be distributed among the research groups and cooperating research groups of the expert panel. Each expert can explain how the score should be used and if questions arise, the experts can answer these questions. Next, the META scoring system will be sent to all 57 experts, who were initially invited to participate in this study, since they have shown their interest in this topic. Furthermore, we want to present the results of this manuscript and the new 
scoring system at several congresses, in particular at hernia specific congresses. With this strategy, a broad audience will be reached.

\section{Conclusion}

The META scoring system is a consensus-based minimal set of outcome parameters for clinical and animal (anti)adhesive research. It was agreed by a wide array of experts in the field of mesh-related adhesions to be a scoring system that can increase study comparability between different research groups and different research models and improve translatability into clinical practice. Wide implementation is however key and the support of the scoring system by the current group of authors will hopefully be followed by new research groups and journal editors alike. 


\section{References}

1. Luijendijk RW, de Lange DC, Wauters CC, Hop WC, Duron JJ, Pailler JL, et al. Foreign material in postoperative adhesions. Ann Surg. 1996;223(3):242-8.

2. Turza KC, Butler CE. Adhesions and meshes: synthetic versus bioprosthetic. Plast Reconstr Surg. 2012;130(5 Suppl 2):206s-13s.

3. ten Broek RP, Issa Y, van Santbrink EJ, Bouvy ND, Kruitwagen RF, Jeekel J, et al. Burden of adhesions in abdominal and pelvic surgery: systematic review and met-analysis. BMJ. 2013;347:f5588.

4. Zhu LM, Schuster P, Klinge U. Mesh implants: An overview of crucial mesh parameters. World J Gastrointest Surg. 2015;7(10):226-36.

5. Schreinemacher MH, van Barneveld KW, Dikmans RE, Gijbels MJ, Greve JW, Bouvy ND. Coated meshes for hernia repair provide comparable intraperitoneal adhesion prevention. Surg Endosc. 2013;27(11): 4202-9.

6. Peeters E, van Barneveld KW, Schreinemacher MH, De Hertogh G, Ozog Y, Bouvy N, et al. One-year outcome of biological and synthetic bioabsorbable meshes for augmentation of large abdominal wall defects in a rabbit model. J Surg Res. 2013;180(2):274-83.

7. Gruber-Blum S, Brand J, Keibl C, Redl H, Fortelny RH, May C, et al. The impact of hydrophobic hernia mesh coating by omega fatty acid on atraumatic fibrin sealant fixation. Hernia. 2015;19(4):651-7.

8. Diamond MP, Linsky CB, Cunningham T, Constantine B, diZerega GS, DeCherney AH. A model for sidewall adhesions in the rabbit: reduction by an absorbable barrier. Microsurgery. 1987;8(4):197-200.

9. de Oliveira N, Paschoa AF, Crespo CC, Massumoto CM, Adam C. [Use of the combination of a nitrofurazone derivative with polyethylene glycols in the prevention of the formation of peritoneal adhesions - experimental study]. Arq Gastroenterol. 1981;18(2):54-9.

10. Zuhlke HV, Lorenz EM, Straub EM, Savvas V. [Pathophysiology and classification of adhesions]. Langenbecks Archiv fur Chirurgie Supplement II, Verhandlungen der Deutschen Gesellschaft fur Chirurgie Deutsche Gesellschaft fur Chirurgie Kongress. 1990:1009-16.

11. Dubcenco E, Assumpcao L, Dray X, Gabrielson KL, Ruben DS, Pipitone LJ, et al. Adhesion formation after peritoneoscopy with liver biopsy in a survival porcine model: comparison of laparotomy, laparoscopy, and transgastric natural orifice transluminal endoscopic surgery (NOTES). Endoscopy. 2009;41(11): 971-8.

12. Claudio RH, Diogo Filho A, Mamede Filho DO. Peritoneostomy with latex coated polypropylene: experimental study in rats. Acta Cir Bras. 2006;21(6):402-8.

13. Schreinemacher $M$, Henatsch $D$, van Barneveld K, Bouvy $N$. The need for standardised animal models and scoring systems in assessing mesh biocompatibility. Hernia. 2010;14(3):335-6.

14. Dalkey NC. Delphi. Santa Monica, CA: RAND Corporation. 1967.

15. Fitch K, Bernstein SJ, Aguilar MD, Burnand B, LaCalle JR, Lazaro P, et al. The RAND/UCLA Appropriateness Method User's Manual. Santa Monica, CA: RAND Corporation. 2001.

16. Vogels RRM, Kaufmann R, van den Hil LCL, van Steensel S, Schreinemacher MHF, Lange JF, et al. Critical overview of all available animal models for abdominal wall hernia research. Hernia. 2017;21(5):667-75.

17. Moossdorff M, van Roozendaal LM, Strobbe LJ, Aebi S, Cameron DA, Dixon JM, et al. Maastricht Delphi consensus on event definitions for classification of recurrence in breast cancer research. J Natl Cancer Inst. 2014;106(12).

18. Bellon JM, Contreras LA, Bujan J, Jurado F. Effect of phosphatidylcholine on the process of peritoneal adhesion following implantation of a polypropylene mesh prosthesis. Biomaterials. 1996;17(14): 1369-72.

19. Garrard CL, Clements RH, Nanney L, Davidson JM, Richards WO. Adhesion formation is reduced after laparoscopic surgery. Surg Endosc-Ultras. 1999;13(1):10-3.

20. Diamond MP, Wexner SD, diZereg GS, Korell M, Zmora O, Van Goor H, et al. Adhesion prevention and reduction: current status and future recommendations of a multinational interdisciplinary consensus conference. Surg Innov. 2010;17(3):183-8.

21. ten Broek RP, Strik C, Issa Y, Bleichrodt RP, van Goor H. Adhesiolysis-related morbidity in abdominal surgery. Ann Surg. 2013;258(1):98-106.

22. Losanoff JE, Richman BW, Jones JW. Entero-colocutaneous fistula: a late consequence of polypropylene mesh abdominal wall repair: case report and review of the literature. Hernia. 2002;6(3):144-7. 
23. van den Beukel BA, de Ree R, van Leuven S, Bakkum EA, Strik C, van Goor H, et al. Surgical treatment of adhesion-related chronic abdominal and pelvic pain after gynaecological and general surgery: a systematic review and meta-analysis. Hum Reprod Update. 2017;23(3):276-88.

24. Matthews BD, Mostafa G, Carbonell AM, Joels CS, Kercher KW, Austin C, et al. Evaluation of adhesion formation and host tissue response to intra-abdominal polytetrafluoroethylene mesh and composite prosthetic mesh. J Surg Res. 2005;123(2):227-34.

25. Anderson JM, Rodriguez A, Chang DT. Foreign body reaction to biomaterials. Semin Immunol. 2008;20(2):86-100.

26. Gomez-Gil V, Garcia-Honduvilla N, Pascual G, Rodriguez M, Bujan J, Bellon JM. Peritoneal adhesion formation and reformation tracked by sequential laparoscopy: optimizing the time point for adhesiolysis. Surgery. 2010;147(3):378-91. 




\section{PART II}

Abdominal wall closure and hernia repair; experimental findings 



\section{Chapter 4}

Prevention of incisional hernia using different suture materials for closing the abdominal wall; a comparison of PDS ${ }^{\circledR}$, Vicryl $^{\circledR}$ and Prolene ${ }^{\circledR}$ in a rat model

S. van Steensel

L. C. L. van den Hil

A. Bloemen

M. J. Gijbels

S. O. Breukink

J. Melenhorst

K. Lenaerts

N. D. Bouvy 


\section{Abstract}

\section{Purpose}

An incisional hernia occurs frequently after a midline incision with an incidence of $12.8 \%$. The choice of suture material used for abdominal wall closure is not straightforward and the conflicting literature focuses on clinical outcomes. This study compares a non-absorbable, slow-absorbable and fast-absorbable suture in a rat model, focusing on histological outcomes, predicting better fascia healing.

\section{Material and methods}

Thirty three male Wistar rats were divided in three groups, each receiving two separate $1 \mathrm{~cm}$ incisions closed with either Prolene ${ }^{\circledR} 4 / 0$, PDS $^{\circledR} 4 / 0$ or Vicryl ${ }^{\circledR} 4 / 0$. At 7 days and 21 days, one of the incisions was explanted. Tissue was semi-quantitatively scored regarding the presence of inflammatory cells and collagen fibers. Using qPCR macrophage polarisation, fibroblast activity and vascularization were evaluated. Data were analyzed by Kruskal-Wallis test with Mann-Whitney $U$ post hoc test. A $p$-value of 0.017 was considered significant after Bonferroni correction.

\section{Results}

All animals recovered without complications and completed the 21 days of follow-up. The Vicryl $^{\circledR}$ group showed a higher presence of macrophages after 21 days in comparison with Prolene ${ }^{\circledR}(p=0.003)$ and PDS $^{\circledast}(p=0.006)$ and more foreign body giant cells compared to Prolene ${ }^{\circledR}$ at 7 days $(p=0.010)$ and PDS ${ }^{\circledast}$ at 21 days $(p<0.001)$. qPCR showed 2.5-fold higher expression of clec10A in PDS $^{\circledR}$ compared to Prolene ${ }^{\circledR}$ after 7 days $(p=0.007)$.

\section{Conclusions}

The results of this study reluctantly support the use of PDS ${ }^{\circledR}$ suture, compared to Prolene $^{\circledR}$ and Vicryl $^{\circledR}$, in abdominal wall closure based on a favourable macrophage response. The heterogeneity and variability in the data might be explained by the spectrum of the macrophage subtype paradigm. 


\section{Introduction}

An incisional hernia is a frequent complication following abdominal surgery and is defined as any abdominal wall gap with or without a bulge in the area of a postoperative scar perceptible or palpable by clinical examination or imaging. ${ }^{1,2}$ Bulging, discomfort or pain and cosmetic issues have a significant impact on the quality of life of patients. ${ }^{3}$

At a weighted mean follow-up of 23.7 months, $12.8 \%$ of the patients have developed an incisional hernia and the estimated risk to undergo an incisional hernia repair after a midline incision is $5.2 \% .{ }^{4}$ In high-risk patients, the incidence increases to up to $30 \% .{ }^{5,6}$ The identified patient-related risk factors are obesity $\left(\mathrm{BMI}>25 \mathrm{~kg} / \mathrm{m}^{2}\right)$, the presence of an abdominal aortic aneurysm and congenital connective tissue disorders. ${ }^{7-12}$ Furthermore, postoperative wound complications are an independent risk factor for the development of an incisional hernia. ${ }^{9}$

With unacceptable high recurrence rates after incisional hernia repair, that ranges from $23.8 \%$ to $32 \%{ }^{13-16}$, a preventive strategy has become the focus of scientific research. In high-risk patients, preventive mesh placement proves an effective tool in reducing incisional hernia rates. ${ }^{6,17,18}$ However, if the mesh is placed intra-peritoneally, delayed wound healing and increased pain after 6 week follow-up are observed. ${ }^{19}$ Thus, improving the technique of primary abdominal wall closure might be advantageous.

The technique for closure of the abdominal wall after a midline incision has evolved from using interrupted sutures to a continuous running monofilament suture technique. ${ }^{20,21}$ Also, a small stitch suture technique, with a $4: 1$ suture length to wound length ratio, decreases the incidence of incisional hernia. ${ }^{22,23}$ The European Hernia Society formulated a guideline for the closure of the abdominal wall incorporating the previous statements. This guideline makes a weak recommendation for abdominal wall closure with slow-absorbable sutures, which is adopted in standard clinical practice. ${ }^{24}$ Multiple meta-analyses report conflicting results regarding the preferable suture material, caused by substantial heterogeneity between studies and inclusion criteria. $^{4,20,21,25}$

Two meta-analyses suggested the use of slow-absorbable sutures based on a lower occurrence of suture sinuses and wound pain, but in the absence of a difference in incisional hernia occurrence. ${ }^{21,25}$ The most recent meta-analysis recommended slowabsorbable sutures based on a decrease of incisional hernia compared to fastabsorbable sutures, but a separate comparison between only slow-absorbable and nonabsorbable sutures was not performed. ${ }^{20}$ Lastly, Bosanquet et al. suggested in a metaregression that suture material does not have influence on incisional hernia rate or on the occurrence of suture sinuses. ${ }^{4}$

Collagen metabolism plays a central role in the healing of the abdominal wall. Collagen maturation and collagen breakdown in particular are crucial. A decreased collagen I/III ratio is indicative of a low presence of mature collagen. Also increased MMP activity, responsible for collagen type I denaturation, is involved in abdominal 
hernia development. ${ }^{26}$ However, the healing process of the abdominal wall is still not fully understood. This unknown factor complicates the discussion regarding incisional hernia prevention.

The aim of this study is to investigate the effect of different types of suture materials on the healing of the abdominal wall in a rat model. Giving insight to physiological and pathophysiological processes might lead to new starting points for preventive strategies.

\section{Material and methods}

The protocol was approved by the animal ethics committee of the Maastricht University conform the Dutch Experiments on Animals Act.

\section{Materials}

A non-absorbable monofilament polypropylene suture (Prolene ${ }^{\circledR} 4 / 0$, Ethicon Inc; Johnson \& Johnson, Somerville, NJ, USA), a slow-absorbable monofilament polydioxanone suture $\left(\mathrm{PDS}^{\circledR}\right.$ || 4/0, Ethicon Inc; Johnson \& Johnson, Somerville, NJ, USA), and a fast-absorbable multifilament polyglactine suture (Vicryl $\left.\right|^{\circledR} 4 / 0$, Ethicon Inc; Johnson \& Johnson, Somerville, NJ, USA) were obtained commercially.

\section{Study design}

Thirty three male Wistar rats between 240 and $260 \mathrm{~g}$ were acquired from a registered breeding facility (Envigo, Horst, the Netherlands), housed at the Maastricht University animal facilities and cared for according to local protocol. The animals were socially housed in filter-topped cages with a $12 \mathrm{~h}$ day-night cycle and had free access to food and water. Because of hormonal influences on wound healing by progesterone and estrogen ${ }^{27}$ and a faster postoperative weight recovery of males compared to females ${ }^{28}$, only male rats were used in this experiment. The animals were randomly assigned to one of the three groups for abdominal wall closure of two separate midline incisions by either Prolene ${ }^{\circledast} 4 / 0$, PDS $^{\circledast} 4 / 0$ or Vicryl ${ }^{\circledR} 4 / 0$. There were two time points for tissue evaluation, after 7 days and 21 days of follow-up.

\section{Procedure}

After a 1-week acclimatization period, preoperative pain medication (buprenorphine $0.05 \mathrm{mg} / \mathrm{kg}$ ) was administered. Anesthesia was induced using $3-4 \%$ isoflurane and maintained with $2.5 \%$ isoflurane through inhalation of an air mixture. The animal was placed on a sterile field after the abdomen was shaved and the skin was disinfected with $2 \%$ iodine solution. 
Via a midline incision of $6 \mathrm{~cm}$ in the skin, the abdominal wall was exposed. Two smaller full-thickness incisions of approximately $1 \mathrm{~cm}$ were made in the midline of the exposed abdominal wall, with a minimal distance of $2 \mathrm{~cm}$ between the two incisions. The two incisions were closed with either Prolene ${ }^{\circledR} 4 / 0$, PDS $^{\circledR} 4 / 0$ or Vicryl ${ }^{\circledR} 4 / 0$ using a continuous suture technique; the skin was closed with Monocryl 4/0 (Ethicon Inc; Johnson \& Johnson, Somerville, NJ, USA). Postoperatively, the animals were administrated fluid resuscitation and recovered under a heat lamp.

After 7 days of follow-up, one of the closed midline incisions was explanted and after 21 days of follow-up the second previously closed midline incision was explanted after killing, using the operative procedure as described above. Using the previous midline incision, randomly either the upper or lower abdominal wall incision was explanted equally distributed over the experimental groups. The explanted specimens were cut in half and one half was preserved in liquid nitrogen and the other half in formaldehyde $4 \%$ for further analysis. The animals were killed by carbon dioxide overdose at the completion of the follow-up at 21 days.

\section{Histology}

Half of the explanted incision was fixed in $4 \%$ formaldehyde, dehydrated and embedded in paraffin. Subsequently, $4 \mu \mathrm{m}$ thick tissue sections were cut and a hematoxylin-eosin staining was performed. An experienced animal pathologist, who was blinded to the group allocation, evaluated the stained sections microscopically. To compare inflammation and collagen deposition, granulocytes, macrophages, foreign body giant cells and collagen fibers were scored using a four point semi-quantitative scoring system (not present, slightly present, moderately present or abundantly present). ${ }^{29-32}$

\section{RNA isolation and quantitative real time PCR}

Total RNA was isolated from the snap-frozen abdominal wall specimen using TRI reagent (Sigma, NL). 750 ng DNAse-treated RNA was used to synthesise cDNA (SensiFAST ${ }^{\mathrm{TM}}$, cDNA synthesis kit, Bioline, London, UK). For qPCRs, a volume of $10 \mu \mathrm{l}$ consisting of the CDNA equivalent of $2.5 \mathrm{ng}$ total RNA, $1 \times$ Absolute qPCR SYBR Green Fluorescein Mix (SensiFAST TM SYBR Hi-ROX Kit, Bioline, London, UK) and $0.15 \mu \mathrm{M}$ of gene-specific primers (Sigma, NL) was used (Supplementary Table S4.1). The LightCycler ${ }^{\circledR} 480$ Instrument II (Roche Molecular Systems, Inc.) was used to perform the qPCR. LinRegPCR software was used to establish gene expression levels. The geometric mean of two internal control genes, Rplp0 and beta-actin (Actb), was calculated and used as normalisation factor. In one sample in the Vicryl ${ }^{\circledR}$ group, insufficient cDNA was available for analysis with Actb, resulting in unreliable data. Rplp0 showed no expression in one sample from the Prolene ${ }^{\circledR}$ group. For both samples, one reliable housekeeping gene was available, which was used as normalization factor. Relevant 
primers were identified from the literature and built using a primer designing tool (Primer-blast) $^{33}$; the sequences are reported in Table 4.1.

Table 4.1 All primers were tested for transcription of the intended gene.

\begin{tabular}{|c|c|c|c|c|}
\hline Gene name & $\begin{array}{l}\text { Product } \\
\text { length }\end{array}$ & & GC\% & Sequence \\
\hline \multirow[t]{2}{*}{ rplpO (ribosomal protein lateral stalk subunit P0) } & 190 & $f$ & 55.00 & CCTCACCGAGATTAGGGACA \\
\hline & & $r$ & 45.00 & ATCGCTCAGGATTTCAATGG \\
\hline \multirow[t]{2}{*}{ actb (actin, beta) } & 297 & $f$ & 55.00 & CCGCGAGTACAACCTTCTTG \\
\hline & & $r$ & 55.00 & CAGTTGGTGACAATGCCGTG \\
\hline \multirow[t]{2}{*}{ il6 (Interleukin 6) } & 246 & $f$ & 57.14 & СTCTCCGCAAGAGACTTCCAG \\
\hline & & r & 47.62 & TTCTGACAGTGCATCATCGCT \\
\hline \multirow[t]{2}{*}{ nos2 (iNOS) } & 234 & $f$ & 52.38 & TAGTCAACTACAAGCCCCACG \\
\hline & & $r$ & 60 & GTGAGGAACTGGGGGAAACC \\
\hline \multirow[t]{2}{*}{ cd86 (CD86) } & 164 & $f$ & 45.45 & AGACATGTGTAACCTGCACCAT \\
\hline & & $r$ & 55 & TACGAGCTCACTCGGGCTTA \\
\hline \multirow[t]{2}{*}{ il10 (Interleukin 10) } & 186 & $f$ & 52.38 & CGACGCTGTCATCGATTTCTC \\
\hline & & $r$ & 60.00 & CAGTAGATGCCGGGTGGTTC \\
\hline \multirow[t]{2}{*}{ clec10a (C-type lectin domain containing 10a) } & 164 & $f$ & 60.00 & GAGGCTTGAGCCAGAAGGTG \\
\hline & & $r$ & 52.38 & TGCTGAGCCGTTGTTCTTGAG \\
\hline \multirow[t]{2}{*}{ mrc1 (mannose receptor $C$ typ 1 ) } & 212 & $f$ & 60.00 & CCCGCTCCTCAAGACAATCC \\
\hline & & $r$ & 55.00 & AAATACGGTGACTGCCCACC \\
\hline \multirow[t]{2}{*}{ cd163 (CD163) } & 131 & $f$ & 60 & CTCTGAAGCGACGACAGACC \\
\hline & & r & 50 & ATGCCAACCCGAGGATTTCA \\
\hline \multirow[t]{2}{*}{$\operatorname{tgfb1}$ (transforming growth factor- $\beta$ ) } & 115 & $f$ & 60.00 & GGCTGAACCAAGGAGACGGA \\
\hline & & $r$ & 55.00 & CCTCGACGTTTGGGACTGAT \\
\hline \multirow[t]{2}{*}{ vegfa (vascular endothelial growth factor a) } & 235 & $f$ & 60 & AGAAGGGGAGCAGAAAGCCC \\
\hline & & $r$ & 47.83 & GATCCGCATGATCTGCATAGTGA \\
\hline \multirow[t]{2}{*}{ angpt2 (angiopoietin 2) } & 168 & $f$ & 55 & CATGATGTCATCGCCCGACT \\
\hline & & $r$ & 52.38 & TCCATGTCACAGTAGGCCTTG \\
\hline \multirow[t]{2}{*}{ nos3 (eNOS) } & 139 & $f$ & 52.38 & GAATGGAGAGAGCTTTGCAGC \\
\hline & & $r$ & 60 & CCGCCAAGAGGATACCAGTG \\
\hline \multirow[t]{2}{*}{ col1a1 (collagen type 1 alpha 1 chain) } & 237 & $f$ & 60 & CTGACTGGAAGAGCGGAGAG \\
\hline & & $r$ & 55.00 & CAGGATCGGAACCTTCGCTT \\
\hline \multirow[t]{2}{*}{ mmp1 (matrix metallopeptidase 1 ) } & 144 & $f$ & 55.00 & AAGGCCACTGGTGATCTTGC \\
\hline & & $r$ & 43.48 & GGTATTTCCAGACTGTTTCCACA \\
\hline \multirow[t]{2}{*}{ fn1 (Fibronectin 1) } & 165 & $f$ & 63.16 & TCCCCTCCCAGAGAAGTGG \\
\hline & & $r$ & 43.48 & TTGGGGAAGCTCATCTGTCTTTT \\
\hline
\end{tabular}

\section{Statistical analysis}

A sample-size calculation was performed in preparation of the experiment. A difference of $20 \%$ in inflammation on a histological level was considered relevant, with a variance of $\pm 16 \%$. Alpha was chosen at 0.05 and with a power of 0.80 , resulting in a needed group size of 11 animals per group.

All data were expressed as a median with range or mean with $95 \%$ confidence interval. Nonparametric tests were performed using a Kruskal-Wallis test. In case of significance, a Mann-Whitney $U$ post hoc test was performed to identify specific differences between the groups. A Bonferroni correction was used to correct for 
multiple testing, so a $p$-value of $0.017(0.05 / 3)$ was considered significant. SPSS 23.0 for Mac (SPSS Inc., Chicago, IL, USA) was used for the statistical analysis.

\section{Results}

Recovery was uncomplicated for all rats. No postoperative complications were encountered and all animals completed the 21 days of follow-up.

\section{Histology}

For the histological evaluation, 31 out of 33 samples at 7 days and 30 out of 33 samples at 21 days were available for analysis. Two samples in the PDS ${ }^{\circledR}$ group were missing for both time points and one sample for the Vicryl ${ }^{\circledR}$ group at 21 days of follow-up.

The presence of granulocytes ranged from absent to abundantly present at 7 days of follow-up (Figure 4.1a). The presence of granulocytes declined at 21 days of followup to a score of slightly present (Figure 4.1b). At 7 days and 21 days, the differences between the three groups were not significant, $p=0.621$ and $p=0.539$, respectively. Macrophages were slightly to abundantly present at seven days of follow-up, without significant differences between the groups $(p=0.257)$. The overall presence of macrophages decreased, but remained significantly higher in the Vicryl ${ }^{\circledR}$ group compared to both Prolene ${ }^{\circledR}(p=0.003)$ and $\operatorname{PDS}^{\circledR}(p=0.006)$ at 21 days of follow-up. The presence of macrophages did not differ significantly between Prolene ${ }^{\circledR}$ and PDS ${ }^{\circledR}$ after 21 days $(p=0.324)$ (Figure 4.2). The Vicry ${ }^{\circledR}$ group showed the highest presence of foreign body giant cells at both time points compared to both Prolene ${ }^{\circledR}(p=0.010)$ at both 7 days and 21 days $(p=0.001)$ and compared to PDS $^{\circledR}$ at 21 days $(p<0.001)$. At 7 days follow-up, no significant difference was detected between Vicryl ${ }^{\circledR}$ and PDS $^{\circledR}$ regarding foreign body giant cells $(p=0.021)$. Furthermore, Prolene ${ }^{\circledR}$ and PDS ${ }^{\circledast}$ were comparable regarding the presence of foreign body giant cells at both time points ( $p=0.830$ and 0.053 , respectively) (Figure 4.3).

Collagen was moderately present at 7 days in almost all samples $(p=0.403)$. After 21 days, no significant difference was detected between the three groups regarding the presence of collagen ( $p=0.202$ ) (Figure 4.4).

\section{qPCR}

No samples were excluded in the gene expression analysis. Expression of genes in the PDS $^{\circledR}$ group was set as the norm and the expression in the Prolene ${ }^{\circledR}$ and Vicryl ${ }^{\circledR}$ groups was presented in relation to set norm. 
Figure 4.1 Semi-quantitative scoring of the presence of granulocytes at 7 days and 21 days follow-up per suture type. At 7 days: $p=0.621$, at 21 days: $p=0.539$.

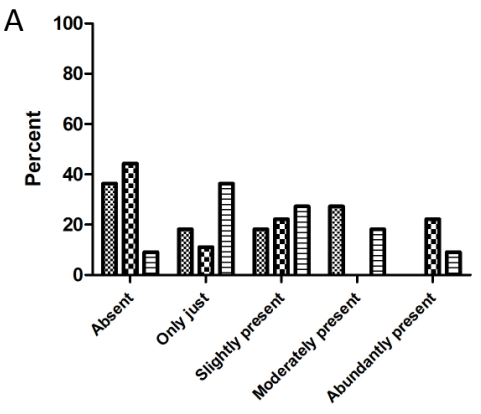

Granylocyte presence at 7 days follow-up
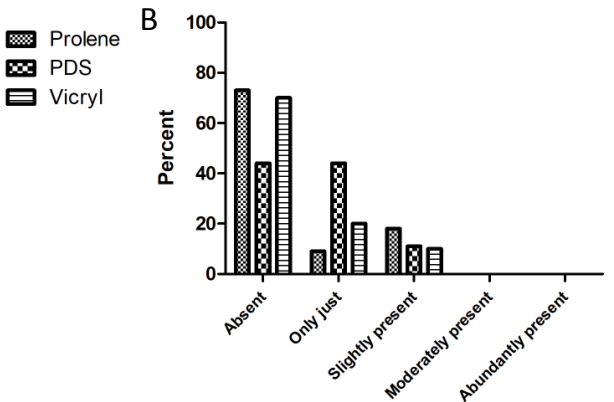

Granylocyte presence at 21 days follow-up

Figure 4.2 Semi-quantitative scoring of the presence of macrophages at 7 days and 21 days follow-up per suture type. At 7 days: $p=0.257$, at 21 days: Prolene ${ }^{\circledR}$ versus Vicry $\left.\right|^{\circledR} p=0.003$, PDS ${ }^{\circledR}$ versus Vicryl ${ }^{\circledR} p=0.006$, Prolene $^{\circledR}$ versus PDS $p=0.324$.

A

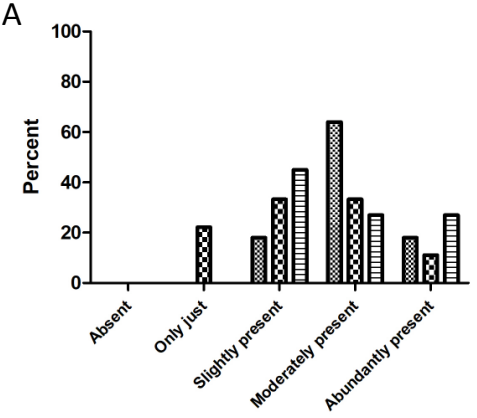

Macrophage presence at 7 days follow-up

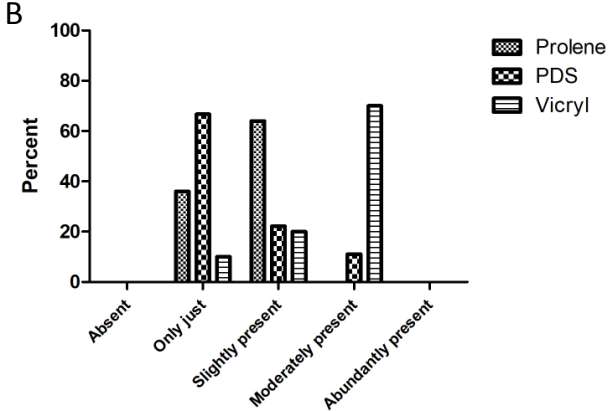

Macrophage presence at 21 days follow-up

Figure 4.3 Semi-quantitative scoring of the presence of foreign-body giant cells at 7 days and 21 days follow-up per suture type. At 7 days: Vicryl ${ }^{\circledR}$ versus Prolene $^{\circledR} p=0.010$, Vicryl ${ }^{\circledR}$ versus PDS $p=0.021$, Prolene $^{\circledR}$ versus PDS ${ }^{\circledR} p=0.830$, at 21 days: Vicryl ${ }^{\circledR}$ versus Prolene ${ }^{\circledR} p=0.001$, Vicryl $^{\circledR}$ versus PDS ${ }^{\circledR} p<0.001$, Prolene ${ }^{\circledR}$ versus PDS ${ }^{\circledR} p=0.053$.

A

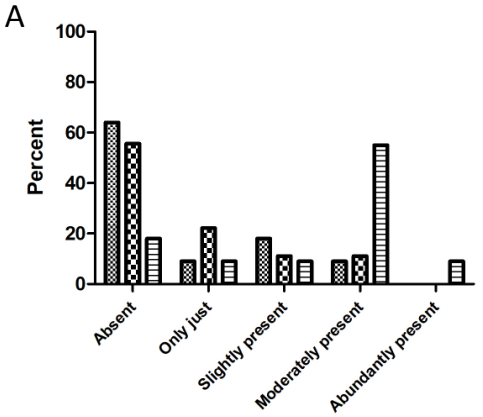

Foreign-body giant cell presence at 7 days follow-up

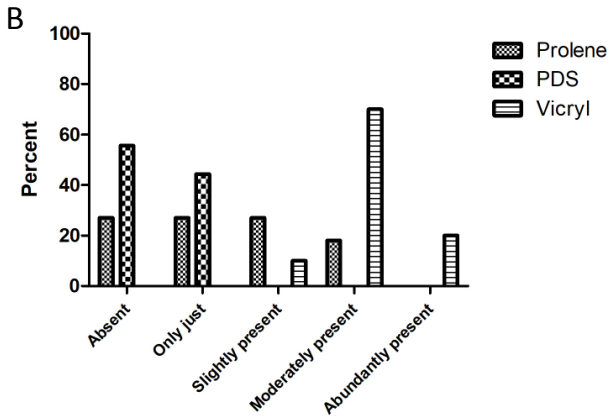

Foreign-body giant cell presence at 21 days follow-up 
Figure 4.4 Semi-quantitative scoring of the presence of collagen at $\mathbf{7}$ days and 21 days follow-up per suture type. At 7 days: $p=0.403$, at 21 days: $p=0.202$.

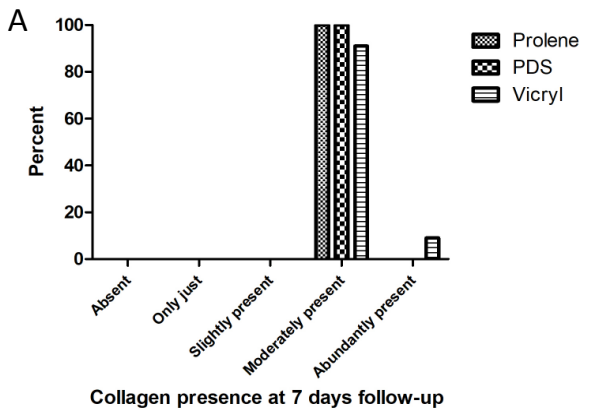

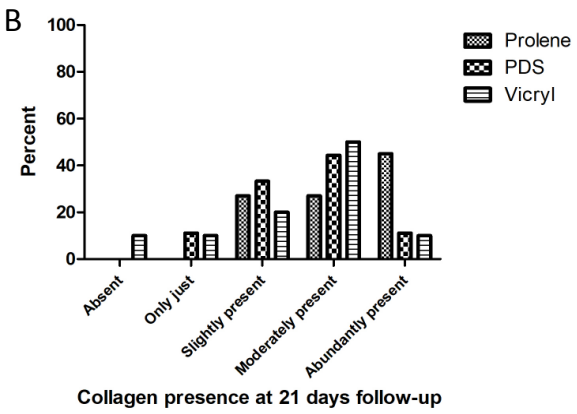

\section{Macrophage polarization}

Two macrophage subtypes are known, subtype 1 (M1) has pro-inflammatory properties and is associated with tissue injury. Subtype $2(\mathrm{M} 2)$ is associated with extracellular matrix remodeling and regulation of fibroblasts. ${ }^{34-36}$ To evaluate the presence of macrophage subtype 1, the expression of interleukin 6 (il6), nos2 and cd86 was determined. Nos2 expression was a 2 -fold lower in the Prolene ${ }^{\circledR}$ group at 7 days followup, compared with the PDS ${ }^{\circledR}$ group, but not significantly $(p=0.932)$. 116, cd86 and nos 2 expression did not differ significantly between groups on both time points (see Figure 4.5). $\mathrm{M} 2$ polarization is induced by interleukin $10(i / 10)^{36,37}$ and macrophage subtype 2 is identified by an increased expression of i10, clec10a, mrc1 (cd206), cd163 and tgfb1. $T g f b 1$ is typically expressed by the macrophage subtype $2 c{ }^{36,38-40}$ A significantly higher expression of clec10a was found in the PDS ${ }^{\circledR}$ group in comparison to Prolene ${ }^{\circledR}$ at 7 days follow-up, namely 2.5 -fold higher ( $p=0.007$ ). At 21 days, no significant differences were detected and the clec10a expression in both the Prolene ${ }^{\circledR}$ and Vicryl ${ }^{\circledR}$ groups was comparable to the $\mathrm{PDS}^{\circledR}$ group. Although not significantly, a twofold lower il10 expression was observed at 7 days follow-up in the Prolene ${ }^{\circledR}$ group compared to the PDS $^{\circledR}$ group. Mrc1 expression was 2.5-fold higher in the PDS $^{\circledR}$ group compared to Prolene $^{\circledR}$ and Vicryl $^{\circledR}$ at 7 days follow-up $(p=0.761)$ without reaching significance. The expression of $t g f b 1$ was a 1.4-fold lower in the Prolene ${ }^{\circledR}$ group compared to the PDS ${ }^{\circledR}$ group at 7 days follow-up ( $p=0.619$ ). A 3.3-fold and 1.4-fold lower expression of $c d 163$ was encountered in the Prolene ${ }^{\circledR}$ and Vicryl ${ }^{\circledR}$ groups, respectively, in comparison to the PDS $^{\circledR}$ group at 7 days follow-up $(p=0.117)$. The differences between groups in expression of $i l 10, m r c 1, \operatorname{tg} f b 1$ and $c d 163$ were not significant at both time points (see Figure 4.6). 
Figure 4.5 Scatterplots of relative expression of genes typically expressed by macrophage subtype 1 (cd86, nos2 and il6) at 7 days and 21 days follow-up. The expression in the Vicryl ${ }^{\circledR}$ and Prolene ${ }^{\circledR}$ group are depicted in relation to the PDS ${ }^{\circledR}$ group, which was set as the norm.

cd86
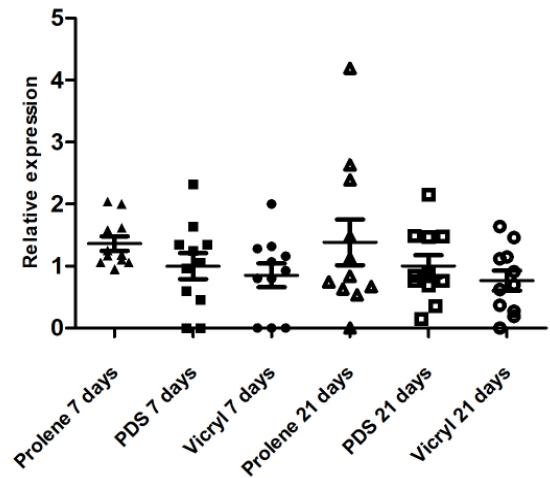

116

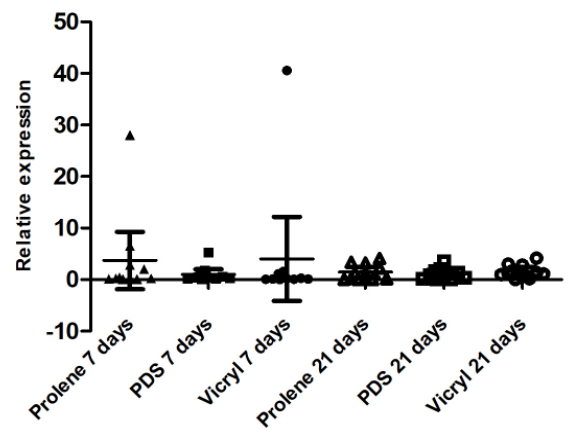

nos2

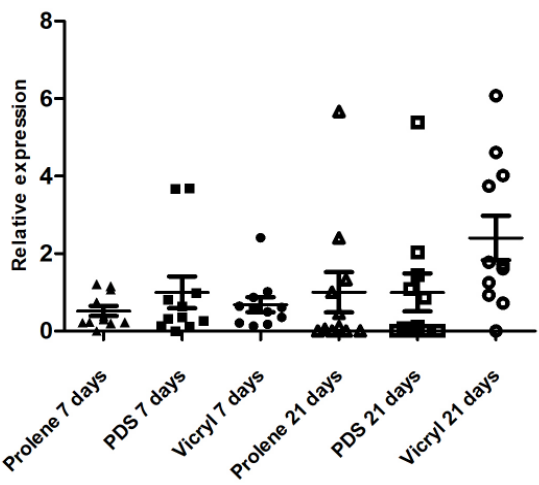

\section{Vascularization and fibroblast expression}

Furthermore, vascularization was evaluated using vegfa, angtp2 and nos3 expression $^{41,42}$, but no significant difference was detected between the groups regarding the expression (see Figure 4.7). Collagen type 1 alpha 1 chain (colla1), mmp1 and $f n 1$ expression were a measure for fibroblast activity. ${ }^{39,43}$ Prolene $^{\circledR}$ induced a 2.5 -fold lower expressions of $m m p 1$ at 7 days $(p=0.161)$ and twofold lower at 21 days $(p=0.180)$ in comparison to $\mathrm{PDS}^{\circledR}$. The comparison between groups regarding the expression of $f n 1, c o l 1 a 1$ and $m m p 1$ did not reveal significant differences (see Figure 4.7). 
Figure 4.6 Scatterplots of relative expression of genes typically expressed by macrophage subtype 2 (clec10a, il10, mrc1, tgfb1 and $c d 163$ ) at 7 days and 21 days follow-up. The expression in the Vicryl ${ }^{\circledR}$ and Prolene ${ }^{\circledR}$ group are depicted in relation to the PDS $^{\circledR}$ group, which was set as the norm. ${ }^{*} p=0.014$.

clec10a
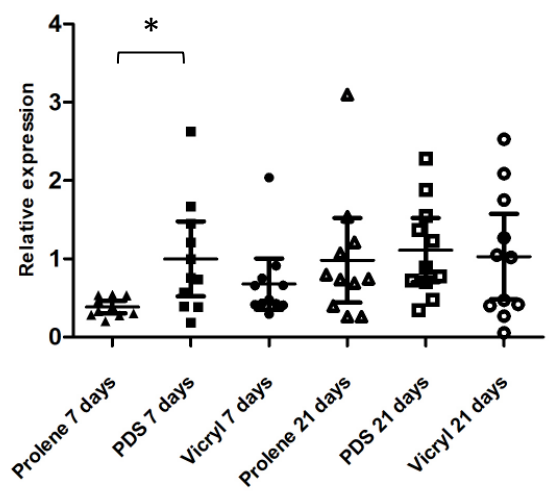

mrc1
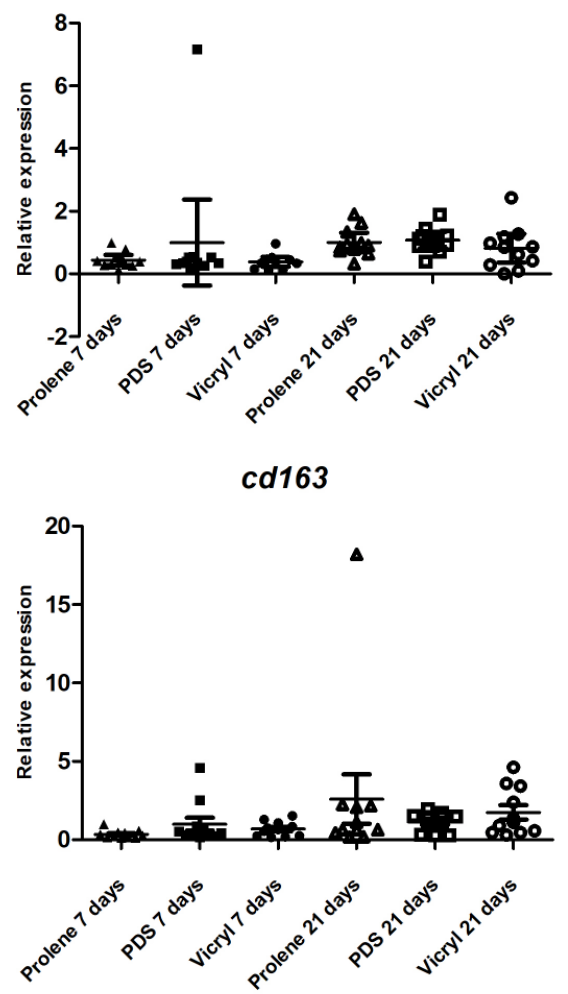

||10

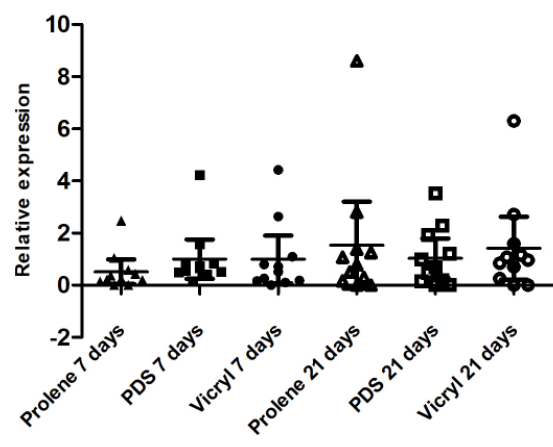

tgfb1

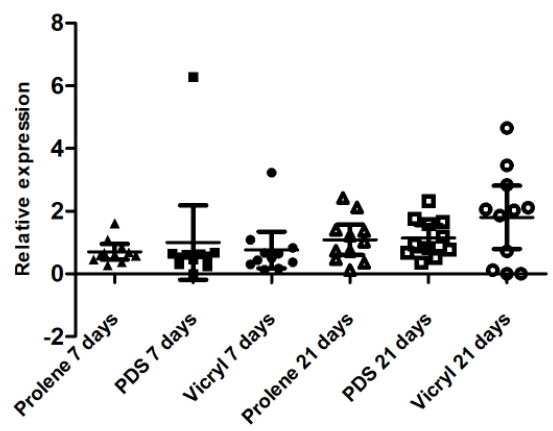


Figure 4.7 Scatterplots of relative expression of genes typically expressed in case of vascularization (vegfa, angtp2 and nos3) and by fibroblast (col1a1, mmp1 and fn1) at 7 days and 21 days follow-up. The expression in the Vicryl ${ }^{\circledR}$ and Prolene ${ }^{\circledR}$ group are depicted in relation to the PDS $^{\circledR}$ group, which was set as the norm.

vegfa
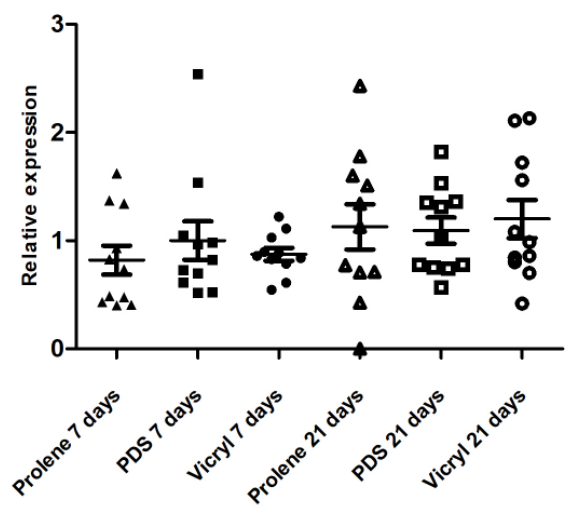

nos3
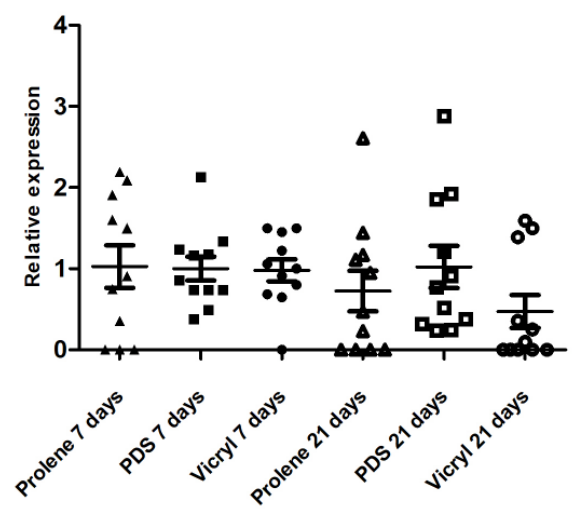

mmp1
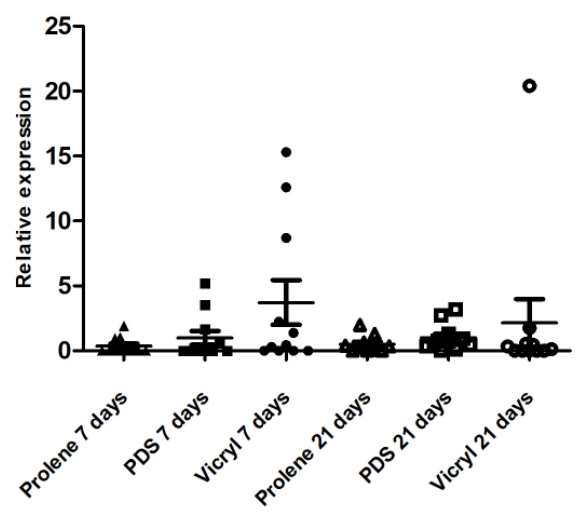

angtp2

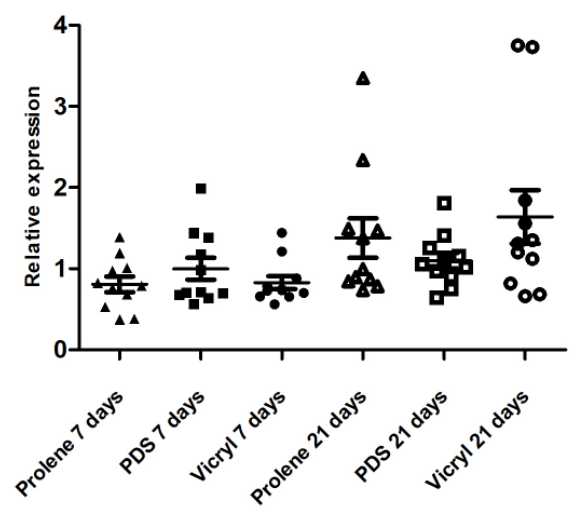

col1a1
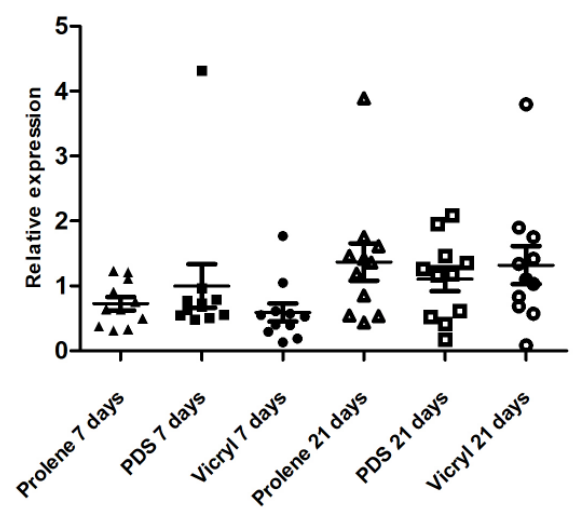

fn1
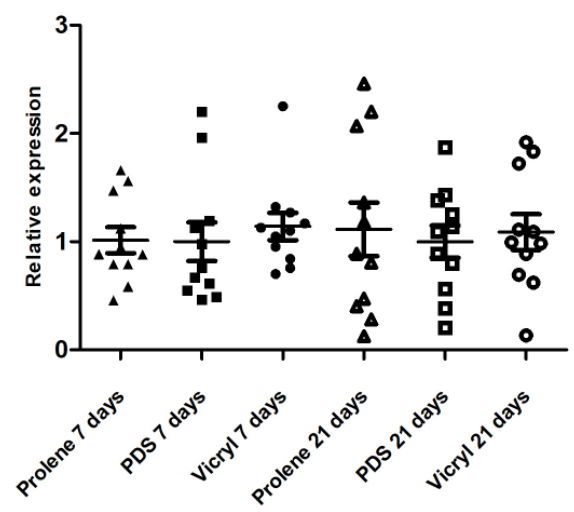


\section{Discussion}

The technique for closure of the abdominal wall is evolving to prevent incisional hernia development. Both the use of a small bite technique shows a reduction in the incidence of incisional hernia ${ }^{22,23}$, as well as mesh placement after a laparotomy prevents incisional hernia in high-risk patients. ${ }^{6,18}$ Reports in the literature regarding the optimal suture material for the closure of the abdominal wall are conflicting and focus on clinical outcomes, such as incisional hernia, suture sinuses and wound pain., 21,25,44

The meta-analyses comparing non-absorbable sutures versus slow-absorbable sutures are confounded by factors in the study population; multiple types of incisions, emergency versus elective surgery and different suture materials or techniques are included. In the comparison between non-absorbable and slow-absorbable sutures, no differences are detected regarding the incisional hernia rate. ${ }^{21,25}$ However, slowabsorbable sutures do result in less wound pain and suture sinuses. This experiment intends to provide a pathophysiological foundation for the choice in suture material, hypothesizing that improved healing of the abdominal wall leads to a reduction of the incidence of incisional hernia.

A fast-absorbable, slow-absorbable and non-absorbable suture material was compared in a rat model. In general, the foreign body reaction to biomaterials is subdivided into four phases: protein absorption, cell recruitment and adhesion, foreign body giant cell formation and finally extracellular matrix formation and fibrotic encapsulation. ${ }^{45,46}$ In this experiment, the focus lies on the last three phases. Tissues were microscopically examined regarding the presence of different types of cells and collagen fibers. Consequently, the gene expression was determined using qPCR to explore vascularization, fibroblast activity and macrophage polarization.

The presence of macrophages was significantly higher in the Vicryl ${ }^{\circledR}$ group after 21 days and simultaneously more foreign body giant cells were encountered compared to Prolene ${ }^{\circledR}$ at 7 days and compared to PDS $^{\circledR}$ at 21 days. PDS ${ }^{\circledR}$ and Vicryl ${ }^{\circledR}$ are both absorbable sutures which rely on hydrolysis for degradation. ${ }^{47,48}$ Polylactic and polyglycolid acids, polymers both present in $\operatorname{Vicryl}^{\circledR}$, depend on phagocytosis by macrophages and especially foreign body giant cells for complete absorption. ${ }^{45,49}$ Vicryl ${ }^{\circledR}$ elicits a stronger macrophage response in comparison to Prolene ${ }^{\circledR}$ and PDS $^{\circledR}$, which also results in more foreign body giant cells. The interaction between host and suture might play a role in its degradation and absorption. Although, in that case a similar finding would be expected in $\mathrm{PDS}^{\circledR}$. PDS ${ }^{\circledR}$ differs from Vicryl ${ }^{\circledR}$ in the polymer used and the fact that it is a monofilament suture in contrast to Vicryl ${ }^{\circledR}$ which is braided. ${ }^{48}$ These factors contribute to the difference in absorption rate between PDS $^{\circledR}$ and $\mathrm{Vicry}^{\circledR}{ }^{\circledR}$, which, in the case of the faster absorption rate of $\mathrm{Vicryl}^{\circledR}$, can negatively affect the occurrence of incisional hernia. This concurs with clinically based results from a previous report, in which slow-absorbable sutures were considered superior regarding the incidence of incisional hernia compared to fast-absorbable sutures. ${ }^{20}$ 
After determining the quantity of macrophages present, the polarization between macrophage subtype 1 and 2 was evaluated using qPCR. Macrophage subtype 2 and its signaling play an essential role in liver regeneration, skeletal muscle healing and scar formation after injury of the skin..$^{50-52}$ Therefore, it was hypothesized that the macrophage subtype 2, which modulates extracellular matrix and activates fibroblasts ${ }^{34-36}$, would have a positive effect on abdominal wall healing.

Clec10a expression, typical for macrophage subtype 2, was significantly higher in the PDS $^{\circledR}$ group compared to the Prolene ${ }^{\circledR}$ group. This suggests a more dominant presence of macrophage subtype 2 in the healing process. A striking number of genes (il10, mrc1, cd163, tgf -b) typical for subtype 2 macrophages showed higher expression, although not significantly, when the abdominal wall was closed with PDS ${ }^{\circledR}$ instead of Prolene $^{\circledR}$ after 7 days follow-up. The expression levels of the genes $m r c 1$ and $c d 163$ were higher in the presence of PDS ${ }^{\circledR}$ compared to Vicryl ${ }^{\circledR}$ and Prolene ${ }^{\circledR}$ after 7 days, without reaching significance. Nos2, typically expressed by the macrophage subtype 1 , and $m m p 1$ showed a similar pattern. Although no significant differences could be detected, multiple genes typically expressed by subtype 2 macrophages were high in expression in the PDS $^{\circledast}$ group versus one subtype 1 specific gene. This could be interpreted as a distinct pattern, suggesting a dominant macrophage subtype 2 presence after abdominal wall closure with PDS $^{\circledR}$. The effect disappears after 21 days of follow-up, which coincides with the progression of the healing process. The findings regarding macrophage polarization concur with reports on scaffolds of different biomaterials, concluding a mainly anti-inflammatory macrophage polarization in reaction to PDS $^{\circledast}$ (polydioxanone). Regarding polypropylene and polylactic acid, both the pro-inflammatory and anti-inflammatory macrophage responses were reported. ${ }^{53}$

The presence of different cell types in the analyzed samples might result in various expression patterns, which could influence qPCR results. In addition, the macrophage polarization is described as a spectrum rather than a black and white differentiation. ${ }^{54-56}$ This may cause heterogeneity in the qPCR data and might limit the ability to reach a statistical difference. This might also be an argument for a larger sample size than calculated for this experiment to reach adequate power.

Recording the mere presence of macrophages no longer suffices in evaluation of the healing process of the abdominal wall and novel insights in macrophage polarization need to be taken into account. Subtyping and activation of macrophages provide additional information on the regenerative process taking place in the abdominal wall. The anti-inflammatory subtype 2 macrophage is associated with tissue regeneration and is, therefore, assumed to have a positive effect on the healing process. ${ }^{34-36,50-52}$ The results of this experiment suggest a favorable macrophage response to $\mathrm{PDS}^{\circledR}$ in comparison to Prolene ${ }^{\circledR}$ and Vicryl ${ }^{\circledR}$, which in turn might benefit the regenerative capacity of the abdominal wall. This provides a new perspective on the dilemma of appropriate suture material in abdominal wall closure, which is of added value to the existing literature, which is mostly based on clinical outcomes. 


\section{Conclusion}

This study provides an argument reluctantly supporting the use of PDS ${ }^{\circledR}$ suture, in comparison to Vicryl ${ }^{\circledR}$ or Prolene ${ }^{\circledR}$ for closure of the abdominal wall. This is based on limited evidence indicating macrophage subtype 2 polarization, a favorable macrophage response which could play a role in the regeneration process of the abdominal wall. 


\section{References}

1. Korenkov M, Paul A, Sauerland S, Neugebauer E, Arndt M, Chevrel JP, et al. Classification and surgical treatment of incisional hernia. Results of an experts' meeting. Langenbecks Arch Surg. 2001;386(1): 65-73.

2. Muysoms FE, Miserez M, Berrevoet F, Campanelli G, Champault GG, Chelala E, et al. Classification of primary and incisional abdominal wall hernias. Hernia. 2009;13(4):407-14.

3. van Ramshorst GH, Eker HH, Hop WC, Jeekel J, Lange JF. Impact of incisional hernia on health-related quality of life and body image: a prospective cohort study. Am J Surg. 2012;204(2):144-50.

4. Bosanquet DC, Ansell J, Abdelrahman T, Cornish J, Harries R, Stimpson A, et al. Systematic Review and Meta-Regression of Factors Affecting Midline Incisional Hernia Rates: Analysis of 14,618 Patients. PLoS One. 2015;10(9):e0138745.

5. Bloemen A, van Dooren P, Huizinga BF, Hoofwijk AG. Comparison of ultrasonography and physical examination in the diagnosis of incisional hernia in a prospective study. Hernia. 2012;16(1):53-7.

6. Jairam AP, Timmermans L, Eker HH, Pierik R, van Klaveren D, Steyerberg EW, et al. Prevention of incisional hernia with prophylactic onlay and sublay mesh reinforcement versus primary suture only in midline laparotomies (PRIMA): 2-year follow-up of a multicentre, double-blind, randomised controlled trial. Lancet. 2017;390(10094):567-76.

7. Antoniou GA, Georgiadis GS, Antoniou SA, Granderath FA, Giannoukas AD, Lazarides MK. Abdominal aortic aneurysm and abdominal wall hernia as manifestations of a connective tissue disorder. J Vasc Surg. 2011;54(4):1175-81.

8. Henriksen NA, Helgstrand F, Vogt KC, Jorgensen LN, Bisgaard T, Danish Hernia D, et al. Risk factors for incisional hernia repair after aortic reconstructive surgery in a nationwide study. J Vasc Surg. 2013; 57(6):1524-30, 30 e1-3.

9. Hoer J, Lawong G, Klinge U, Schumpelick V. [Factors influencing the development of incisional hernia. A retrospective study of 2,983 laparotomy patients over a period of 10 years]. Chirurg. 2002;73(5):474-80.

10. Judge DP, Dietz HC. Marfan's syndrome. Lancet. 2005;366(9501):1965-76.

11. Kroese LF, Mommers EH, Robbens C, Bouvy ND, Lange JF, Berrevoet F. Complications and recurrence rates of patients with Ehlers-Danlos syndrome undergoing ventral hernioplasty: a case series. Hernia. 2018;22(4):611-6.

12. Uden A, Lindhagen T. Inguinal hernia in patients with congenital dislocation of the hip. A sign of general connective tissue disorder. Acta Orthop Scand. 1988;59(6):667-8.

13. Burger JW, Luijendijk RW, Hop WC, Halm JA, Verdaasdonk EG, Jeekel J. Long-term follow-up of a randomized controlled trial of suture versus mesh repair of incisional hernia. Ann Surg. 2004;240(4): 578-83; discussion 83-5.

14. Flum DR, Horvath K, Koepsell T. Have outcomes of incisional hernia repair improved with time? A population-based analysis. Ann Surg. 2003;237(1):129-35.

15. Helgstrand F, Rosenberg J, Kehlet $H$, Strandfelt $P$, Bisgaard T. Reoperation versus clinical recurrence rate after ventral hernia repair. Ann Surg. 2012;256(6):955-8.

16. Luijendijk RW, Hop WC, van den Tol MP, de Lange DC, Braaksma MM, JN IJ, et al. A comparison of suture repair with mesh repair for incisional hernia. N Engl J Med. 2000;343(6):392-8.

17. Bevis PM, Windhaber RA, Lear PA, Poskitt KR, Earnshaw JJ, Mitchell DC. Randomized clinical trial of mesh versus sutured wound closure after open abdominal aortic aneurysm surgery. Br J Surg. 2010;97(10):1497-502.

18. Muysoms FE, Detry O, Vierendeels T, Huyghe M, Miserez M, Ruppert M, et al. Prevention of Incisional Hernias by Prophylactic Mesh-augmented Reinforcement of Midline Laparotomies for Abdominal Aortic Aneurysm Treatment: A Randomized Controlled Trial. Ann Surg. 2016;263(4):638-45.

19. Kohler A, Lavanchy JL, Lenoir U, Kurmann A, Candinas D, Beldi G. Effectiveness of Prophylactic Intraperitoneal Mesh Implantation for Prevention of Incisional Hernia in Patients Undergoing Open Abdominal Surgery: A Randomized Clinical Trial. JAMA Surg. 2019;154(2):109-15.

20. Diener MK, Voss S, Jensen K, Buchler MW, Seiler CM. Elective midline laparotomy closure: the INLINE systematic review and meta-analysis. Ann Surg. 2010;251(5):843-56.

21. van 't Riet M, Steyerberg EW, Nellensteyn J, Bonjer HJ, Jeekel J. Meta-analysis of techniques for closure of midline abdominal incisions. Br J Surg. 2002;89(11):1350-6. 
22. Deerenberg EB, Harlaar JJ, Steyerberg EW, Lont HE, van Doorn HC, Heisterkamp J, et al. Small bites versus large bites for closure of abdominal midline incisions (STITCH): a double-blind, multicentre, randomised controlled trial. Lancet. 2015;386(10000):1254-60.

23. Millbourn D, Cengiz Y, Israelsson LA. Effect of stitch length on wound complications after closure of midline incisions: a randomized controlled trial. Arch Surg. 2009;144(11):1056-9.

24. Muysoms FE, Antoniou SA, Bury K, Campanelli G, Conze J, Cuccurullo D, et al. European Hernia Society guidelines on the closure of abdominal wall incisions. Hernia. 2015;19(1):1-24.

25. Sajid MS, Parampalli U, Baig MK, McFall MR. A systematic review on the effectiveness of slowlyabsorbable versus non-absorbable sutures for abdominal fascial closure following laparotomy. Int J Surg. 2011;9(8):615-25.

26. Henriksen NA, Yadete DH, Sorensen LT, Agren MS, Jorgensen LN. Connective tissue alteration in abdominal wall hernia. Br J Surg. 2011;98(2):210-9.

27. Gilliver SC, Ashworth JJ, Ashcroft GS. The hormonal regulation of cutaneous wound healing. Clin Dermatol. 2007;25(1):56-62.

28. Mommers EH, Hong L, Jongen A, Bouvy ND. Baseline performance of the ischaemic button model for induction of adhesions in laboratory rats. Lab Anim. 2019;53(1):63-71.

29. Schreinemacher MH, Emans PJ, Gijbels MJ, Greve JW, Beets GL, Bouvy ND. Degradation of mesh coatings and intraperitoneal adhesion formation in an experimental model. Br J Surg. 2009;96(3): 305-13.

30. Schreinemacher MH, van Barneveld KW, Dikmans RE, Gijbels MJ, Greve JW, Bouvy ND. Coated meshes for hernia repair provide comparable intraperitoneal adhesion prevention. Surg Endosc. 2013;27(11):4202-9.

31. van den Hil LCL, Vogels RRM, van Barneveld KWY, Gijbels MJJ, Peutz-Kootstra CJ, Cleutjens JPM, et al. Comparability of histological outcomes in rats and humans in a hernia model. J Surg Res. 2018;229: 271-6.

32. Vogels RR, van Barneveld KW, Bosmans JW, Beets G, Gijbels MJ, Schreinemacher MH, et al. Long-term evaluation of adhesion formation and foreign body response to three new meshes. Surg Endosc. 2015;29(8):2251-9.

33. Ye J, Coulouris G, Zaretskaya I, Cutcutache I, Rozen S, Madden TL. Primer-BLAST: a tool to design targetspecific primers for polymerase chain reaction. BMC Bioinformatics. 2012;13:134.

34. Martin P, Leibovich SJ. Inflammatory cells during wound repair: the good, the bad and the ugly. Trends Cell Biol. 2005;15(11):599-607.

35. Wynn TA, Barron L. Macrophages: master regulators of inflammation and fibrosis. Semin Liver Dis. 2010;30(3):245-57.

36. Martinez FO, Gordon S. The M1 and M2 paradigm of macrophage activation: time for reassessment. F1000Prime Rep. 2014;6:13.

37. Murray PJ, Wynn TA. Obstacles and opportunities for understanding macrophage polarization. J Leukoc Biol. 2011;89(4):557-63.

38. Barros MH, Hauck F, Dreyer JH, Kempkes B, Niedobitek G. Macrophage polarisation: an immunohistochemical approach for identifying $M 1$ and $M 2$ macrophages. PLoS One. 2013;8(11): e80908.

39. Ploeger DT, Hosper NA, Schipper M, Koerts JA, de Rond S, Bank RA. Cell plasticity in wound healing: paracrine factors of $M 1 / M 2$ polarized macrophages influence the phenotypical state of dermal fibroblasts. Cell Commun Signal. 2013;11(1):29.

40. Wolf MT, Dearth CL, Ranallo CA, LoPresti ST, Carey LE, Daly KA, et al. Macrophage polarization in response to ECM coated polypropylene mesh. Biomaterials. 2014;35(25):6838-49.

41. Fukumura D, Gohongi T, Kadambi A, Izumi Y, Ang J, Yun CO, et al. Predominant role of endothelial nitric oxide synthase in vascular endothelial growth factor-induced angiogenesis and vascular permeability. Proc Natl Acad Sci U S A. 2001;98(5):2604-9.

42. Gale NW, Thurston G, Hackett SF, Renard R, Wang Q, McClain J, et al. Angiopoietin-2 is required for postnatal angiogenesis and lymphatic patterning, and only the latter role is rescued by Angiopoietin- 1 . Dev Cell. 2002;3(3):411-23.

43. Klinge U, Zheng H, Si Z, Schumpelick V, Bhardwaj RS, Muys L, et al. Expression of the extracellular matrix proteins collagen I, collagen III and fibronectin and matrix metalloproteinase- 1 and -13 in the skin of patients with inguinal hernia. Eur Surg Res. 1999;31(6):480-90. 
44. Hodgson NC, Malthaner RA, Ostbye T. The search for an ideal method of abdominal fascial closure: a meta-analysis. Ann Surg. 2000;231(3):436-42.

45. Anderson JM, Rodriguez A, Chang DT. Foreign body reaction to biomaterials. Semin Immunol. 2008; 20(2):86-100.

46. Junge K, Binnebosel M, von Trotha KT, Rosch R, Klinge U, Neumann UP, et al. Mesh biocompatibility: effects of cellular inflammation and tissue remodelling. Langenbecks Arch Surg. 2012;397(2):255-70.

47. Bourne RB, Bitar H, Andreae PR, Martin LM, Finlay JB, Marquis F. In-vivo comparison of four absorbable sutures: Vicryl, Dexon Plus, Maxon and PDS. Can J Surg. 1988;31(1):43-5.

48. Hochberg J, Meyer KM, Marion MD. Suture choice and other methods of skin closure. Surg Clin North Am. 2009;89(3):627-41.

49. Matlaga BF, Salthouse TN. Ultrastructural observations of cells at the interface of a biodegradable polymer: Polyglactin 910. J Biomed Mater Res. 1983;17(1):185-97.

50. Goh YP, Henderson NC, Heredia JE, Red Eagle A, Odegaard JI, Lehwald N, et al. Eosinophils secrete IL-4 to facilitate liver regeneration. Proc Natl Acad Sci U S A. 2013;110(24):9914-9.

51. Heredia JE, Mukundan L, Chen FM, Mueller AA, Deo RC, Locksley RM, et al. Type 2 innate signals stimulate fibro/adipogenic progenitors to facilitate muscle regeneration. Cell. 2013;153(2):376-88.

52. Knipper JA, Willenborg S, Brinckmann J, Bloch W, Maass T, Wagener R, et al. Interleukin-4 Receptor alpha Signaling in Myeloid Cells Controls Collagen Fibril Assembly in Skin Repair. Immunity. 2015; 43(4):803-16.

53. Boersema GS, Grotenhuis N, Bayon Y, Lange JF, Bastiaansen-Jenniskens YM. The Effect of Biomaterials Used for Tissue Regeneration Purposes on Polarization of Macrophages. Biores Open Access. 2016; 5(1):6-14.

54. Biswas SK, Mantovani A. Macrophage plasticity and interaction with lymphocyte subsets: cancer as a paradigm. Nat Immunol. 2010;11(10):889-96.

55. Edwards JP, Zhang X, Frauwirth KA, Mosser DM. Biochemical and functional characterization of three activated macrophage populations. J Leukoc Biol. 2006;80(6):1298-307.

56. Stout RD, Jiang C, Matta B, Tietzel I, Watkins SK, Suttles J. Macrophages sequentially change their functional phenotype in response to changes in microenvironmental influences. J Immunol. 2005;175(1):342-9. 


\section{Supplementary material}

Table S4.1 Gene specific primers used, build using a primer designing tool (Primer-blast). ${ }^{33}$

\begin{tabular}{|c|c|c|c|c|}
\hline Gene name & $\begin{array}{l}\text { Product } \\
\text { length }\end{array}$ & & GC\% & sequence \\
\hline rplpO (ribosomal protein lateral stalk subunit & 190 & $f$ & 55.00 & CCTCACCGAGATTAGGGACA \\
\hline P0) & & r & 45.00 & ATCGCTCAGGATTTCAATGG \\
\hline \multirow[t]{2}{*}{ actb (actin, beta) } & 297 & $f$ & 55.00 & CCGCGAGTACAACCTTCTTG \\
\hline & & r & 55.00 & CAGTTGGTGACAATGCCGTG \\
\hline \multirow[t]{2}{*}{ il6 (Interleukin 6) } & 246 & $f$ & 57.14 & СTCTCCGCAAGAGACTTCCAG \\
\hline & & r & 47.62 & TTCTGACAGTGCATCATCGCT \\
\hline \multirow[t]{2}{*}{ nos2 (iNOS) } & 234 & $f$ & 52.38 & TAGTCAACTACAAGCCCCACG \\
\hline & & r & 60 & GTGAGGAACTGGGGGAAACC \\
\hline \multirow[t]{2}{*}{ cd86 (CD86) } & 164 & $f$ & 45.45 & AGACATGTGTAACCTGCACCAT \\
\hline & & r & 55 & TACGAGCTCACTCGGGCTTA \\
\hline \multirow[t]{2}{*}{ il10 (Interleukin 10) } & 186 & $f$ & 52.38 & CGACGCTGTCATCGATTTCTC \\
\hline & & r & 60.00 & CAGTAGATGCCGGGTGGTTC \\
\hline \multirow[t]{2}{*}{ clec10a (C-type lectin domain containing 10a) } & 164 & $f$ & 60.00 & GAGGCTTGAGCCAGAAGGTG \\
\hline & & r & 52.38 & TGCTGAGCCGTTGTTCTTGAG \\
\hline \multirow[t]{2}{*}{ mrc1 (mannose receptor C typ 1) } & 212 & $f$ & 60.00 & CCCGCTCCTCAAGACAATCC \\
\hline & & r & 55.00 & AAATACGGTGACTGCCCACC \\
\hline \multirow[t]{2}{*}{ cd163 (CD163) } & 131 & $f$ & 60 & CTCTGAAGCGACGACAGACC \\
\hline & & r & 50 & ATGCCAACCCGAGGATTTCA \\
\hline \multirow[t]{2}{*}{$\operatorname{tgfb1}$ (transforming growth factor- $\beta$ ) } & 115 & $f$ & 60.00 & GGCTGAACCAAGGAGACGGA \\
\hline & & r & 55.00 & CCTCGACGTTTGGGACTGAT \\
\hline \multirow[t]{2}{*}{ vegfa (vascular endothelial growth factor a) } & 235 & $f$ & 60 & AGAAGGGGAGCAGAAAGCCC \\
\hline & & r & 47.83 & GATCCGCATGATCTGCATAGTGA \\
\hline \multirow[t]{2}{*}{ angpt2 (angiopoietin 2) } & 168 & $f$ & 55 & CATGATGTCATCGCCCGACT \\
\hline & & r & 52.38 & TCCATGTCACAGTAGGCCTTG \\
\hline \multirow[t]{2}{*}{ nos3 (eNOS) } & 139 & $f$ & 52.38 & GAATGGAGAGAGCTTTGCAGC \\
\hline & & r & 60 & CCGCCAAGAGGATACCAGTG \\
\hline \multirow[t]{2}{*}{ col1a1 (collagen type 1 alpha 1 chain) } & 237 & $f$ & 60 & CTGACTGGAAGAGCGGAGAG \\
\hline & & r & 55.00 & CAGGATCGGAACCTTCGCTT \\
\hline \multirow[t]{2}{*}{ mmp1 (matrix metallopeptidase 1 ) } & 144 & $f$ & 55.00 & AAGGCCACTGGTGATCTTGC \\
\hline & & r & 43.48 & GGTATTTCCAGACTGTTTCCACA \\
\hline \multirow[t]{2}{*}{ fn1 (Fibronectin 1) } & 165 & $f$ & 63.16 & TCCCCTCCCAGAGAAGTGG \\
\hline & & $\mathrm{r}$ & 43.48 & TTGGGGAAGCTCATCTGTCTTTT \\
\hline
\end{tabular}





\title{
Chapter 5
}

Analysis of adhesion formation of a new elastic thermoplastic polyurethane (TPU) mesh in comparison to polypropylene (PP) meshes in IPOM position

\author{
A. Lambertz \\ L.C.L. v.d.Hil \\ D.S. Schöb \\ M. Binnebösel \\ A. Kroh \\ U. Klinge \\ U.P. Neumann \\ C.D. Klink
}




\section{Abstract}

\section{Background}

Postsurgical adhesions severely affect the patients' quality of life causing various complications like bowel obstruction or chronic pain. Especially the implantation of alloplastic prostheses in IPOM position for hernia repair carries a high risk of adhesion formation due to the close contact between mesh and viscera. The extent of adhesions mainly depends on the type and textile characteristics of the implanted mesh. The aim of this study was to examine the degree of adhesion formation of a newly developed, elastic thermoplastic polyurethane (TPU) mesh in comparison to polypropylene (PP) meshes in IPOM position in a rabbit model.

\section{Material and methods}

Sixteen female chinchilla rabbits were laparoscopically operated. Two different meshes were placed to the left and the right lower abdominal wall in IPOM position in each rabbit. After 7 or 21 days, midline laparotomy was performed, the degree of adhesion formation was examined by the Diamond score and mesh elongation was measured under a force of $3 \mathrm{~N}$. Finally, the abdominal walls were explanted for immunohistochemical and histopathological investigations.

\section{Results}

TPU meshes showed significantly lower Diamond scores than PP meshes. After explantation, mesh elongation of the TPU mesh was significantly larger than expansion of PP under a force of $3 \mathrm{~N}$. Thus, the TPU mesh preserved its elastic properties after 7 and 21 days. The amount of CD68 positive, Ki67 positive and apoptotic cells within the granuloma around the fibers did not show significant differences between the study groups.

\section{Conclusions}

The newly developed TPU mesh seems to reduce peritoneal adhesion formation in IPOM position in a rabbit model compared to PP meshes after 7 and 21 days. Immunohistochemistry did not reveal differences in biocompatibility of the two meshes used. 


\section{Introduction}

Postoperative peritoneal adhesion formation remains a relevant problem in abdominal surgery. ${ }^{1,2}$ More than $90 \%$ of the patients who had one or more previous operations show intra-abdominal adhesions later on. ${ }^{3,4}$ In these cases, adhesions are a consequence of injured tissue surfaces fusing together by scar tissue. Postsurgical adhesions severely affect the patients' quality of life causing various complications like bowel obstruction or chronic pain. ${ }^{5,6}$ Several approaches like intraabdominal or systemic application of various substances could not reduce adhesion formation significantly. ${ }^{7-10}$

Surgical trauma causes adhesions, which is independent from the material used. However, it is known for polypropylene that it stimulates adhesiogenesis due to its inflammatory stimulus, and thereby increases the risk for fistula formation when in contact with bowel. Others, such as Polyvinylidene fluoride (PVDF) or expanded Polytetrafluoroethylene (ePTFE), may create adhesions as well, but are not suspected to increase the risk for bowel injuries. Animal models with placement of meshes on the intact peritoneum without surgical trauma by further dissection are able to demonstrate the intrinsic inflammatory power of the mesh materials to form adhesions.

Especially the implantation of alloplastic prostheses in intraperitoneal onlay mesh (IPOM) position for hernia repair carries a high risk of adhesions with close contact between mesh and viscera. ${ }^{11}$ Here, the extent of adhesions mainly depends on both the type of polymer and the textile characteristics of the implanted mesh. ${ }^{12,13}$ It was shown that the meshes pore size, in particular, is decisive for tissue reaction and small porous meshes were identified to show significantly stronger adhesion formation than meshes with larger pores. ${ }^{13,14}$

In a highly flexible anatomic region like the abdominal wall, any mechanical strain with elongation of the device leads to a collapse of the pores due to the inelasticity of all current mesh polymers. ${ }^{15,16}$ Even though the meshes pores were sufficiently large initially, they become longer but smaller under strain what correspondingly increases the risk of adhesion formation.

Thus, we developed new elastic thermoplastic polyurethane (TPU) meshes that show high structural resistance to pore collapse under mechanical strain. ${ }^{17,18}$ In the current study, we examined the degree of adhesion formation of a TPU large pore construction in IPOM position in comparison to a polypropylene (PP) mesh with a similar textile configuration in a rabbit model.

\section{Materials and methods}

The experiments were officially approved by the local Animal Care and Use Review Committee (TVA-AZ: 84-02.04.2013.A501). All animals received humane care in 
accordance with the requirements of the German Tierschutzgesetz, $\S 8$ Abs. 1 and in accordance to the Guide for the Care and Use of Laboratory Animals published by the National Institute of Health.

\section{Animals}

Sixteen female, 12 weeks old chinchilla rabbits (New Zealand white rabbits, Charles River Laboratories International, Erkrath, Germany) with a mean bodyweight of $3411 \pm 418 \mathrm{~g}$ were laparoscopically operated; in every rabbit, we randomly placed two different meshes $\left(3 \times 3 \mathrm{~cm}^{2}\right.$, TPU and PP) to the left and the right lower abdominal wall in IPOM position. The rabbit's acclimatization period took one week. All animals were kept under standardized conditions: temperature between $22^{\circ} \mathrm{C}$ and $24^{\circ} \mathrm{C}$; relative humidity $50-60 \%$; $12 \mathrm{~h}$ of light following $12 \mathrm{~h}$ of darkness. The animals had free access to food and water. Food was withdrawn $12 \mathrm{~h}$ before and after surgery. Rabbits were randomized to be euthanized after 7 days or 21 days. Midline laparotomy was performed and the degree of adhesion formation was documented. Abdominal walls were explanted and immunohistochemically examined to get an insight into the different phases of wound healing and host response.

\section{Materials}

The experimental mesh was made out of non-absorbable monofilament polycarbonatebased thermoplastic urethane (TPU) threads (used polymer: Chronoflex C93A by Advan Source, Wilmington, MA, USA), which were already used before to develop an elastic mesh. ${ }^{18}$ The control meshes used were polypropylene (PP) meshes with a similar textile configuration of the same size $\left(3 \times 3 \mathrm{~cm}^{2}\right)$ (Figure 5.1). Technical data of both meshes are listed in Table 5.1.

Figure 5.1 TPU and PP mesh (light microscopy).

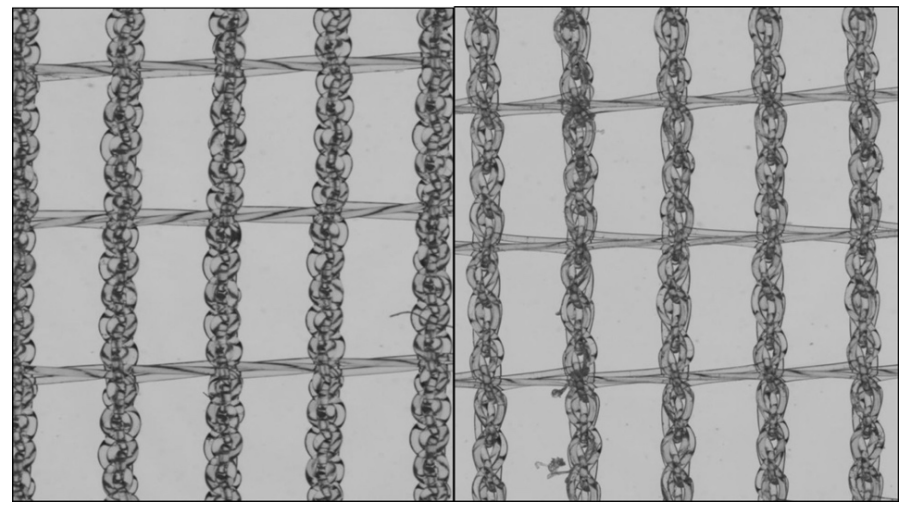


Table 5.1 Technical data of TPU and Polypropylene meshes.

\begin{tabular}{lcc}
\hline & TPU mesh & Polypropylene mesh \\
\hline Mesh size (mm) & $30 \times 30$ & $30 \times 30$ \\
Filament size (mm) & 0.14 & 0.14 \\
Weight (g) & 0.22 & 0.14 \\
Tensile strength (longitudinal, N/cm) & 25.8 & 120.4 \\
Elongation (longitudinal, \%) & 168 & 28.8 \\
Surface area (qm/qm mesh) & 2.6 & 2.9 \\
Effective porosity (\%) & 58.1 & 59.4 \\
\hline
\end{tabular}

\section{Tensile tests}

The tensile tests were performed on a tensile tester ( $Z 2.5$ by Zwick Roell AG, Ulm, Germany) under standard atmosphere $\left(20^{\circ} \mathrm{C} ; 65 \%\right.$ humidity). A clamping length of $40 \mathrm{~mm}$ was chosen. All samples were tested at a testing speed of $300 \mathrm{~mm} / \mathrm{min}$ and an initial load of $0.05 \mathrm{~N}$ (Table 5.1).

\section{Adhesion score}

Postoperative peritoneal adhesions were scored by observers who were blinded to the study groups using an established adhesion score published by Diamond et al. (Table 5.2) based on extent, type and tenacity of the adhesion tissue both for visceral and parietal peritoneum. ${ }^{8,19}$

Table 5.2 Adhesion score according to Diamond et al. ${ }^{19}$

\begin{tabular}{ll}
\hline & Score \\
\hline Extent & \\
$0 \%$ & 0 \\
$<25 \%$ & 1 \\
$26-50 \%$ & 2 \\
$51-75 \%$ & 3 \\
$>75 \%$ & 4 \\
Type & \\
No adhesions & 0 \\
Filmy adhesions, no vessels & 1 \\
Opaque adhesions, no vessels & 2 \\
Opaque adhesions, small vessels & 3 \\
Opaque adhesions, large vessels & 4 \\
Tenacity & \\
No adhesions & 0 \\
Adhesions easily lysed & 1 \\
Adhesions lysed with traction & 2 \\
Adhesions required sharp dissection & 3 \\
Total score & 11 \\
\hline
\end{tabular}

\section{Surgical procedure}

All operations were carried out under general anesthesia, aseptic and sterile surgical conditions and were performed by two different and independent surgeons. Anesthesia 
was induced with $0.2 \mathrm{mg} / \mathrm{kg}$ of $10 \%$ Ketamin (Ketamin $10 \%$, Fa. Sanofi-Ceva, Düsseldorf, Germany) and $0.3 \mathrm{ml} / \mathrm{kg}$ Domitor (Farmos, Gräub). The rabbits were placed in supine position; the abdomen was shaved and disinfected with polyvidone-iodine solution. A 5-mm optic trocar was inserted through a median abdominal incision, and a pneumoperitoneum of $3 \mathrm{mmHg}$ was established $\left(\mathrm{CO}_{2}\right.$ insufflator, Richard Wolf, Knittlingen, Germany). Two more $5 \mathrm{~mm}$ trocars were placed in the right and left upper abdomen under direct vision (Figure 5.2). The meshes with a standardized size of $3 \times 3 \mathrm{~cm}^{2}$ were rolled and passed through the left trocar into the abdominal cavity. One mesh was fixated to the left and another one to the right lower abdominal wall onto the parietal peritoneum with four staples per mesh at all four corners with an endoscopic Multi-Stapler (AbsorbaTack ${ }^{\circledR} 5 \mathrm{~mm}$, Covidien, Mansfield, USA) (Figure 5.3). Skin was sutured intracutaneously with Monocryl (U.S.P. size 4-0).

Figure 5.2 Laparoscopy with pneumoperitoneum in a rabbit.

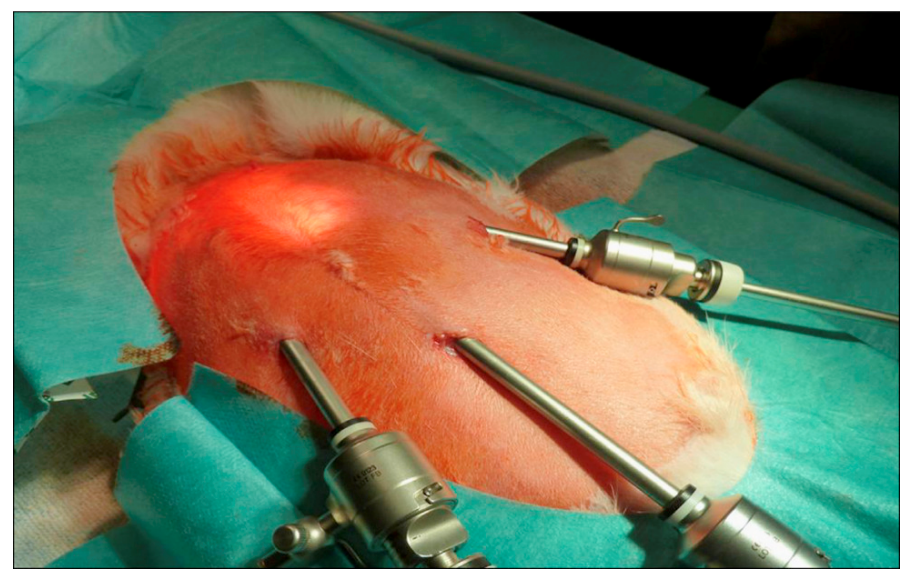

Figure 5.3 TPU mesh laparoscopically fixated with four staples in IPOM position.

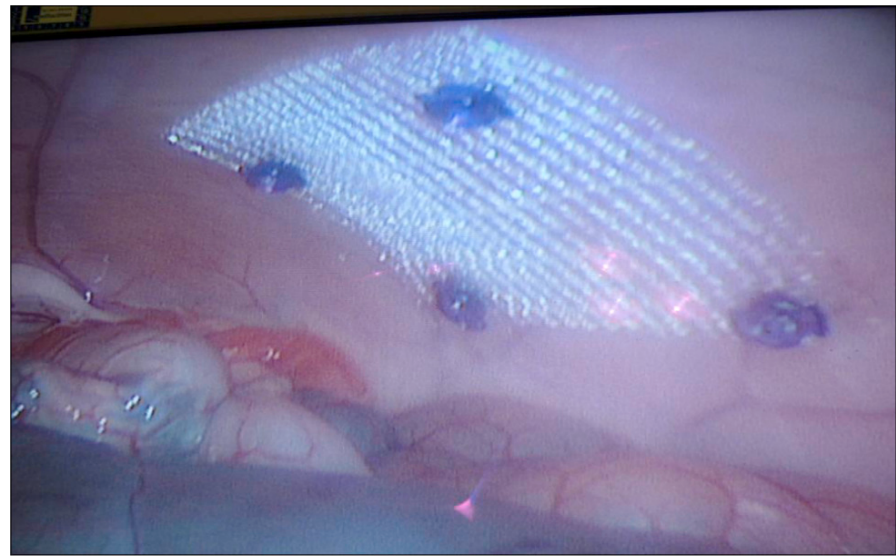


After 7 or 21 days, midline laparotomy was performed, the degree of adhesion formation was examined (Figure 5.4, Figure 5.5) and longitudinal mesh elongation was measured under a force of $3 \mathrm{~N}$. Finally, the animals were euthanized using a lethal dose of $500 \mathrm{mg}$ Pentobarbital-Natrium (Narcoren, Fa. Rhône Merieux, Laupheim). The entire abdominal wall was resected and was immediately fixed in $10 \%$ formaldehyde for later histological and immunohistochemical assessment.

Figure 5.4 Polypropylene mesh with bowel adhesions explanted after 21 days of follow-up. Representative macroscopic view of adhesions to polypropylene meshes 21 days after implantation.

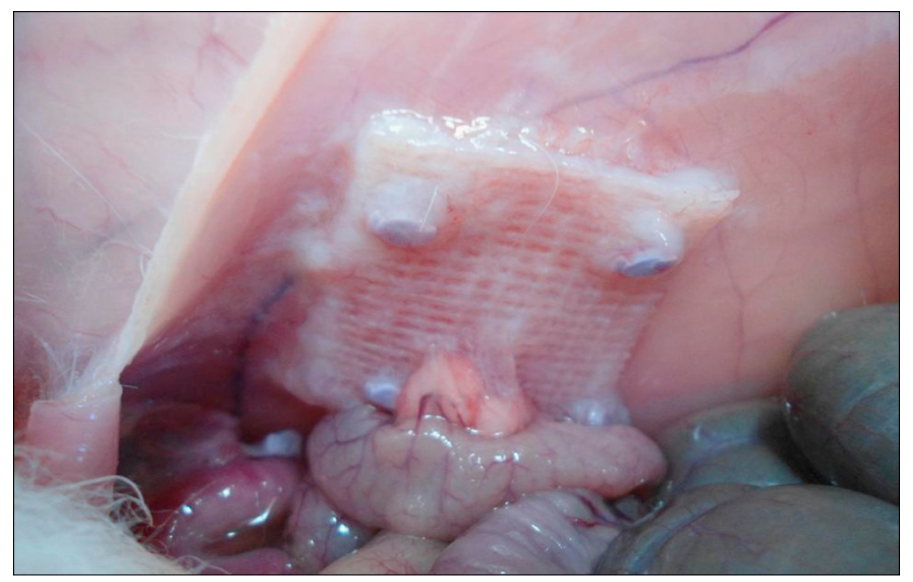

Figure 5.5 TPU mesh without adhesions explanted after 21 days of follow-up. Representative macroscopic view of adhesions to TPU meshes 21 days after implantation.

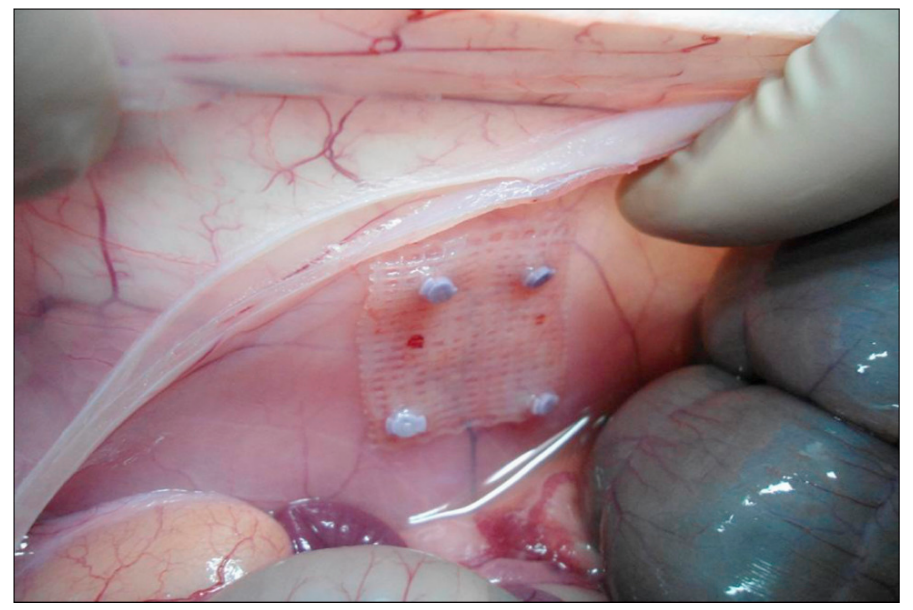




\section{Histological assessment and immunohistochemical analysis}

Samples were embedded in paraffin and cut in $3 \mu \mathrm{m}$ sections after formaldehyde fixation. All sections were routinely stained with hematoxylin and eosin (H\&E) and processed at the same time to reduce internal staining variations.

The amount of inflammatory and connective tissue formation was analyzed semiquantitatively by measuring the diameter of the inner and outer foreign body granuloma representing the inflammatory infiltrate and the fibrotic tissue reaction. After capturing 4 granuloma per sample with a digital camera (Olympus C-3030, Hamburg, Germany) separate measurements were performed with the help of a digital image analyzing software (Image-Pro Plus, Media Cybernetics, Silver Spring, MD, USA). By adding the measurements of each granuloma and building averages, total granuloma size was calculated. Histological investigations were performed by two blinded and independent observers.

Immunohistochemistry was used to analyze the host response. After pretreatment of the fixed specimen with microwave and citrate-buffer $\mathrm{pH} 6$ for three times, cells were identified by different monoclonal antibodies from Dako (Glostrup, Denmark). The inflammation was assessed by counting the number of macrophages (CD68 expression) in the foreign body granuloma. As a marker for cell proliferation, Ki67 expression was measured. "Terminal deoxynucleotidyl transferase nick end labeling" (TUNEL) histochemistry was used as a staining for DNA fragments indicating apoptosis in the granuloma as previously described by Junge et al. ${ }^{20}$ Finally, measurements of the quality of collagen were performed using Sirius Red staining. These sections were analyzed for ratio of Collagen I/III by crosspolarization microscopy (CPM). Therefore, $5 \mu \mathrm{m}$ sections were stained for $1 \mathrm{~h}$ in Picrosirius solution $(0.1 \%$ solution of Sirius Red F3BA in saturated aqueous picric acid, $\mathrm{pH} 2$ ). ${ }^{21}$ The sections were washed for 2 minutes in $0.01 \mathrm{~N} \mathrm{HCl}$, dehydrated, cleared, and mounted in synthetic resin. In crosspolarization microscopy, thicker collagen type I fibers were stained in red-orange shades, whereas thinner collagen type III appeared as pale-green shades.

All other sections were examined by standard light microscopy (Olympus BX51, Olympus, Hamburg, Germany). The percentage of positive stained cells was assessed in an area of $100 \mu \mathrm{m} \times 100 \mu \mathrm{m}$ with 400-fold magnification and captured by a digital camera (Olympus C-3030, Olympus, Hamburg, Germany). Analysis was performed using a digital image analyzing software (Image-Pro Plus, Media Cybernetics, Silver Spring, MD, USA).

\section{Statistical analysis}

Statistical analysis was carried out using the Statistical Package for Social Sciences software (SPSS ${ }^{\circ}$, Vers.17.0, Chicago, IL, USA). Differences between study groups were analyzed by Kruskal-Wallis test for non-parametric data and in case of significant differences confirmed by Mann-Whitney $U$ test. For numeric data differences were analyzed by ANOVA and in case of significance confirmed by $T$-Test. $P$-values $<0.05$ 
were considered to be significant. All data are represented as mean \pm standard deviation.

\section{Results}

\section{Animal experiments}

All animals recovered quickly after the operations. No complications occurred due to surgery or anesthesia procedure. During follow-up there were no signs of wound infection or discomfort due to implanted materials. None of the rabbits died during the postoperative observational period. At the day of explantation, animals had a mean bodyweight of $3485 \pm 309 \mathrm{~g}$. There were no significant differences between the study groups.

The TPU mesh showed its elastic properties after explantation. Mesh elongation under a force of $3 \mathrm{~N}$ was significantly larger than expansion of PP after 7 and 21 days (7 days: TPU $2.0 \pm 0.6 \mathrm{~cm}$ vs. PP $0.6 \pm 0.3 \mathrm{~cm}, p=0.003 ; 21$ days: TPU $1.2 \pm 0.7 \mathrm{~cm}$ vs. PP $0.3 \pm 0.1 \mathrm{~cm}, p=0.008$ ) (Table 5.3).

Table 5.3 Diamond score and longitudinal mesh elongation after $\mathbf{7}$ and 21 days of follow-up.

\begin{tabular}{|c|c|c|c|c|c|c|}
\hline & \multicolumn{3}{|c|}{7 days of follow-up } & \multicolumn{3}{|c|}{21 days of follow-up } \\
\hline & $\begin{array}{c}\text { TPU } \\
(n=8)\end{array}$ & $\begin{array}{c}\text { Polypropylene } \\
(n=8)\end{array}$ & $p$-value ${ }^{\text {a }}$ & $\begin{array}{c}\text { TPU } \\
(n=8)\end{array}$ & $\begin{array}{c}\text { Polypropylene } \\
(n=8)\end{array}$ & $p$-value ${ }^{a}$ \\
\hline Diamond score & $1.0 \pm 1.9$ & $4.3 \pm 1.8$ & 0.005 & $0.9 \pm 1.6$ & $3.5 \pm 2.9$ & 0.048 \\
\hline Mesh elongation $(3 \mathrm{~N})$ in $\mathrm{cm}$ & $2.0 \pm 0.6$ & $0.6 \pm 0.3$ & 0.003 & $1.2 \pm 0.7$ & $0.3 \pm 0.1$ & 0.008 \\
\hline
\end{tabular}

${ }^{a} p$-values $<0.05$ were considered significant

\section{Adhesion formation}

Regarding Diamond score, TPU meshes showed significantly lower postoperative peritoneal adhesions than PP meshes after 7 (1.0 \pm 1.9 vs. $4.3 \pm 1.8, p=0.005)$ and 21 days ( $0.9 \pm 1.6$ vs. $3.5 \pm 2.9, p=0.048$ ) (Table 5.3 ).

\section{Size and expansion of granuloma}

After 7 days, sizes of the inner and outer foreign body granuloma were significantly smaller in TPU meshes compared to PP meshes $(p<0.001)$. After 21 days, inner granuloma sizes did not show significant differences between the study groups. Outer granuloma sizes were larger in TPU meshes compared to PP (Table 5.4). There was no fibrotic bridging between the mesh filaments in the study groups and the foreign body granuloma only surrounded single sutures. 


\section{Immunohistochemical observations}

To analyze the foreign body reaction to the implanted material, we investigated the presence of inflammatory cells (CD68), proliferating cells (Ki67) and apoptotic cells within the granuloma surrounding the different materials. We did not find significant differences between the study groups after 7 and 21 days (Table 5.4).

\section{Collagen type I/III ratio}

Reflecting the maturity of the scar, we analyzed the collagen type I/III ratio. There were no significant differences between the two different mesh types after 7 and 21 days (Table 5.4).

Table 5.4 Histological assessment and immunohistochemical analysis after 7 and 21 days of follow-up.

\begin{tabular}{lcccccc}
\hline & \multicolumn{3}{c}{$\mathbf{7}$ days of follow-up } & \multicolumn{3}{c}{ 21 days of follow-up } \\
\cline { 2 - 7 } & $\begin{array}{c}\text { TPU } \\
(\mathbf{n}=\mathbf{8})\end{array}$ & $\begin{array}{c}\text { Polypropylene } \\
(\mathbf{n}=\mathbf{8})\end{array}$ & $\boldsymbol{p}$-value & $\begin{array}{c}\text { TPU } \\
(\mathbf{n}=\mathbf{8})\end{array}$ & $\begin{array}{c}\text { Polypropylene } \\
\boldsymbol{p} \text {-value }\end{array}$ \\
& $\mathbf{( n = 8 )}$ & \\
\hline Inner granuloma size in $\mu \mathrm{m}$ & $9.1 \pm 2.3$ & $11.8 \pm 2.7$ & $<0.001$ & $10.8 \pm 2.5$ & $10.2 \pm 2.7$ & 0.075 \\
Outer granuloma size in $\mu \mathrm{m}$ & $40.3 \pm 11.1$ & $56.5 \pm 16.3$ & $<0.001$ & $117.5 \pm 31.4$ & $98.4 \pm 30.7$ & $<0.001$ \\
Ki67 positive cells (\%) & $11.1 \pm 3.9$ & $11.4 \pm 3.5$ & 0.956 & $5.7 \pm 2.0$ & $4.3 \pm 1.4$ & 0.057 \\
CD68 positive cells (\%) & $2.1 \pm 1.4$ & $2.7 \pm 1.7$ & 0.158 & $3.3 \pm 2.0$ & $2.5 \pm 1.5$ & 0.315 \\
Apoptosis & $10.3 \pm 4.1$ & $11.2 \pm 3.6$ & 0.232 & $10.7 \pm 5.4$ & $8.7 \pm 3.1$ & 0.497 \\
Collagen I/III ration & $3.9 \pm 0.6$ & $3.6 \pm 0.8$ & 0.811 & $4.2 \pm 0.8$ & $4 \pm 0.9$ & 0.183 \\
\hline
\end{tabular}

${ }^{a} p$-values $<0.05$ were considered significant

\section{Discussion}

Postoperative peritoneal adhesion formation is an ongoing problem in abdominal surgery, since more than $90 \%$ of the patients who had one or more previous operations show intra-abdominal adhesions later on. ${ }^{3,22}$

The implantation of foreign materials like hernia meshes causes a peritoneal inflammatory reaction that potentiates adhesion formation, especially with concomitant peritoneal damage. ${ }^{23-25}$ An alloplastic prostheses in IPOM position for hernia repair carries a particularly high risk of adhesion formation due to the close contact between mesh and viscera. ${ }^{11}$ Thus, various previous studies tried to reduce adhesion formation of meshes in IPOM position. Rosch et al. showed for example that there are no pressure or gas-dependent effects on adhesion formation. ${ }^{11}$ Other authors tried to use coated meshes with antiadhesive barriers, but the problem is still unsolved. $^{26}$

It is well known that the extent of adhesions mainly depends on the type and textile characteristics of the implanted mesh. ${ }^{12,13}$ Thus, it is obvious to try to optimize mesh material and structure to reduce foreign body reaction and the resulting peritoneal adhesion formation. 
In this context, the geometric structure and the porosity of the implanted materials were found to be decisive in predicting host reaction. ${ }^{27}$ Only sufficiently large pores are able to prevent a bridging of granulation tissue between the pores, which leaves no space for further tissue ingrowth. ${ }^{28,29} \mathrm{~A}$ reduction of the meshes pore size leads to a higher inflammatory foreign body reaction and decrease of biocompatibility. ${ }^{30,31}$ The concept of effective porosity by Muhl et al. described this correlation. ${ }^{32}$ Accordingly, small porous meshes were identified to show significantly stronger adhesion formation than meshes with larger pores. ${ }^{13}$ Other authors showed this correlation as well. ${ }^{33}$

After implantation of a conventional mesh, the high degree of flexibility of the abdominal wall leads to structural deformation of the device due to his non-elastic properties. ${ }^{16,34}$ Pores become longer but smaller and the mesh loses its effective porosity under strain.

Thus, an optimal mesh needs large pores, flexibility from material properties and structural stability at the same time to preserve its effective porosity and accordingly its biocompatibility. This mesh might be able to reduce peritoneal adhesion formation simultaneously.

Our research group was able to develop a new elastic TPU mesh that might fulfill these requirements. ${ }^{18}$ The thesis of the present study was that TPU meshes should show less adhesion after implantation in IPOM position than conventionally used PP meshes of a similar structural configuration.

This could be demonstrated in a rabbit model after 7 and 21 days. TPU meshes showed significantly lower Diamond scores than PP. Furthermore, the new meshes preserved their elastic properties after explantation. Immunohistochemically, quality of foreign body reaction to implanted material regarding Ki67-, CD68-positive and apoptotic cells was similar between the study groups but TPU meshes showed significantly smaller sizes of the inner and outer foreign body granuloma compared to PP after 7 days. This underlines our thesis formulated before.

The newly developed elastic TPU meshes seem to reduce peritoneal adhesion formation due to their superior material properties.

On the other hand, there were no differences in inner granuloma sizes after 21 days anymore and TPU meshes even had bigger outer granuloma sizes after this period of time. Thus, to prove long-term capability of the newly developed mesh and to confirm our findings further experimental studies need to be conducted.

To mention some major limitations of our study, it is not possible to transfer results generated by animal experiments directly to the situation in humans. In particular, the animals cannot reflect any underlying human disease or co-morbidity. Our observational period was relatively short additionally. We analyzed a relatively small sample size with high standard deviations.

Furthermore, it has to be mentioned that creating a mesh of TPU filaments consequentially leads to a lower stiffness of the device in comparison to PP meshes. A TPU mesh has been mechanically tested and has nevertheless proven a sufficient 
tensile strength in earlier studies. ${ }^{18}$ Thus, its lower disposition to create peritoneal adhesions might not only be a result of material and structural properties, but might also be due to a different mechanical behavior. In this context, the study groups might not be completely comparable. To analyze mechanical characteristics of different conventionally used hernia meshes and to compare these properties with an elastic TPU mesh would be a task for further studies.

The described mesh fixation with four staples per mesh might have caused adhesions independent from mesh material additionally. On the other hand, we did not find an accumulation of adhesions around the staples and we used the same staples in both study groups.

To conclude, our newly developed TPU mesh seems to reduce peritoneal adhesion formation in IPOM position in a rabbit model compared to PP meshes after 7 and 21 days. Immunohistochemistry indicates similar biocompatibility of both meshes. 


\section{References}

1. Ergul E, Korukluoglu B. Peritoneal adhesions: facing the enemy. Int J Surg. 2008;6(3):253-60.

2. Schnuriger B, Barmparas G, Branco BC, Lustenberger T, Inaba K, Demetriades D. Prevention of postoperative peritoneal adhesions: a review of the literature. Am J Surg. 2011;201(1):111-21.

3. Menzies D, Ellis H. Intestinal obstruction from adhesions--how big is the problem? Ann R Coll Surg Engl. 1990;72(1):60-3.

4. Liakakos T, Thomakos N, Fine PM, Dervenis C, Young RL. Peritoneal adhesions: etiology, pathophysiology, and clinical significance. Recent advances in prevention and management. Dig Surg. 2001;18(4):260-73.

5. Suslavich FJ, Turner NA, King PS, Brown HK. Intraabdominal adhesions: intraoperative US. Radiology. 1989;172(2):387-8.

6. Monk BJ, Berman ML, Montz FJ. Adhesions after extensive gynecologic surgery: clinical significance, etiology, and prevention. Am J Obstet Gynecol. 1994;170(5 Pt 1):1396-403.

7. Tepetes K, Asprodini EK, Christodoulidis G, Spyridakis M, Kouvaras E, Hatzitheofilou K. Prevention of postoperative adhesion formation by individual and combined administration of 4 per cent icodextrin and dimetindene maleate. Br J Surg. 2009;96(12):1476-83.

8. Klink CD, Schickhaus P, Binnebosel M, Jockenhoevel S, Rosch R, Tolba R, et al. Influence of $4 \%$ icodextrin solution on peritoneal tissue response and adhesion formation. BMC Surg. 2013;13:34.

9. Catena F, Ansaloni L, Di Saverio S, Pinna AD, World Society of Emergency S. P.O.P.A. study: prevention of postoperative abdominal adhesions by icodextrin $4 \%$ solution after laparotomy for adhesive small bowel obstruction. A prospective randomized controlled trial. J Gastrointest Surg. 2012;16(2):382-8.

10. Sahbaz A, Isik H, Aynioglu O, Gungorduk K, Gun BD. Effect of intraabdominal administration of Allium sativum (garlic) oil on postoperative peritoneal adhesion. Eur J Obstet Gynecol Reprod Biol. 2014; 177:44-7.

11. Rosch R, Binnebosel M, Klink CD, Otto J, Junge K, Neumann UP. Impact of pressure and gas type on adhesion formation and biomaterial integration in laparoscopy. Surg Endosc. 2011;25(11):3605-12.

12. Zinther NB, Wara P, Friis-Andersen H. Intraperitoneal onlay mesh: an experimental study of adhesion formation in a sheep model. Hernia. 2010;14(3):283-9.

13. Conze J, Rosch R, Klinge U, Weiss C, Anurov M, Titkowa S, et al. Polypropylene in the intra-abdominal position: influence of pore size and surface area. Hernia. 2004;8(4):365-72.

14. Conze J, Junge $K$, Weiss $C$, Anurov $M$, Oettinger A, Klinge $U$, et al. New polymer for intra-abdominal meshes--PVDF copolymer. J Biomed Mater Res B Appl Biomater. 2008;87(2):321-8.

15. Anurov MV, Titkova SM, Oettinger AP. Biomechanical compatibility of surgical mesh and fascia being reinforced: dependence of experimental hernia defect repair results on anisotropic surgical mesh positioning. Hernia. 2012;16(2):199-210.

16. Hernandez-Gascon B, Pena E, Pascual G, Rodriguez M, Bellon JM, Calvo B. Long-term anisotropic mechanical response of surgical meshes used to repair abdominal wall defects. J Mech Behav Biomed Mater. 2012;5(1):257-71.

17. Lambertz A, Vogels RR, Busch D, Schuster P, Jockenhovel S, Neumann UP, et al. Laparotomy closure using an elastic suture: a promising approach. J Biomed Mater Res B Appl Biomater. 2015;103(2): 417-23.

18. Lambertz A, Vogels RR, Binnebosel M, Schob DS, Kossel K, Klinge U, et al. Elastic mesh with thermoplastic polyurethane filaments preserves effective porosity of textile implants. J Biomed Mater Res A. 2015;103(8):2654-60.

19. Diamond MP, Linsky CB, Cunningham T, Constantine B, diZerega GS, DeCherney AH. A model for sidewall adhesions in the rabbit: reduction by an absorbable barrier. Microsurgery. 1987;8(4):197-200.

20. Junge K, Klinge U, Rosch R, Klosterhalfen B, Schumpelick V. Functional and morphologic properties of a modified mesh for inguinal hernia repair. World J Surg. 2002;26(12):1472-80.

21. Junqueira LC, Cossermelli W, Brentani R. Differential staining of collagens type I, II and III by Sirius Red and polarization microscopy. Arch Histol Jpn. 1978;41(3):267-74.

22. Weibel MA, Majno G. Peritoneal adhesions and their relation to abdominal surgery. A postmortem study. Am J Surg. 1973;126(3):345-53.

23. McEntee GP, Stuart RC, Byrne PJ, Leen E, Hennessy TP. Experimental study of starch-induced intraperitoneal adhesions. Br J Surg. 1990;77(10):1113-4. 
24. Binnebosel M, Klink CD, Serno J, Jansen PL, von Trotha KT, Neumann UP, et al. Chronological evaluation of inflammatory mediators during peritoneal adhesion formation using a rat model. Langenbecks Arch Surg. 2011;396(3):371-8.

25. Binnebosel M, Rosch R, Junge K, Lynen-Jansen P, Schumpelick V, Klinge U. Macrophage and Tlymphocyte infiltrates in human peritoneal adhesions indicate a chronic inflammatory disease. World J Surg. 2008;32(2):296-304.

26. Gruber-Blum S, Petter-Puchner AH, Brand J, Fortelny RH, Walder N, Oehlinger W, et al. Comparison of three separate antiadhesive barriers for intraperitoneal onlay mesh hernia repair in an experimental model. Br J Surg. 2011;98(3):442-9.

27. Klinge $U$, Klosterhalfen B. Modified classification of surgical meshes for hernia repair based on the analyses of 1,000 explanted meshes. Hernia. 2012;16(3):251-8.

28. Klinge $U$, Junge $K$, Stumpf M, Ap AP, Klosterhalfen B. Functional and morphological evaluation of a lowweight, monofilament polypropylene mesh for hernia repair. J Biomed Mater Res. 2002;63(2):129-36.

29. Klinge U, Klosterhalfen B, Birkenhauer V, Junge K, Conze J, Schumpelick V. Impact of polymer pore size on the interface scar formation in a rat model. J Surg Res. 2002;103(2):208-14.

30. Bellon JM, Jurado F, Garcia-Honduvilla N, Lopez R, Carrera-San Martin A, Bujan J. The structure of a biomaterial rather than its chemical composition modulates the repair process at the peritoneal level. Am J Surg. 2002;184(2):154-9.

31. Weyhe D, Schmitz I, Belyaev O, Grabs R, Muller KM, Uhl W, et al. Experimental comparison of monofile light and heavy polypropylene meshes: less weight does not mean less biological response. World J Surg. 2006;30(8):1586-91.

32. Muhl T, Binnebosel M, Klinge U, Goedderz T. New objective measurement to characterize the porosity of textile implants. J Biomed Mater Res B Appl Biomater. 2008;84(1):176-83.

33. Weyhe D, Cobb W, Lecuivre J, Alves A, Ladet S, Lomanto D, et al. Large pore size and controlled mesh elongation are relevant predictors for mesh integration quality and low shrinkage--Systematic analysis of key parameters of meshes in a novel minipig hernia model. Int J Surg. 2015;22:46-53.

34. Smietanski M, Bury K, Tomaszewska A, Lubowiecka I, Szymczak C. Biomechanics of the front abdominal wall as a potential factor leading to recurrence with laparoscopic ventral hernia repair. Surg Endosc. 2012;26(5):1461-7. 




\title{
Chapter 6
}

\section{MRI Evaluation of an Elastic TPU Mesh under Pneumoperitoneum in IPOM Position in a Porcine Model}

\author{
A. Lambertz* \\ L.C.L. v.d.Hil* \\ A. Ciritsis \\ R. Eickhoff \\ N. A. Kraemer \\ N. D. Bouvy \\ A. Müllen \\ U. Klinge \\ U.P. Neumann \\ C.D. Klink \\ * Contributed equally
}




\section{Abstract}

\section{Background}

The frequency of laparoscopic approaches increased in hernia surgery over the past years. After mesh placement in IPOM position, the real extent of the meshes configurational changes after termination of pneumoperitoneum is still largely unknown. To prevent a later mesh folding, it might be useful to place the mesh while it is kept under tension. Conventionally used meshes may lose their effective porosity under these conditions due to poor elastic properties. The aim of this study was to evaluate a newly developed elastic thermoplastic polyurethane (TPU) containing mesh that retains its effective porosity under mechanical strain in IPOM position in a porcine model. It was visualized under pneumoperitoneum using $\mathrm{MRI}$ in comparison to polyvinylidenefluoride (PVDF) meshes with similar structure.

\section{Methods}

In each of ten minipigs, a mesh (TPU containing or native PVDF, $10{ }^{\circ} \varnothing 20 \mathrm{~cm}$ ) was randomly placed in IPOM position at the center of the abdominal wall. After 8 weeks, six pigs underwent MRI evaluation with and without pneumoperitoneum to assess the visibility and elasticity of the mesh. Finally, pigs were euthanized and abdominal walls were explanted for histological and immunohistochemical assessment. The degree of adhesion formation was documented.

\section{Results}

Laparoscopic implantation of elastic TPU meshes in IPOM position was feasible and safe in a minipig model. Mesh position could be precisely visualized and assessed with and without pneumoperitoneum using MRI after 8 weeks. Elastic TPU meshes showed a significantly higher surface increase under pneumoperitoneum in comparison to PVDF. Immunohistochemically, the amount of CD45-positive cells was significantly lower and the Collagen I/III ratio was significantly higher in TPU meshes after 8 weeks. There were no differences regarding adhesion formation between study groups.

\section{Conclusions}

The TPU mesh preserves its elastic properties in IPOM position in a porcine model after 8 weeks. Immunohistochemistry indicates superior biocompatibility regarding CD45positive cells and Collagen I/III ratio in comparison to PVDF meshes with a similar structure. 


\section{Introduction}

Annually, 300,000 hernia repairs are performed in Europe. ${ }^{1}$ Mesh placement is nowadays seen as the standard approach, since suture hernia repair is associated with higher recurrence rates. ${ }^{2}$

Hernia repair can be performed through the open technique or laparoscopically. The frequency of the laparoscopic approach increased over the last years, since it is seen to provide several advantages. It seems to be associated with lower rates of wound infections and a shorter hospital stay. ${ }^{1,3}$ However, it is suggested that laparoscopic mesh placement in intraperitoneal onlay mesh (IPOM) position can lead to mesh folding. ${ }^{4}$ During the phase of pneumoperitoneum there is an elevated pressure in the abdominal cavity that leads to extension of the abdominal wall. Thus, meshes will be placed when the abdominal wall is extended. After termination of the pneumoperitoneum, this extension of the abdominal wall is no longer present and mesh folding seems likely. ${ }^{4}$ A possible technique to prevent this folding might be the placement of a mesh, while it is kept under tension. This is only possible when the mesh has the property to elongate, to cover the extension of the abdominal wall. Although the currently available meshes are able to elongate, they cannot retain an effective porosity in an elongated condition. ${ }^{5}$ Their pores become longer but smaller. On the other hand, it was shown that large pores improve ingrowth of the mesh in surrounding tissue. ${ }^{6,7}$ Although a part of the currently available meshes have large pores, these pores do not retain their shape after this placement. ${ }^{5}$ In addition, due to the poor elastic properties of these meshes an initial straining will not be fully recovered. This so called plastic deformation may lead to folds and structural deformation of the mesh.

Furthermore, these meshes could not be visualized with imaging techniques. Recent studies have demonstrated that it is possible to visualize meshes, but only if iron particles have been added to the mesh fibers. Visualization of meshes may be helpful to identify mesh related complications, due to shrinkage or adhesion formation. $^{8,9}$

It could be previously shown that a newly developed mesh with elastic thermoplastic polyurethane (TPU) fibers retains its effective porosity under mechanical strain. ${ }^{10}$ Due to its elastic properties and its structural stability it is possible to place this mesh under strain, in order to cover the extension of the abdominal wall during the pneumoperitoneum phase.

The aim of this study was to evaluate this newly developed elastic TPU mesh in IPOM position in a porcine model and to assess its visualization under pneumoperitoneum using MRI in comparison to structural similar but considerably stiffer polyvinylidene fluoride (PVDF) meshes. 


\section{Methods}

The experiments were officially approved by the local Animal Care and Use Review Committee (TVA-AZ: 84-02.04.2014.A291). All animals received humane care in accordance with the requirements of the German Tierschutzgesetz, §8 Abs. 1 and in accordance to the Guide for the Care and Use of Laboratory Animals published by the National Institute of Health.

\section{Animals}

Ten female minipigs (Ellegaard, Denmark) with a mean bodyweight of $34 \pm 7 \mathrm{~kg}$ were laparoscopically operated. In each pig, a mesh (TPU or PVDF, $10 \times 20 \mathrm{~cm}$ ) was randomly placed in IPOM position at the center of the abdominal wall. The animals' acclimatization period took one week. All animals were kept under standardized conditions: temperature between $22^{\circ} \mathrm{C}$ and $24^{\circ} \mathrm{C}$; relative humidity $50-60 \% ; 12 \mathrm{~h}$ of light following $12 \mathrm{~h}$ of darkness. The animals had free access to food and water. Food was withdrawn $12 \mathrm{~h}$ before and after surgery. After 8 weeks, six pigs underwent MRI evaluation under anesthesia with and without pneumoperitoneum to assess the visibility and elasticity of the mesh. Subsequently, pigs were euthanized and abdominal walls were explanted for histological and immunohistochemical assessment. The degree of adhesion formation was documented.

\section{Prosthetic material}

The experimental mesh was made out of a mixture of PVDF monofilaments and nonabsorbable monofilament polycarbonate-based thermoplastic urethane (TPU) threads with high elasticity, which were already used before to develop an elastic mesh. The melt spinning process was performed on a single screw extruder spinning machine (Fourné Polymertechnik GmbH, Germany). Processing temperatures of $193^{\circ} \mathrm{C}$ up to $218^{\circ} \mathrm{C}$ were used. The filaments were quenched in a water bath, drawn and spooled onto a spool by a winding machine. Monofilaments with a draw ratio of 3.5 were produced. Prior to the melt spinning process the polymer was dried under vacuum conditions at a temperature of $80^{\circ} \mathrm{C}$ for at least 16 hours. To avoid absorption of water after drying the feeding hopper of the spinning machine was continuously purged with nitrogen. For the production of the meshes a warp knitting machine was used. ${ }^{10}$ Polyvinylidene fluoride (PVDF) meshes with a similar textile configuration of the same size $(10 \times 20 \mathrm{~cm})$ were used as control meshes. Iron particles were added to the PVDF threads to make the mesh visible on MRI. 


\section{Adhesion score}

Postoperative peritoneal adhesions were scored by two blinded observers using the adhesion score developed by Diamond et al. ${ }^{11}$ This score is based on extent, type, and tenacity of the adhesion tissue both for visceral and parietal peritoneum.

\section{Surgical procedure}

All operations were carried out under general anesthesia, aseptic and sterile surgical conditions and were performed by two different and independent surgeons. Anesthesia was induced with $0.5 \mathrm{mg}$ Atropinsulfat (Atropin ${ }^{\circledR}$ ) and $200 \mathrm{mg}$ Azaperon (Stresnil ${ }^{\circledR}$ ) i.m. After 10 minutes, $10 \mathrm{mg} / \mathrm{kg}$ of Ketamin (Ketamin ${ }^{\circledR}$, Fa. Sanofi-Ceva, Düsseldorf, Germany) and $10 \mathrm{mg} / \mathrm{kg}$ Pentobarbital-Natrium (Narcoren ${ }^{\circledR}$ ) were given. Endotracheal intubation was performed with tubes between 34 and $36 \mathrm{Ch}$. Pigs were placed in supine position. The abdomen was shaved and disinfected with polyvidone iodine solution. Subsequently, the planned position of the mesh was marked on the skin (Figure 6.1). A $10 \mathrm{~mm}$ optic trocar was inserted through an incision in the right middle abdomen and a pneumoperitoneum of $15 \mathrm{mmHg}$ was established (CO2 insufflator, Richard Wolf, Knittlingen, Germany) (Figure 6.2). Two $5 \mathrm{~mm}$ trocars were placed in the right upper and lower abdomen under direct vision. The mesh with a standardized size of $10 \times 20 \mathrm{~cm}$ was rolled and passed through the $10 \mathrm{~mm}$ trocar into the abdominal cavity.

The correct mesh position was assessed using the markings on the skin by transfascial sutures. This way it was possible to place the mesh under a tension, which was demanded by the pneumoperitoneum. Hereafter, the mesh was fixated in IPOM position with 7 staples per mesh using an endoscopic Multi-Stapler (AbsorbaTacks, $5 \mathrm{~mm}$, Covidien, Mansfield, USA). Tacks were placed in every corner, in the middle of the long sites and in the center of each mesh. Trocars were removed and the muscular layers were closed using UCLX sutures (Vicryl ${ }^{\circledR}$, USP-Size 2-0, FA Ethicon Inc., Somerville, N.J., USA). Skin was sutured intracutaneously with Monocryl ${ }^{\circledR}$ (USP-Size 4-0). After 12 and 24 hours postoperatively, animals got Buprenorphin (Temgesic ${ }^{\circledR}$ ) $0.05-0.1 \mathrm{mg} / \mathrm{kg}$ (Essex Phar-ma GmbH, München) for analgesia.

Eight weeks after the initial operation, pigs received anesthesia and again a $10 \mathrm{~mm}$ optic trocar was inserted in order to create a pneumoperitoneum and to score the adhesions. MRI scans were performed in six animals with and without pneumoperitoneum. Finally, the animals were euthanized using a lethal dose of $500 \mathrm{mg}$ Pentobarbital-Natrium (Narcoren ${ }^{\circledR}$, Fa. Rhône Merieux, Laupheim). The entire abdominal wall was resected and was immediately fixed in $10 \%$ formaldehyde for later histological and immunohistochemical assessment. The degree of adhesion formation was documented. 
Figure 6.1 Marking of preoperative mesh position on a mini pigs skin.

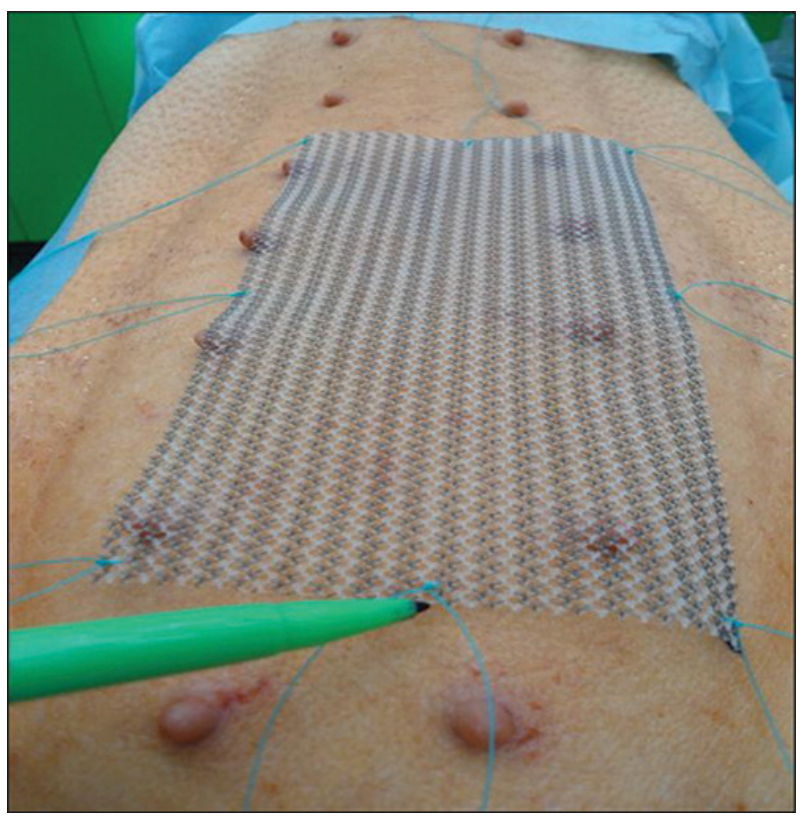

Figure 6.2 Abdominal wall under pneumoperitoneum in a mini pig model.

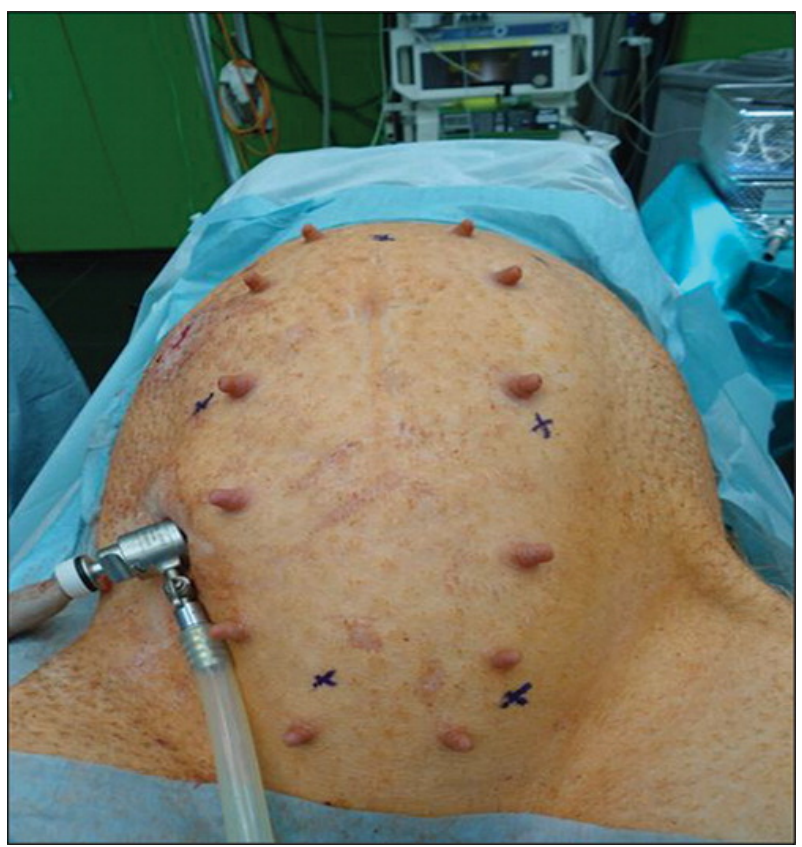




\section{MRI evaluation}

MRI examinations were performed eight weeks after surgery on a clinical 1.5 Tesla scanner (Achieva, Philips Healthcare, Best, The Netherlands) using a multi-channel torso coil to acquire the signal (Sense XL Torso Coil, Philips Healthcare, The Netherlands). Under general anesthesia, the animals were examined in supine position. The MR sequence protocol included T2-weighted turbo spin echo sequences (T2W-TSE) and a T1-weighted spoiled gradient echo sequence (GRE) that was selected to highlight mesh induced susceptibility artifacts to a relatively hyperintense surrounding. The images were acquired in transverse and sagittal orientations.

\section{Histological assessment and immunohistochemical analysis}

Histological and immunohistochemical stainings were performed as described previously. ${ }^{12}$ Samples were embedded in paraffin and cut in $3 \mu \mathrm{m}$ sections after formaldehyde fixation. All sections were routinely stained with hematoxylin and eosin ( $H \& E)$ and processed at the same time to reduce internal staining variations. The amount of inflammatory and connective tissue formation was analyzed semiquantitatively by measuring the diameter of the inner and outer foreign body granuloma representing the inflammatory infiltrate and the fibrotic tissue reaction. After capturing 4 granuloma per sample with a digital camera (Olympus C-3030, Hamburg, Germany) separate measurements were performed with the help of a digital image analyzing software (Image-Pro Plus, Media Cybernetics, Silver Spring, MD, USA). By adding the measurements of each granuloma and building averages, total granuloma size was calculated. Histological investigations were performed by two blinded and independent observers.

Immunohistochemistry was used to analyze the host response. After pretreatment of the fixed specimen with microwave and citrate-buffer $\mathrm{pH} 6$ for three times, cells were identified by different monoclonal antibodies from Dako (Glostrup, Denmark). The inflammation was assessed by counting the number of macrophages (CD68 expression) in the foreign body granuloma. As a marker for cell proliferation, Ki67 expression was measured. "Terminal deoxynucleotidyl transferase nick end labeling" (TUNEL) histochemistry was used as a staining for DNA fragments indicating apoptosis in the granuloma as previously described by Junge et al. ${ }^{13}$ All sections were examined by standard light microscopy (Olympus BX51, Olympus, Hamburg, Germany). Furthermore, a Sirius Red staining was performed to measure the collagen I/III ratio, using crosspolarization microscopy (CPM), as described by Junqueira et al. ${ }^{14}$ All assessments were performed by two blinded and independent observers.

\section{Statistical analysis}

Statistical analysis was carried out using the Statistical Package for Social Sciences software (SPSS ${ }^{\circledR}$, Vers.17.0, Chicago, IL, USA). Differences between study groups were analyzed by Kruskal-Wallis test for nonparametric data and in case of significant 
differences confirmed by Mann-Whitney $U$ test. For numeric data differences were analyzed by ANOVA and in case of significance confirmed by $t$-Test. $P$-values $<0.05$ were considered to be significant. All data are represented as mean \pm standard deviation.

\section{Results}

\section{Animal experiments}

All animals recovered quickly after the operations. No complications occurred due to surgery or anesthesia procedure. During follow-up there were no signs of wound infection or discomfort due to implanted materials. None of the pigs died during the postoperative observational period. At the day of explantation, animals had a mean bodyweight of $37 \pm 5 \mathrm{~kg}$. There were no significant differences between the study groups.

\section{MRI evaluation}

After eight weeks, meshes could be detected as a signal free structure in all pigs and mesh position could be precisely assessed using MRI (Figures 6.3 and 6.4). TPU meshes had a good integration with the abdominal wall and no folds could be seen during the $0 \mathrm{mmHg}$ and the $15 \mathrm{mmHg}$ phase of the MRI. PVDF meshes also showed to have a good integration, however, multiple folds of the mesh could be detected in the $0 \mathrm{mmHg}$ phase of the MRI. During the $15 \mathrm{mmHg}$ phase, no decrease of mesh folding was observed.

Mesh surfaces measured without pneumoperitoneum ranged from $199.3 \mathrm{~cm}^{2}$ to $213 \mathrm{~cm}^{2}$ in the TPU group and from $198 \mathrm{~cm}^{2}$ to $218 \mathrm{~cm}^{2}$ in the PVDF group (Table 6.1). Under a pneumoperitoneum of $15 \mathrm{mmHg}$, mesh surfaces ranged from $268 \mathrm{~cm}^{2}$ to $280 \mathrm{~cm}^{2}$ (TPU) and $211 \mathrm{~cm}^{2}$ to $238 \mathrm{~cm}^{2}$ (PVDF). Thus, TPU meshes showed a significant higher surface increase under pneumoperitoneum in comparison to PVDF meshes (33\% vs. $8 \%, p=0.043$ ) indicating a favorable elastic behavior after 8 weeks.

\section{Size and expansion of granuloma}

Inner and outer foreign body granuloma sizes did not differ between the TPU and PVDF group (Inner granuloma: $6.1 \pm 1.8 \mu \mathrm{m}$ vs. $5.7 \pm 1.6 \mu \mathrm{m}, p=0.101$; Outer granuloma: $39.5 \pm 13.7 \mu \mathrm{m}$ vs. $41.4 \pm 11.8 \mu \mathrm{m}, p=0.110$ ) (Table 6.2). No fibrotic bridging between mesh filaments was observed in both groups. Foreign body granuloma was only seen surrounding single sutures. 
Figure 6.3 MRI-Visualization (T2w-TSE) of TPU mesh in IPOM position without pneumoperitoneum in a mini pig model after 8 weeks of follow-up.

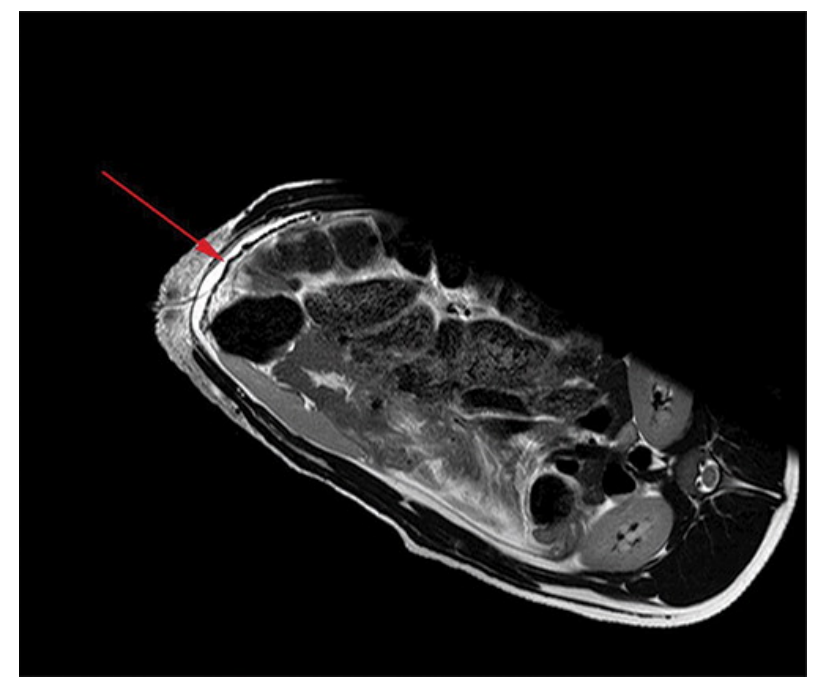

Figure 6.4 MRI-Visualization (GRE) of TPU mesh in IPOM position with pneumoperitoneum (15 $\mathrm{mmHg}$ ) in a mini pig model after 8 weeks of follow-up.

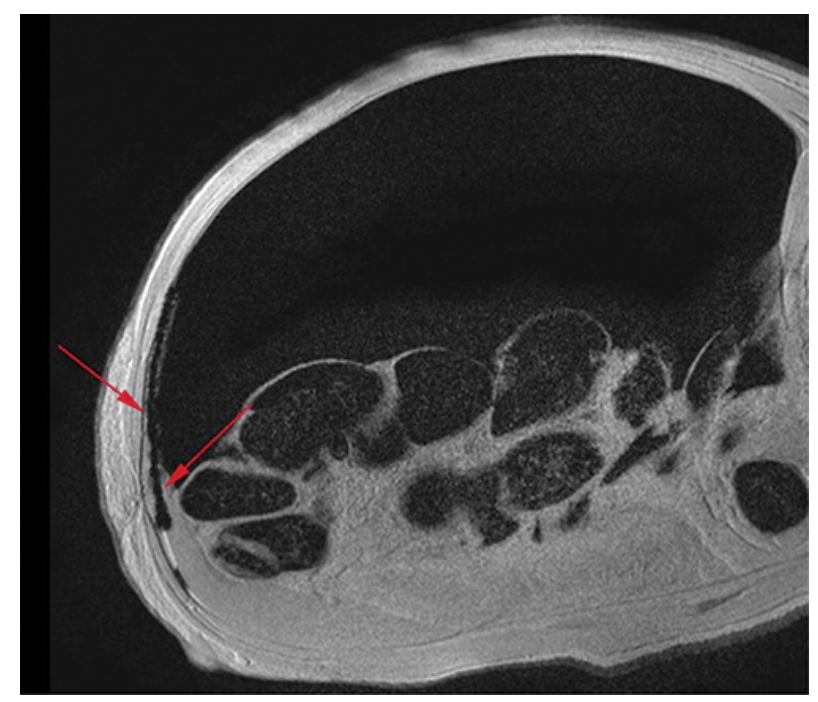


Table 6.1 MRI-measurements of different meshes after 8 weeks of follow-up.

\begin{tabular}{lccccc}
\hline Animal & Mesh & $\begin{array}{c}\text { Surface } \\
\mathbf{0 ~} \mathbf{~ m H g}\end{array}$ & $\begin{array}{c}\text { Surface } \\
\mathbf{1 5 ~} \mathbf{~ m m H}\end{array}$ & $\begin{array}{c}\text { Increase } \\
\text { in } \mathbf{~ m}^{\mathbf{2}}\end{array}$ & $\begin{array}{c}\text { Increase } \\
\text { in \% }\end{array}$ \\
\hline 1 & TPU & $207.9 \mathrm{~cm}^{2}$ & $267.8 \mathrm{~cm}^{2}$ & $59.9 \mathrm{~cm}^{2}$ & $28.8 \%$ \\
2 & PVDF & $198.4 \mathrm{~cm}^{2}$ & $215.7 \mathrm{~cm}^{2}$ & $17.3 \mathrm{~cm}^{2}$ & $8.7 \%$ \\
3 & PVDF & $217.9 \mathrm{~cm}^{2}$ & $237.9 \mathrm{~cm}^{2}$ & $20 \mathrm{~cm}^{2}$ & $9.2 \%$ \\
4 & TPU & $199.3 \mathrm{~cm}^{2}$ & $280.4 \mathrm{~cm}^{2}$ & $81.1 \mathrm{~cm}^{2}$ & $40.7 \%$ \\
5 & PVDF & $200.2 \mathrm{~cm}^{2}$ & $210.8 \mathrm{~cm}^{2}$ & $10.6 \mathrm{~cm}^{2}$ & $5.2 \%$ \\
6 & TPU & $213.1 \mathrm{~cm}^{2}$ & $275.6 \mathrm{~cm}^{2}$ & $62.5 \mathrm{~cm}^{2}$ & $29.3 \%$ \\
\hline
\end{tabular}

\section{Immunohistochemical observations}

To analyze the foreign body reaction to the implanted material, we investigated the presence of inflammatory cells (CD68), proliferating cells (Ki67) and apoptotic cells within the granuloma surrounding the different materials. We did not find significant differences between the study groups after 8 weeks (Table 6.2). Regarding CD45positive cells (leukocyte-marker), TPU meshes showed significant lower levels in comparison to PVDF $(2.4 \pm 0.9$ vs. $5.1 \pm 2, p=0.047)$.

\section{Collagen type I/III ratio}

Reflecting the maturity of the scar, we analyzed the collagen type I/III ratio. It was significantly higher in elastic TPU meshes after the observational period of 8 weeks $(9 \pm 0.5$ vs. $4.9 \pm 0.8, p<0.001)$ (Table 6.2).

Table 6.2 Histological assessment and immunohistochemical analysis after 8 weeks.

\begin{tabular}{lccc}
\hline & TPU & PVDF & $\boldsymbol{p}^{\text {-value }}$ a $^{\text {a }}$ \\
\hline Inner Granuloma size in $\mu \mathrm{m}$ & $6.1 \pm 1.8$ & $5.7 \pm 1.6$ & 0.101 \\
Outer Granuloma size in $\mu \mathrm{m}$ & $39.5 \pm 13.7$ & $41.4 \pm 11.8$ & 0.110 \\
Ki67 \% positive cells & $6.2 \pm 3.1$ & $5.6 \pm 1.6$ & 0.917 \\
CD68 \% positive cells & $1.3 \pm 0.6$ & $1.1 \pm 0.4$ & 0.598 \\
CD45 \% positive cells & $2.4 \pm 0.9$ & $5.1 \pm 2$ & 0.047 \\
Apoptosis & $15 \pm 2.9$ & $11.9 \pm 4.3$ & 0.251 \\
Collagen I/III ratio & $9 \pm 0.5$ & $4.9 \pm 0.8$ & $<0.001$ \\
\hline
\end{tabular}

${ }^{a} p$-values $<0.05$ were considered significant.

\section{Adhesion score}

Postoperative peritoneal adhesions were scored using the adhesion score developed by Diamond et al. ${ }^{11}$ They were documented without any statistical significance between study groups (TPU: $9 \pm 1.6$ vs. PVDF: $9.2 \pm 0.8, p=0.830$ ). 


\section{Discussion}

Hernia development is a common complication after intra-abdominal surgery, with reported incidences from $12 \%$ after laparotomy and $6 \%$ after laparoscopy. ${ }^{15}$ Due to their risks for complications like pain and incarceration, hernias usually require an operative mesh repair. ${ }^{1,16}$

In the last decades, several types of meshes have been developed. These meshes differ in mesh material, mesh weight, pore size and elasticity. ${ }^{17}$ These characteristics are determining factors for biocompatibility of meshes. It was shown that meshes with large pores provide improved tissue integration and that the use of heavyweight meshes with small pores leads to a more severe foreign body reaction with scar formation compared to lightweight meshes with large pores. ${ }^{6,7}$ However, previous studies have shown that lightweight meshes have an increased shrinkage. ${ }^{6,18}$ Based on these findings, Weyhe et al. hypothesized that stable mesh structures are an important factor to assess improved biocompatibility. ${ }^{6}$ This hypothesis was underlined by Mühl et al., who revealed that an effective porosity is an essential parameter to improve the meshes biocompatibility. ${ }^{5}$ These new insights may help to develop the "ideal mesh", which has not been found yet. It is thought that it should be a lightweight mesh with large pores, good tissue integration and little foreign body reaction. Furthermore, it should have a small risk of infections and adhesion formation.

The new elastic TPU mesh investigated in the present study is a promising approach since we could show that its elasticity and thus the effective porosity is preserved under mechanical strain. We used the polymer group of polyurethanes which are known for their superior mechanical properties and biocompatibility. Since the 1960s polyurethanes are used in medical applications like balloon catheters or artificial heart valves. It is possible to synthesize rigid and inelastic or flexible and elastic polyurethanes depending on their chemical structure and applied monomers. For the usage in elastic hernia mesh implants, monofilaments with an appropriate elasticity and high resistance against hydrolytic degradation are needed. Thermoplastic polycarbonate urethanes (TPU) can meet these requirements. In addition, they are meltable and can be spun solvent-free using the melt spinning process. ${ }^{10}$ Furthermore, it seems to reduce adhesion formation in a rabbit model. ${ }^{12}$ In these previous studies, we were able to investigate early phases of wound healing and foreign body reaction with similar TPU meshes after 7 and 21 days. The aim of the present study was to prove long-term capability of the newly developed mesh and to confirm our findings in a minipig model. In the current study, iron particles were added to the newly developed meshes to make them visible with MRI. This might be of added value since visualization of meshes can be helpful to detect mesh-related complications like adhesion formation and mesh shrinkage. ${ }^{8,9}$ Previous studies have shown that parts of the meshes used for hernia repair can be visualized with MRI. However, not all types of meshes have this potential. ${ }^{19-21}$ The described mesh fixation with a relatively low numbers of tacks per mesh was chosen due to the fact that tacks might have caused adhesions independent 
from mesh material, in addition. On the other hand, we finally did not find an accumulation of adhesions around the staples and no significant differences regarding adhesion formation in both study groups.

MRI results were promising in our study. Both meshes could be clearly detected and it was possible to measure the mesh surface after 8 weeks. Mesh surfaces were approximately similar in both groups in the phase without pneumoperitoneum. However, TPU meshes preserved their elastic properties with a significantly more increased mesh surface during the phase of pneumoperitoneum. Although mesh surface measured with MRI showed mesh shrinkage of around $30 \%$ compared to the mesh size at implantation, this could not be confirmed during explantation of the meshes. This phenomenon was previously described. ${ }^{9}$ It was also seen in a study regarding ex vivo skin shrinkage, which showed that skin shrinkage already occurred before formalin fixation. It was thought that this could be related to the elasticity of the skin. $^{22}$ Since the abdominal wall has elastic properties as well, this could also explain the shrinkage that was observed after explantation in the present study. Furthermore, it might be possible that differences in abdominal pressure have occurred during the measurements. This could also explain the discrepancy between MRI and ex vivo measurements. Moreover, if mesh sizes were assessed with MRI during inspiration, this may have led to slightly increased mesh sizes, compared to ex vivo measurements.

Immunohistochemical comparisons between both groups revealed significant differences regarding the amounts of CD45-positive cells within the granulomas between the TPU mesh and PVDF mesh. The percentage of CD68-positive cells was similar in both groups. Apparently, not only CD68-positive macrophages are involved in the foreign body reaction, but also other types of leucocytes play an important role. This observation was also described by Klinge et al. ${ }^{23}$ The presence of more CD45positive cells in the PVDF group suggests a higher inflammatory response, possibly caused by less biocompatibility of PVDF compared to TPU meshes. Regarding the fact that the current TPU meshes consist of more than $80 \%$ out of PVDF, the described results are more likely due to the new elastic properties than due to the materials itself.

However, it is also suggested that CD45-positive cells represent fibrocytes that can differentiate into other cells, e.g. macrophages or fibroblasts. ${ }^{24}$ These fibrocytes are important in the process of wound healing. During the differentiation phase, fibrocytes lose their surface markers, such as CD45. ${ }^{24}$ It can be assumed that materials like TPU and PVDF influence normal wound healing. Due to differences in biocompatibility, it might be possible that both groups can be found in different stages of wound healing. In the TPU group, wound healing might be in a next stage, in which CD45-positive cells are already differentiated into other cell types. It is shown that patients with severe skin burns have an up-regulated fibrocytes differentiation. Furthermore, an increased percentage of collagen I fibrocytes was detected in these patients. ${ }^{25}$ It is possible that more fibrocytes have been differentiated into collagen I producing cells compared to the PVDF group. This would also explain the higher collagen I/III ratio that was observed in the TPU group. 
A major limitation of our study is the lack of evidence that animal studies can be translated to a human situation. In particular, animals cannot reflect any underlying human disease or co-morbidity. Our observational period was relatively short and we analyzed a relatively small sample size, in addition. Unfortunately, the described preserved effective porosity of the TPU meshes under mechanical strain could only be shown in vitro in previous studies. Despite high technical efforts, MRI was not able to show the mesh pores itself. On the other hand, it was possible to prove the preservation of mesh elasticity after 8 weeks. Thus, it can only be assumed that the indicated superior biocompatibility of TPU meshes in the present study is due to their elasticity with structural stability and preserved effective porosity under strain.

In conclusion, laparoscopic implantation of elastic TPU meshes in IPOM position was feasible and safe in a porcine model. Mesh position could be precisely visualized and assessed with and without pneumoperitoneum using MRI after 8 weeks. The TPU mesh preserves its elastic properties showing a significant higher surface increase under pneumoperitoneum in comparison to PVDF. Immunohistochemistry indicates superior biocompatibility of TPU meshes regarding CD45-positive cells and Collagen I/III ratio. 


\section{References}

1. Sauerland S, Walgenbach M, Habermalz B, Seiler CM, Miserez M. Laparoscopic versus open surgical techniques for ventral or incisional hernia repair. Cochrane Database Syst Rev. 2011(3):CD007781.

2. Burger JW, Luijendijk RW, Hop WC, Halm JA, Verdaasdonk EG, Jeekel J. Long-term follow-up of a randomized controlled trial of suture versus mesh repair of incisional hernia. Ann Surg. 2004;240(4):578-83; discussion 83-5.

3. Zhang $\mathrm{Y}$, Zhou H, Chai $\mathrm{Y}$, Cao C, Jin K, Hu Z. Laparoscopic versus open incisional and ventral hernia repair: a systematic review and meta-analysis. World J Surg. 2014;38(9):2233-40.

4. Otto J, Kuehnert N, Kraemer NA, Ciritsis A, Hansen NL, Kuhl C, et al. First in vivo visualization of MRIvisible IPOM in a rabbit model. J Biomed Mater Res B Appl Biomater. 2014;102(6):1165-9.

5. Muhl T, Binnebosel M, Klinge U, Goedderz T. New objective measurement to characterize the porosity of textile implants. J Biomed Mater Res B Appl Biomater. 2008;84(1):176-83.

6. Weyhe D, Cobb W, Lecuivre J, Alves A, Ladet S, Lomanto D, et al. Large pore size and controlled mesh elongation are relevant predictors for mesh integration quality and low shrinkage - Systematic analysis of key parameters of meshes in a novel minipig hernia model. Int J Surg. 2015.

7. Lake SP, Ray S, Zihni AM, Thompson DM, Jr., Gluckstein J, Deeken CR. Pore size and pore shape--but not mesh density--alter the mechanical strength of tissue ingrowth and host tissue response to synthetic mesh materials in a porcine model of ventral hernia repair. J Mech Behav Biomed Mater. 2015;42:18697.

8. Langbach O, Holmedal SH, Grandal OJ, Rokke O. Adhesions to Mesh after Ventral Hernia Mesh Repair Are Detected by MRI but Are Not a Cause of Long Term Chronic Abdominal Pain. Gastroenterol Res Pract. 2016;2016:2631598.

9. Kuehnert N, Kraemer NA, Otto J, Donker HC, Slabu I, Baumann M, et al. In vivo MRI visualization of mesh shrinkage using surgical implants loaded with superparamagnetic iron oxides. Surg Endosc. 2012;26(5):1468-75.

10. Lambertz A, Vogels RR, Binnebosel M, Schob DS, Kossel K, Klinge U, et al. Elastic mesh with thermoplastic polyurethane filaments preserves effective porosity of textile implants. J Biomed Mater Res A. 2015;103(8):2654-60.

11. Diamond MP, Linsky CB, Cunningham T, Constantine B, diZerega GS, DeCherney AH. A model for sidewall adhesions in the rabbit: reduction by an absorbable barrier. Microsurgery. 1987;8(4):197-200.

12. Lambertz A, Hil LV, Schob DS, Binnebosel M, Kroh A, Klinge U, et al. Analysis of adhesion formation of a new elastic thermoplastic polyurethane (TPU) mesh in comparison to polypropylene (PP) meshes in IPOM position. J Mech Behav Biomed Mater. 2016;53:366-72.

13. Junge $K$, Klinge $U$, Rosch R, Klosterhalfen B, Schumpelick V. Functional and morphologic properties of a modified mesh for inguinal hernia repair. World J Surg. 2002;26(12):1472-80.

14. Junqueira LC, Cossermelli W, Brentani R. Differential staining of collagens type I, II and III by Sirius Red and polarization microscopy. Arch Histol Jpn. 1978;41(3):267-74.

15. Le Huu Nho R, Mege D, Ouaissi M, Sielezneff I, Sastre B. Incidence and prevention of ventral incisional hernia. J Visc Surg. 2012;149(5 Suppl):e3-14.

16. Courtney CA, Lee AC, Wilson C, O'Dwyer PJ. Ventral hernia repair: a study of current practice. Hernia. 2003;7(1):44-6.

17. Brown CN, Finch JG. Which mesh for hernia repair? Ann R Coll Surg Engl. 2010;92(4):272-8.

18. Zogbi L, Trindade EN, Trindade MR. Comparative study of shrinkage, inflammatory response and fibroplasia in heavyweight and lightweight meshes. Hernia. 2013;17(6):765-72.

19. Rakic S, LeBlanc KA. The radiologic appearance of prosthetic materials used in hernia repair and a recommended classification. AJR Am J Roentgenol. 2013;201(6):1180-3.

20. Kirchhoff S, Ladurner R, Kirchhoff C, Mussack T, Reiser MF, Lienemann A. Detection of recurrent hernia and intraabdominal adhesions following incisional hernia repair: a functional cine MRI-study. Abdom Imaging. 2010;35(2):224-31.

21. Kohler G, Pallwein-Prettner L, Koch OO, Luketina RR, Lechner M, Emmanuel K. Magnetic resonancevisible meshes for laparoscopic ventral hernia repair. JSLS. 2015;19(1):e2014 00175.

22. Dauendorffer JN, Bastuji-Garin S, Guero S, Brousse N, Fraitag S. Shrinkage of skin excision specimens: formalin fixation is not the culprit. Br J Dermatol. 2009;160(4):810-4. 
23. Klinge $U$, Dietz $U$, Fet $N$, Klosterhalfen $B$. Characterisation of the cellular infiltrate in the foreign body granuloma of textile meshes with its impact on collagen deposition. Hernia. 2014;18(4):571-8.

24. Bucala R, Spiegel LA, Chesney J, Hogan M, Cerami A. Circulating fibrocytes define a new leukocyte subpopulation that mediates tissue repair. Mol Med. 1994;1(1):71-81.

25. Grieb G, Steffens G, Pallua N, Bernhagen J, Bucala R. Circulating fibrocytes--biology and mechanisms in wound healing and scar formation. Int Rev Cell Mol Biol. 2011;291:1-19. 


\section{PART III}

A human model for adhesion assessment and hernia prevention 



\title{
Chapter 7
}

Comparability of histological outcomes in rats and humans in a hernia model

\author{
L.C.L. van den $\mathrm{Hil}$ \\ R.R.M Vogels \\ K.W.Y. van Barneveld \\ M.J.J. Gijbels \\ C.J. Peutz-Kootstra \\ J.P.M Cleutjens \\ M.H.F. Schreinemacher \\ N.D. Bouvy
}




\section{Abstract}

\section{Background}

Hernia repair is one of the most frequently performed operations. In search of the ideal mesh for hernia repair, animal research is required. Although rats are most often used in experimental mesh experiments, no correlation with clinical findings in humans has ever been shown. Therefore, the aim of our study was to investigate whether adhesion formation and foreign body reactions to meshes in rats are comparable with the reactions in humans.

\section{Materials and methods}

A fixed type of mesh was implanted intraperitoneally in a group of 10 rats and 10 patients undergoing elective, temporary stoma formation. In case of the latter, meshes were placed around the stoma. After a follow-up period of 12 weeks in rats and after a median follow-up of six months in humans, samples of the mesh were collected. Adhesion assessments were performed and (immuno-) histochemical evaluation was performed by a specialized experimental pathologist and an experienced clinical pathologist.

\section{Results}

After the follow-up period, adhesion formation did not differ significantly between rats and humans. Moreover, general inflammation scores were comparable, although granulocytes and giant cells were more present in rats compared to humans. On the other hand, the presence of fibrosis was more evident in humans compared to rats.

\section{Conclusion}

To our knowledge, this is the first study, which showed that a specific animal model, namely a rat model, correlates with adhesion formation and the foreign body reaction to meshes in humans. It can be recommended to use rats in future experimental mesh for incisional hernia research. 


\section{Introduction}

Laparoscopic hernia surgery is commonly performed and has frequently been associated with less wound infections and shorter hospital stay. ${ }^{1,2}$ With the increase of laparoscopic hernia repair, also the number of intraperitoneally placed meshes has been increased. ${ }^{3}$ However, some possible disadvantages of intraperitoneally placed meshes have to be considered. One limitation is the formation of adhesions to the mesh due to the body's inflammatory response to the foreign body. ${ }^{4,5}$ Adhesions are related to chronic pain, bowel obstruction, infertility and inadvertent enterotomies at the time of reoperations. ${ }^{6,7}$ Furthermore, adhesions may complicate future surgery. ${ }^{7}$ In order to reduce those adhesions, several types of meshes with different coatings have been developed in the last decades. However, none of these meshes seem to be able to prevent adhesion formation completely and therefore the development of new antiadhesive meshes still continues. ${ }^{8}$

To assess safety, functionality, and biocompatibility of new medical devices, like surgical meshes, the use of an animal model is generally the first step. Although there is a large variation in the type and species of animals used, most frequently rats are used as test subjects. ${ }^{9-11}$ The rat is a small and easy to handle animal but still large enough for mesh implantation. Furthermore, it is relatively inexpensive.

Unfortunately, little is known about the implications of results in a rat model for a human situation. To date, no translational research has been performed to assess the degree of similarity of the foreign body response to meshes between human and rats.

The aim of this study is to compare the macroscopic and microscopic outcomes in rats and humans after intraperitoneal mesh implantation, using identical meshes. As such, the translatability of mesh research in a rat model towards the human situation can be proved.

\section{Materials and methods}

The experimental animal protocol was approved by the local Animal Ethics Committee of Maastricht University, The Netherlands, according to the Dutch Animal Experimentation Act.

The protocol regarding the human part of this study was approved by the Medical Ethical Committee of Maastricht University Medical Centre, Maastricht, The Netherlands. Informed consent was given by all participants.

Parietex Composite meshes (Covidien, Mansfield, MA, USA), monofilament, polyester meshes of which one side is coated with an absorbable collagen layer to prevent adhesions were used in both the rat model and in the human situation. The meshes were placed intraperitoneally with the coated side in direct contact with the viscera. 


\section{Animals}

Ten male Wistar rats weighing 356 grams (standard deviation $9 \mathrm{~g}$ ) were housed and cared for at the Central Animal Facilities of Maastricht University, according to the local standards. Male rats were chosen, since it is unclear whether progesterone and estrogen in females influence adhesion formation. ${ }^{12}$ Rats had free access to water and food and a day-night cycle of $12 \mathrm{~h}-12 \mathrm{~h}$ was maintained.

Surgery was performed as described earlier, using a rat model. ${ }^{13}$ Briefly, after administration of buprenorphine $0.05 \mathrm{mg} / \mathrm{kg}$ subcutaneously as analgesics, all animals were anesthetized with isoflurane $5 \%$ and anaesthesia was maintained with isoflurane $2.5 \%$.

Subsequently, the abdomen was shaved and skin was disinfected with iodine $2 \%$. A $4 \mathrm{~cm}$ midline-incision was created to enter the abdomen and a sterile mesh of 20x30 mm (Parietex Composite Parastomal ${ }^{\circledR}$, Covidien, Mansfield, MA, USA), was placed and sutured to the intraperitoneal part of the abdominal wall with four sutures of polypropylene 4/0 (Prolene ${ }^{\circledR}$, Ethicon, Johnson \& Johnson, Somerville, New Jersey, USA) in each corner of the mesh. Hereafter, the abdominal wall was closed using a running suture of polyglactin $4 / 0$ (Vicryl ${ }^{\circledR}$, Ethicon Johnson \& Johnson) and the skin was closed intracutaneously with polyglecaprone $4 / 0$ (Monocryl ${ }^{\circledR}$, Ethicon, Johnson \& Johnson).

After 12 weeks, rats were euthanized with an overdose of carbon dioxide. A Ushaped incision was created and adhesions were scored macroscopically. Subsequently, the mesh was explanted for microscopic evaluation as described previously by Schreinemacher et al. ${ }^{13}$

\section{Patients}

Ten consecutive patients who underwent elective open low anterior resection of the rectum with temporary stoma placement were invited for participation in a pilot study to assess safety and feasibility of prophylactic mesh placement to prevent incisional hernias after stoma reversal as well as parastomal hernias as long as the stoma is in place. The favourable results of this study were published earlier and are referred to for further detailed information. ${ }^{14}$ In brief, after marking the preferred stoma site, inducing anaesthesia and administering antibiotics (cefazolin-metronidazole), the abdomen was entered via a midline laparotomy and a bowel resection with anastomosis was performed. At the marked site, a small circular piece of skin with underlying layers of the abdominal wall was excised to create a passage.

Subsequently, after creating an opening in the centre of a mesh with $20 \mathrm{~cm}$ diameter (Parietex Composite Parastomal ${ }^{\circledR}$, Covidien, Mansfield, MA, USA), the bowel was passed through the mesh and the mesh was placed intraperitoneally, with the coated site facing the viscera, and fixed with absorbable tackers (AbsorbaTack, Covidien) at the outer margin of the mesh. Finally, the abdomen was closed and the stoma was sutured in place. 
After a median of six (range 2-15) months, the stoma was reversed. Again, anaesthesia was induced and antibiotics (cefazolin-metronidazole) were administered. Before stoma reversal, laparoscopy was performed to assess adhesion formation. Subsequently, the stoma was dissected free from the subcutaneous tissue, abdominal wall and mesh. An anastomosis was created and a piece of the mesh was excised en bloc and fixed in formaldehyde $4 \%$, for later analysis. Next, the fascia and mesh defect were closed with a running suture followed by skin closure. ${ }^{14}$

\section{Adhesions}

Adhesion formation was scored macroscopically, using a qualitatively and quantitatively scoring system. Adhesions were scored for extent, severity and involvement of organs in adhesions to the mesh in both the rat and human situation. A total score is calculated by summing up the aforementioned sub scores (Table 7.1).

Table 7.1 Adhesion score and number of subjects per sub-classification of adhesion score.

\begin{tabular}{lccc}
\cline { 2 - 3 } Characteristics of adhesions & Score & Rats ( $\mathbf{n}=\mathbf{1 0})$ & Humans $(\mathbf{n}=\mathbf{9})$ \\
\hline Extent & & 0 & 0 \\
No adhesions & 0 & 4 & 3 \\
$1-25 \%$ covered & 1 & 1 & 1 \\
$26-50 \%$ covered & 2 & 2 & 3 \\
$51-75 \%$ covered & 3 & 3 & 2 \\
76-100\% covered & 4 & & 0 \\
Severity & & 0 & 6 \\
No adhesions & 0 & 10 & 3 \\
Mild adhesions & 1 & 0 & 1 \\
Severe adhesions & 2 & & 5 \\
Organ involvement & & 0 & 3 \\
No & 0 & 10 & 0 \\
One organ (including omentum) & 1 & 0 & 0 \\
Multiple organs & 2 & 0 & 1 \\
Total adhesion score & 0 & 0 & 1 \\
& 1 & 0 & 1 \\
& 2 & 4 & 2 \\
& 3 & 1 & 3 \\
& 4 & 2 & 0 \\
\end{tabular}

\section{Histology}

A piece of the mesh with abdominal wall was fixed in formaldehyde $4 \%$, dehydrated and embedded in paraffin. After cutting tissue sections of $4 \mu \mathrm{m}$ thick, a hematoxylineosin staining was performed. The stained sections were evaluated by an experienced animal pathologist (M.J.J.G.) and by an experienced clinical pathologist (C.J.P.K.), using 
a semi-quantitative scoring system (not, slightly, moderately or abundantly present). ${ }^{11,13}$ A histological image of inflammation was defined as the amount of macrophages, granulocytes and neovascularization. Differences in scores between both pathologists were discussed until consensus was reached.

\section{Statistical analysis}

All categorical data are presented as frequency of occurrence. Statistical analyses were performed using the Fisher-Freeman-Halton test. SPSS version 21.0 (SPSS, Chicago, IL, USA) was used for all measurements and a $p$-value lower than 0.05 was considered as statistically significant.

\section{Results}

All rats recovered well, without signs of postoperative complications, such as wound infections or pain due to the mesh.

In the human part of the study, four males and six females were included. Patient characteristics can be found in Table 7.2. Five loop ileostomies and five loop colostomies were created.

After stoma creation, patients stayed in the hospital for eight (range 6-13) days. One patient had to be reoperated due to wound dehiscence. No further complications occurred. After a median of six (range 2-15) months all stomas were reversed.

Table 7.2 Baseline characteristics of the human group.

\begin{tabular}{lc}
\hline & Humans (n=10) \\
\hline Sex (male:female) & $4: 6$ \\
Age & $66(46-77)$ years \\
Weight & $73.5(55-90)$ \\
Height & $1.70(1.63-1.85)$ \\
Body mass index (BMI), kg/m $\mathrm{m}^{2}$ & $25(20-28)$ \\
ASA classification & $2(1-3)$ \\
Current smoker, yes & 1 \\
History of other hernias, yes & 3 \\
Diabetes mellitus, yes & 0 \\
Constipation, yes & 0 \\
Chronic obstructive pulmonary disease (COPD), yes & 1 \\
\hline
\end{tabular}

Data are presented as median (range), unless if stated otherwise

\section{Adhesions}

Mesh related adhesions were observed in all rats and in nine of ten humans. In one patient, laparoscopy was not performed due to newly diagnosed aortic valve stenosis and therefore no adhesion assessment took place. Results are presented in Table 7.1. 
The differences in extent, severity and organ involvement were not statistically significant ( $p=1.00, p=0.09$, and $p=0.09$, respectively), nor were total adhesion scores $(p=0.78)$.

\section{Histology}

In humans eight tissue samples were appropriate for evaluation. In one patient, it was not possible to excise a piece of the mesh for microscopic analysis, whereas the stoma of a second patient was reversed in another hospital and therefore it was not possible to obtain a piece of the mesh. Representative tissue samples are shown in Figure 7.1. Results of histology scoring are shown in Table 7.3. In general, inflammation was scored as slightly present in two rats compared to four humans. In seven rats and four humans inflammation was moderately present. This was not significantly different $(p=0.32)$.

However, the presence of granulocytes, giant cells and fibrosis differed significantly. Granulocytes and giant cells were more present in rats than in humans ( $p=0.006$ and $p<0.001$, respectively). By contrast, fibrosis was less present in rats compared to humans $(p<0.001)$.

Figure 7.1 Representative histologic samples of rat and human. Representative histologic samples of $\mathbf{A}$ rat tissue sample and $\mathbf{B}$ human tissue sample. Both samples are H\&E stained and the original magnification is $\times 20$.

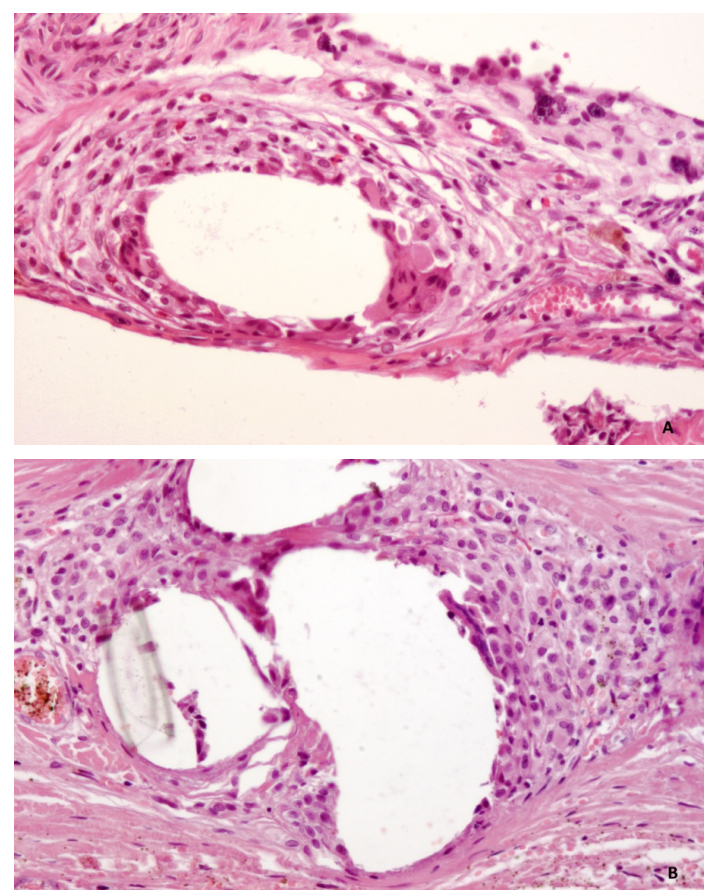


Table 7.3 Number of subjects per sub-classification of histological outcomes.

\begin{tabular}{lccc}
\hline & Score & Rats $(\mathbf{n}=\mathbf{1 0})$ & Humans $(\mathbf{n}=\mathbf{8})$ \\
\hline Inflammation & 0 & 0 & 0 \\
& 1 & 2 & 4 \\
Giant cells & 2 & 7 & 4 \\
& 3 & 1 & 0 \\
& 0 & 0 & 0 \\
Granulocytes & 1 & 0 & 7 \\
& 2 & 9 & 1 \\
Fibrosis & 3 & 1 & 0 \\
& 0 & 0 & 4 \\
& 1 & 4 & 4 \\
& 2 & 6 & 0 \\
& 3 & 0 & 0 \\
& 0 & 0 & 0 \\
& 1 & 2 & 0 \\
& 2 & 8 & 0 \\
\hline
\end{tabular}

Score; 0 - not present, 1 - slightly present, 2 - moderately present, 3 -abundantly present.

\section{Discussion}

The necessity and usefulness of animal research is an increasingly important topic of discussion, even more so since the introduction of a European legislation on animal research called the 'Directive on Animal-based Experiments'. A review has shown that the outcomes of only one third of highly cited animal papers could be repeated in human randomized controlled trials. ${ }^{15}$ Furthermore, the use of several animal species, mesh models and outcome parameters makes it hard to draw general conclusions that can be translated to the human situation. ${ }^{16}$ To make animal studies more valuable, the first step in the right direction is the choice of the most appropriate animal species to perform research on. To our knowledge, however, it never has been investigated that results in rats can be translated to a human situation in hernia research. Therefore, we assessed the comparability of macroscopic and microscopic outcomes in rats and humans after intraperitoneal mesh placement.

The present study shows rats and humans having similar macroscopic adhesion scores. This probably indicates that in both species a grossly comparable foreign body reaction as response to mesh placement has occurred, which subsequently has led to adhesion formation.

Foreign body reactions have microscopically been detected in both rats and humans. As a reaction on mesh implantation, migration of granulocytes, monocytes and macrophages to the tissue around the mesh takes place. Macrophages can fuse and form giant cells. Such foreign body granulomas can be detected as long as the mesh is in vivo. ${ }^{17}$ 
The presence of comparable foreign body reactions in both rats and humans indicates a similar response on meshes in both species. However, differences in presence of granulocytes and giant cells were detected. The most likely explanation for this is the difference in follow-up time between rats and humans. According to literature, one human year in adulthood is comparable with 10.5 rat days. ${ }^{18}$ Taking this into account, the follow-up time in rats should have been substantially shorter than the follow-up time in humans. Although, wound healing in rats is only slightly faster. ${ }^{19}$ To correct for these differences, a shorter follow-up time in rats was chosen, although it could be that a longer follow-up time would have been more appropriate. An indication for this is the difference in the number of granulocytes.

Because granulocytes are commonly regarded as a marker for the acute inflammatory reaction, the presence of granulocytes suggests that the inflammatory system in rats is still in the acute phase, while in humans already the chronic phase has been reached. This is emphasized by the lower amount of giant cells in humans. Nonetheless, according to Kossovsky et al., granulocytes may appear months after mesh implantation, depending on the material of the mesh. ${ }^{20}$

Next, in humans significantly more fibrosis was present. It is thought that the extent of scar tissue depends on both the activity of the inflammatory reaction and the severity of injury. ${ }^{20}$ Because no big differences in inflammatory activity between rats and humans could be detected, the explanation of the difference in amount of fibrosis probably has to be found in the severity of injury. In humans, a more extensive procedure has been performed, because, besides the placement of a mesh, a stoma was also created. Especially the latter has led to a more severe injury, compared with surgery in rats in which only a mesh was placed. These differences in study design may have led to differences in outcomes. However, owing to ethical reasons, the human part of this study could not be modified. Besides, the chosen setting in the animal part of the study was the least harmful for rats. Because it was believed that the mentioned differences in animal and human setting would not lead to differences in outcomes, the current study design seemed to be the most appropriate option for both humans and rats.

Some other limitations of this study also have to be addressed. First, the group sizes of our study were small. Besides, not only follow-up periods differed between rats and humans, but also within the group of humans differences in follow-up period were present. However, because only small variances in outcomes within the groups were detected, it is not likely that these factors caused differences between both groups.

Second, for this study only male rats were used, leading to a very homogeneous group, while in the human part of the study both males and females were included. It might be that this has resulted in differences between the groups. For adhesion formation, it is known that the administration of progesterone resulted in decreased adhesion formation in animals, whereas estrogens have an opposite effect. Yet, these effects on adhesions have never been studied in humans and it is therefore not likely that these possible effects are responsible for the differences found in this study. ${ }^{21-23}$ 
Finally, in this study, only one mesh type has been investigated. It might be that rats and humans react differently to other types of meshes. Although it is unlikely that the inflammatory response in both species is comparable for one material, but different for other materials, this cannot be excluded. Yet, only one mesh type was investigated due to the limited options to obtain human tissue samples.

\section{Conclusion}

This is the first study comparing macroscopic and microscopic outcomes in hernia mesh repair research between rats and humans. Differences in presence of giant cells, granulocytes and amount of fibrosis were detected. However, no differences in adhesion score and general inflammation could be assessed and therefore we believe that rats can make up for an adequate animal model for hernia research, especially to evaluate the amount of adhesions and to get a general impression of biocompatibility. Nevertheless, differences found in this study should be considered, and perhaps future research will show that other animal models are able to predict biocompatibility more precisely. Until such studies are available, we believe that rats can be recommended as an adequate animal model in hernia research. 


\section{References}

1. Zhang $\mathrm{Y}$, Zhou H, Chai $\mathrm{Y}$, Cao $\mathrm{C}$, Jin $\mathrm{K}$, et al. Laparoscopic versus open incisional and ventral hernia repair: a systematic review and meta-analysis. World J Surg. 2014:38:2233-40.

2. Sauerland S, Walgenbach M, Habermalz B, Seiler CM, Miserez M Laparoscopic versus open surgical techniques for ventral or incisional hernia repair. Cochrane Database Syst Rev 2011:CD007781.

3. Tobler WD, Jr., Itani KM Current Status and Challenges of Laparoscopy in Ventral Hernia Repair. Journal of laparoendoscopic \& advanced surgical techniques. Part A 2016:26:281-9.

4. Jenkins ED, Yom V, Melman L, Brunt LM, Eagon JC, et al. Prospective evaluation of adhesion characteristics to intraperitoneal mesh and adhesiolysis-related complications during laparoscopic reexploration after prior ventral hernia repair. Surg Endosc. 2010:24:3002-7.

5. LeBlanc KA Current considerations in laparoscopic incisional and ventral herniorrhaphy. JSLS. 2000:4:131-9.

6. Turza KC, Butler CE Adhesions and meshes: synthetic versus bioprosthetic. Plast Reconstr Surg. 2012:130:206S-13S.

7. ten Broek RP, Issa Y, van Santbrink EJ, Bouvy ND, Kruitwagen RF, et al. Burden of adhesions in abdominal and pelvic surgery: systematic review and met-analysis. BMJ. 2013:347:f5588.

8. Deeken CR, Faucher KM, Matthews BD A review of the composition, characteristics, and effectiveness of barrier mesh prostheses utilized for laparoscopic ventral hernia repair. Surg Endosc. 2012:26:566-75.

9. Reynvoet E, Chiers K, Van Overbeke I, Troisi R, Berrevoet F Intraperitoneal mesh devices for small midline hernias: mesh behavior in a porcine model. Hernia. 2015:19:955-63.

10. Jayanth ST, Pulimood A, Abraham D, Rajaram A, Paul MJ, et al. A randomized controlled experimental study comparing chitosan coated polypropylene mesh and Proceed mesh for abdominal wall defect closure. Ann Med Surg. 2015:4:388-94.

11. Vogels RR, van Barneveld KW, Bosmans JW, Beets G, Gijbels MJ, et al. Long-term evaluation of adhesion formation and foreign body response to three new meshes. Surg Endosc. 2015:29:2251-9.

12. Wiczyk HP, Grow DR, Adams LA, O'Shea DL, Reece MT Pelvic adhesions contain sex steroid receptors and produce angiogenesis growth factors. Fertil Steril. 1998:69:511-6.

13. Schreinemacher MH, van Barneveld KW, Dikmans RE, Gijbels MJ, Greve JW, et al. Coated meshes for hernia repair provide comparable intraperitoneal adhesion prevention. Surg Endosc. 2013:27:4202-9.

14. van Barneveld KW, Vogels RR, Beets GL, Breukink SO, Greve JW, et al. Prophylactic intraperitoneal mesh placement to prevent incisional hernia after stoma reversal: a feasibility study. Surg Endosc. 2014: 28:1522-7.

15. Hackam DG, Redelmeier DA Translation of research evidence from animals to humans. JAMA. 2006:296:1731-2.

16. Schreinemacher $M$, Henatsch $D$, van Barneveld K, Bouvy $N$ The need for standardised animal models and scoring systems in assessing mesh biocompatibility. Hernia. 2010:14:335-6.

17. Anderson JM, Rodriguez A, Chang DT Foreign body reaction to biomaterials. Semin Immunol. 2008:20:86-100.

18. Sengupta P The Laboratory Rat: Relating Its Age With Human's. Int J Prev Med. 2013:4:624-30.

19. Vidinsky B, Gal P, Toporcer T, Longauer F, Lenhardt L, et al. Histological study of the first seven days of skin wound healing in rats. Acta Vet Brno. 2006:75:197-+.

20. Kossovsky N, Freiman CJ, Howarth D Biomaterials pathology. In: Bendavid R, Abrahamson J, Arregui ME, Flament JB, Philips EH eds., Abdominal wall hernias: Principles and managementSpringer Science. 2001:221-34.

21. Montanino-Oliva M, Metzger DA, Luciano AA Use of medroxyprogesterone acetate in the prevention of postoperative adhesions. Fertil Steril. 1996:65:650-4.

22. Kaya U, Oktem M, Zeyneloglu HB, Ozen O, Kuscu E Impact of aromatase inhibitors on adhesion formation in a rat model. Fertil Steril. 2007:87:934-9.

23. Pados G, Venetis CA, Almaloglou K, Tarlatzis BC Prevention of intra-peritoneal adhesions in gynaecological surgery: theory and evidence. Reprod Biomed Online. 2010:21:290-303. 


\section{Chapter 8}

Prophylactic mesh placement to avoid incisional hernias after stoma reversal: a systematic review and meta-analysis

L.C.L. van den Hil

S. van Steensel M.H.F. Schreinemacher N.D. Bouvy 


\section{Abstract}

\section{Purpose}

To provide an overview of the available literature on prevention of incisional hernias after stoma reversal, with the use of prophylactic meshes.

\section{Methods}

A literature search of Pubmed, MEDLINE and EMBASE was performed. Search terms for stoma, enterostomy, mesh, prophylaxis and hernia were used. Search was updated to December 31th 2018. No time limitations were used, while English, Geman, Dutch and French were used as language restrictions. The primary outcome was the incidence of incisional hernia formation after stoma reversal. Secondary outcomes were meshrelated complications. Data on study design, sample size, patient characteristics, stoma and mesh characteristics, duration of follow-up and outcomes were extracted from the included articles.

\section{Results}

A number of 241 articles were identified and three studies with 536 patients were included. A prophylactic mesh was placed in 168 patients to prevent incisional hernias after stoma reversal. Follow-up ranged from 10 to 21 months. The risk of incisional hernia in case of prophylactic mesh placement was significantly lower in comparison to no mesh placement (OR $0.10,95 \% \mathrm{Cl} 0.04-0.27, p<0.001,12=0 \%, \mathrm{Cl} 0-91.40 \%$ ). No differences in surgical site infections were detected between the groups.

\section{Conclusions}

The use of a prophylactic mesh seems to reduce the risk on incisional hernias after stoma reversal and therefore mesh reinforcement should be considered after stoma reversal. 


\section{Introduction}

Stoma formation is most frequently performed for colorectal cancer, followed by both diverticular disease and inflammatory bowel disease. ${ }^{1}$ In up to $30 \%$ of the patients with colorectal cancer the stoma is permanent. ${ }^{2}$ Temporary stomas are constructed mainly to protect distal colorectal anastomoses, aiming to prevent the consequences of leakage of the anastomosis. ${ }^{3}$ Unfortunately, the complication rate after stoma formation is high with reported numbers up to $70 \% .{ }^{4}$ Complications which may occur during the presence of a stoma include a high output stoma, prolapse, stenosis, necrosis, fistulae, retraction and parastomal herniation. ${ }^{4,5}$ After stoma reversal, there is an increased risk to develop incisional hernias. ${ }^{1}$

Parastomal hernias seem to occur more often in patients with a colostomy, compared to patients with an ileostomy. This might be caused by the fact that ileostomies are frequently temporary stomata. lleostomies are intended to be reversed a few months after primary surgery and in this short period of time, less hernias may develop. ${ }^{6}$ Yet, even after closure of a temporary stoma, incisional herniation at the stoma site may occur. This is an underestimated problem with a reported incidence of up to $30 \%-48 \%$ depending on the diagnostic modality used. ${ }^{1,7}$ Incisional hernias can lead to pain, bowel obstruction and strangulation. ${ }^{6,8,9}$ Therefore, $44 \%$ of the clinically relevant incisional hernias necessitated surgical repair with a mesh as well. ${ }^{1}$

In the recent past, several studies regarding prophylactic mesh placement to prevent incisional hernias after laparotomy have shown promising results. ${ }^{10,11}$ Also prophylactic mesh placement around permanent stomata has widely been examined. Last year, multiple meta-analyses regarding this topic were published and showed that prophylactic mesh placement around a stoma is safe and reduces the number of parastomal hernias. ${ }^{12-14}$

Although the risk of incisional hernias is high after reversal of a temporary stoma and thus using a prophylactic mesh during stoma reversal seems favourable, hardly no systematic reviews or meta-analyses could be found regarding this topic. Taking into account that up to $26 \%$ of all temporary stomata will not be reversed eventually, it seems even more likely that these stomata also deserve a prophylactic mesh during stoma formation in order to prevent stoma related hernias. ${ }^{15}$

Therefore, the aim of this study was to to assess the effectiveness of prophylactic meshes in preventing incisional hernia at the site of stoma reversal.

\section{Methods}

To perform an adequate literature search, the following PICO was formulated: In adults $(\mathrm{P})$, does a prophylactic placed mesh (I), compared to conventional treatment without a mesh (C), decrease the risk on incisional hernia after stoma reversal (O)? 


\section{Search}

A literature search of Pubmed, MEDLINE and EMBASE was performed, according to the Preferred Reporting Items for Systematic Reviews and Meta-Analyses (PRISMA) guidelines. ${ }^{16}$ Search terms and synonyms for stoma, enterostomy, mesh, prophylaxis and hernia were used as MeSH and free text terms. Table 8.1 shows the complete search. Subsequently, the reference lists of included articles and previous reviews were searched.

Table 8.1 Terms used in the literature search.

\begin{tabular}{lccc}
\hline Search terms & & & \\
\hline Surgical stoma (MesH) & Surgical Mesh (MesH) & Prophylaxis & Abdominal hernia (MesH) \\
Enterostomy (MesH) & Mesh & Prevention & Hernia \\
Stomas & Meshes & Preventive measures & Hernias \\
Stoma & Prosthesis & Preventive measure & Herniation \\
Stomata & Prosthetic & Preventive therapy & Herniations \\
Enterostomy & Control & Wall defect \\
Enterostomies & Prophylactic & Wall defects \\
Colostomy & & \\
Colostomies & & \\
lleostomy & & \\
lleostomies & & \\
Gastroenterostomy & & \\
Gastroenterostomies & & \\
Bowel continuation & & \\
Digestive continuation & & \\
Bowel restoration & & \\
Digestive restoration & & \\
\hline
\end{tabular}

\section{Study Selection}

Two independent reviewers screened all studies (LCLvdH, SvS). No time limitations were used. English, German, French and Dutch were used as language restrictions. The search was updated up to 31 December 2018. Articles that reported on incisional hernias after prophylactic mesh placement at the stoma site in humans older than 18 years were included. Studies without a control group were excluded for data analysis. Next, case reports (less than 10 patients), letters, animal studies, review articles and meta-analysis were excluded. If articles described the same study population, the most recent publication was used. Disagreements were resolved by reexamination of the involved studies until consensus between the reviewers was reached.

\section{Data extraction and study outcome}

The data were extracted and checked by two reviewers (LCLvdH, SvS). Data on study design, sample size, patient characteristics, stoma and mesh characteristics, duration of 
follow-up and outcomes were extracted from the included articles. Stoma and mesh characteristics include the type of surgery (laparotomy or laparoscopy), type of stoma (e.g ileostomy, colostomy), type of mesh and type of mesh placement (e.g. onlay, sublay). See Figure 8.1 for the different locations of mesh placement. The primary outcome was the incidence of incisional hernia formation at the former stoma site during follow-up. Secondary outcomes were mesh-related complications.

Figure 8.1 Different locations of mesh placement.

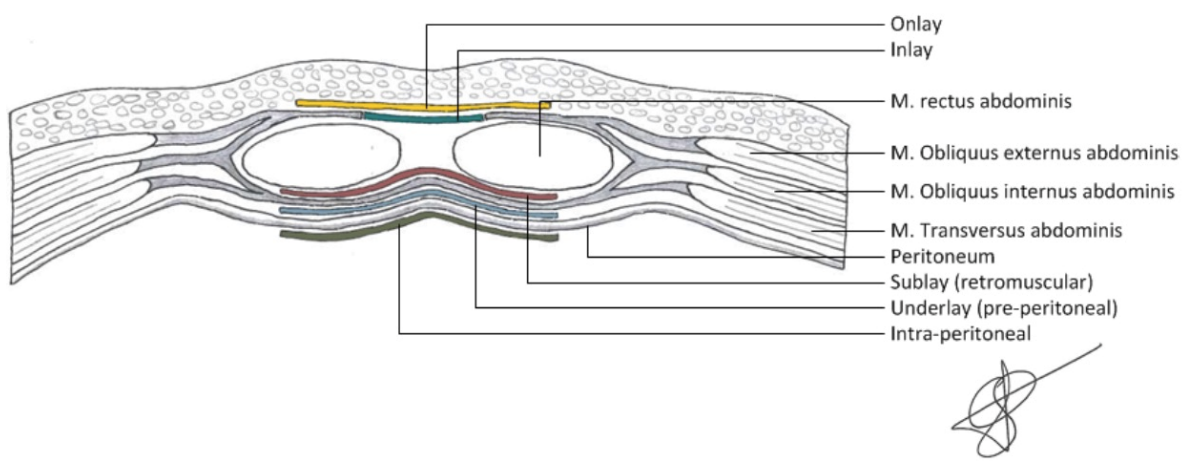

\section{Quality assessment}

The risk of study bias was assessed by one reviewer ( $L C L v d H)$ and controlled by another (SvS), using the Methodological Index for Non-Randomized Studies (MINORS). ${ }^{17}$ This is a validated instrument to assess the degree of bias of non-randomized trials. It consists of 12 items which can be scored from 0 to 2; 0 indicating that the item was not reported, 1 that the item was reported inadequately and 2 that the item was reported adequately.

\section{Data synthesis and analysis}

A meta-analysis was performed for the primary outcome, the incidence of incisional hernia after stoma reversal. The Mantel-Haenszel method was used to calculate the effect on binary outcomes, which were expressed as pooled odds ratios with $95 \%$ confidence intervals. Heterogeneity was expressed using the $\mathrm{I}^{2}$ statistic and the random effect model was applied. To confirm that the results of the present meta-analysis were not based at one single study, a leave-one-out analysis was performed.

Subgroup analyses regarding ileostomy versus colostomy and the occurrence of surgical site infections were performed. Analyses were carried out with RevMan software version 5.3, provided by the Cochrane Collaboration. ${ }^{18}$ 


\section{Results}

In total, a number of 241 articles were identified and screened. Duplicates and studies that did not mention our main outcome were excluded. A total of 3 studies with 536 patients were included. ${ }^{19-21}$ The complete selection procedure is shown in Figure 8.2.

Figure 8.2 Flowchart of study inclusion.
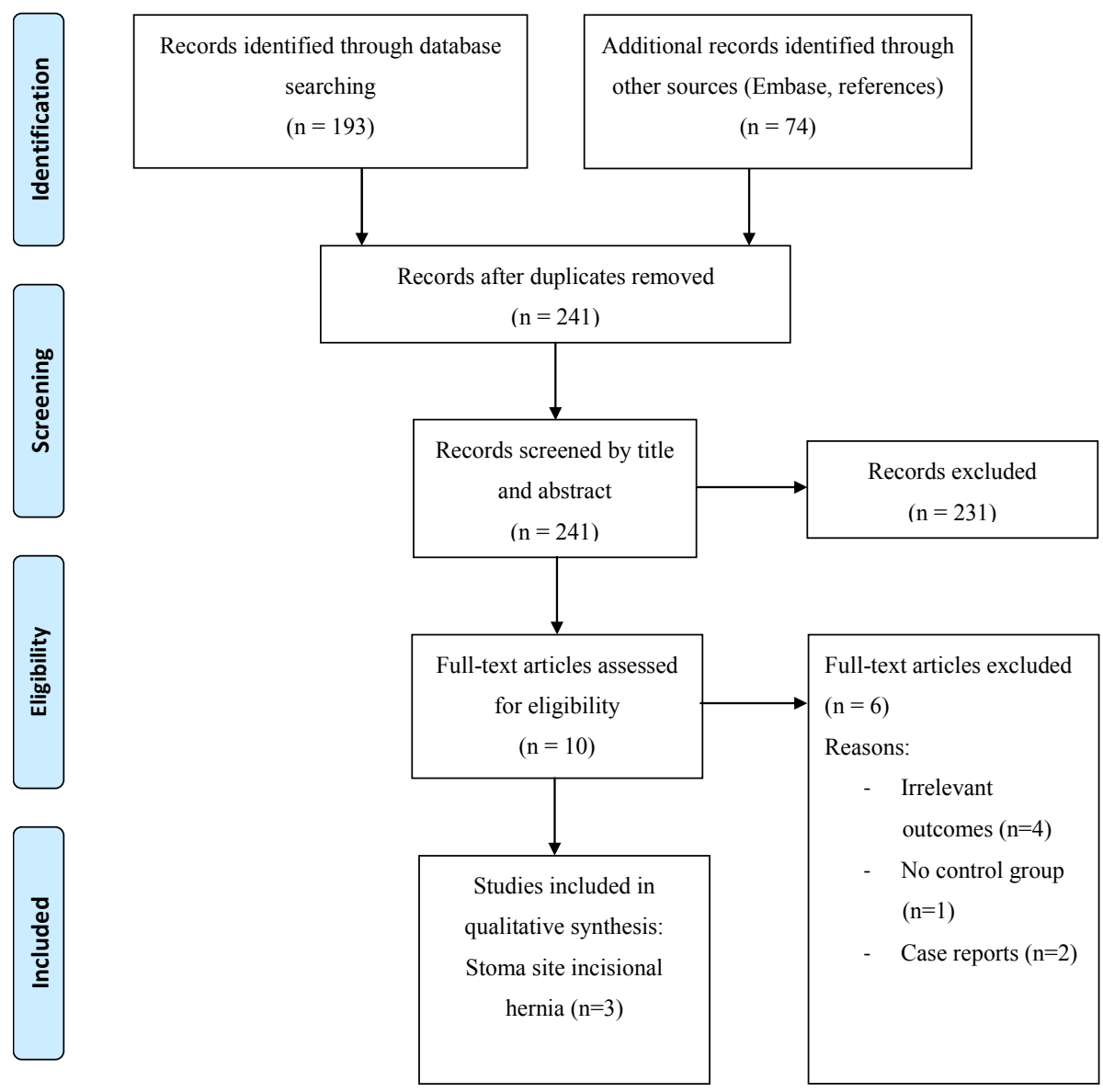

\section{Quality assessment}

The range on the MINOR-index of the included studies varied from 15 points to 20 points. All studies scored poorly on blinding of the researchers or participants. The time of follow-up was adequately mentioned in all included studies. The complete scores can be find in Table 8.2. 
Table 8.2 Outcomes of methodological items for non-randomized studies.

\begin{tabular}{lccc}
\hline Items & Liu et al. & Maggiori et al. & Warren et al. \\
\hline A clearly stated aim & 2 & 1 & 2 \\
Inclusion of consecutive patients & 2 & 2 & 0 \\
Prospective collection of data & 0 & 2 & 1 \\
Endpoints appropriate to the aim of the study & 1 & 1 & 2 \\
Unbiased assessment of the study endpoint & 1 & 1 & 0 \\
Follow-up period appropriate to the aim of the study & 2 & 2 & 1 \\
Loss to follow up less than 5\% & 2 & 2 & 2 \\
Prospective calculation of the study size & 2 & 0 & 0 \\
Additional criteria in the case of comparative study & & & 2 \\
An adequate control group & 2 & 2 & 1 \\
Contemporary groups & 2 & 2 & 2 \\
Baseline equivalence of groups & 2 & 2 & 15 \\
Adequate statistical analyses & 2 & 18 & 2 \\
Total score & 20 & 2 & 2 \\
\hline
\end{tabular}

Items can be scored from $0-2,0$ if the item is not reported, 1 if the item is reported inadequately, 2 if the item is reported adequately.

\section{Characteristics of included studies}

Of the included studies, two had a retrospective design ${ }^{19,21}$ and one was a prospective, case-matched study. ${ }^{20}$ Follow-up of the included studies ranged from 10 to 21 months. Table 8.3 shows the study and patient characteristics of the included studies.

Table 8.3 Study characteristics of the included studies.

\begin{tabular}{|c|c|c|c|c|c|c|c|c|c|}
\hline \multirow[b]{2}{*}{ Author } & \multirow[b]{2}{*}{ Year } & \multirow[b]{2}{*}{ Design } & \multirow[b]{2}{*}{$\begin{array}{l}\text { Level of } \\
\text { evidence }\end{array}$} & \multicolumn{2}{|c|}{ Study details } & \multicolumn{4}{|c|}{ Patients } \\
\hline & & & & Group & $\begin{array}{l}\text { Follow-up time } \\
\text { (months) }\end{array}$ & $\mathbf{N}$ & $\begin{array}{c}\text { Sex } \\
\left(M^{d}, \%\right)\end{array}$ & Age & BMI \\
\hline \multirow[t]{4}{*}{ Liu et al. } & 2013 & $\mathrm{R}^{\mathrm{a}}$ & $2 b$ & Control & 21.1 & 36 & 21 & 65.0 & 27.8 \\
\hline & & & & & $\left(\operatorname{IQR}^{\mathrm{C}} 10.1-33.9\right)$ & & $(58.3 \%)$ & (IQR 57.8-70.5) & (5.3) \\
\hline & & & & Mesh & 18.0 & 47 & 30 & 69.6 & 25.6 \\
\hline & & & & & (IQR 13.8-26.2) & & (63.8\%) & (IQR 57.9-76.0) & (4.6) \\
\hline \multirow{4}{*}{$\begin{array}{l}\text { Maggiori } \\
\text { et al. }\end{array}$} & 2015 & $P^{b}$ & $3 b$ & Control & 39.2 & 64 & 40 & 61 & 25 \\
\hline & & & & & (16.9) & & $(62 \%)$ & (13) & (4) \\
\hline & & & & Mesh & 16.8 & 30 & 18 & 61 & 26 \\
\hline & & & & & (3.3) & & $(60 \%)$ & (13) & (4) \\
\hline \multirow{4}{*}{$\begin{array}{l}\text { Warren } \\
\text { et al. }\end{array}$} & 2017 & $\mathrm{R}$ & $2 b$ & Control & 14 & 268 & 146 & 54.8 & 27.3 \\
\hline & & & & & (IQR 3-30) & & $(54.5 \%)$ & (15.7) & (6.4) \\
\hline & & & & Mesh & 6.5 & 91 & 49 & 57.3 & 30.2 \\
\hline & & & & & (IQR 2.25-14.75) & & (54\%) & (11.3) & (7.1) \\
\hline
\end{tabular}

$\mathrm{N}=$ number. Continuous data are median (interquartile range), median (range) or mean (standard deviation) ${ }^{\mathrm{a}} \mathrm{R}=$ Retrospective study, ${ }^{\mathrm{b}} \mathrm{P}=$ Prospective study, ${ }^{\mathrm{C}} \mathrm{IQR}=$ Inter Quartile Range, ${ }^{\mathrm{d}}$ Male.

Out of 536 patients, 324 patients received an ileostomy. A colostomy was formed in the remaining 212 patients. In 168 patients a prophylactic mesh was placed and 368 patients were included in the control group. In all studies antibiotics were administered peri-operatively. In the study of Warren et al. antibiotics were administered locally. ${ }^{21}$ All studies described mesh placement during stoma reversal. ${ }^{19-21}$ Table 8.4 shows more detailed information on stoma and mesh characteristics. 
Duration to stoma reversal differed between the studies, with a range of 6 weeks to 9 months. Warren et al. did not mention the time between stoma creation and stoma reversal. $^{21}$

During follow-up, physical examination and ultrasonography or CT-scans were performed to detect incisional hernias. One study described the definition of a hernia. ${ }^{20}$

Table 8.4 Stoma and mesh characteristics described in the included studies.

\begin{tabular}{|c|c|c|c|c|c|c|c|c|c|c|c|}
\hline \multirow[t]{2}{*}{ Author } & \multirow[t]{2}{*}{ Year } & \multirow[t]{2}{*}{ Group } & \multirow[t]{2}{*}{ Ostomy } & \multicolumn{5}{|c|}{ Indication } & \multirow{2}{*}{$\begin{array}{l}\text { Mesh } \\
\text { type }\end{array}$} & \multirow{2}{*}{$\begin{array}{c}\text { Mesh } \\
\text { fixation }\end{array}$} & \multirow{2}{*}{$\begin{array}{c}\text { Mesh } \\
\text { location }\end{array}$} \\
\hline & & & & Colostomy & CRC & IBD & Div. & Other & & & \\
\hline \multirow[t]{2}{*}{ Liu et al. } & 2013 & Control & 36 & 0 & 25 & $9 *$ & 6* & $5^{*}$ & N.A. & N.A. & N.A. \\
\hline & & Mesh & 47 & 0 & 38 & & & & PP & Sutures & Onlay \\
\hline \multirow{2}{*}{$\begin{array}{l}\text { Maggiori } \\
\text { et al. }\end{array}$} & 2015 & Control & 64 & 0 & 64 & 0 & 0 & 0 & N.A. & N.A. & N.A. \\
\hline & & Mesh & 30 & 0 & 30 & 0 & 0 & 0 & $\begin{array}{l}\text { NCC } \\
\text { PDM }\end{array}$ & Sutures & Sublay \\
\hline \multirow{2}{*}{$\begin{array}{l}\text { Warren } \\
\text { et al. }\end{array}$} & 2017 & Control & 123 & 145 & N.S. & & & & N.A. & N.A. & N.A. \\
\hline & & Mesh & 24 & 67 & & & & & PP & $\begin{array}{c}\text { Sutures } \\
(n=83) \\
\text { Glue }(n=2) \\
\text { No fixation } \\
(n=6)\end{array}$ & $\begin{array}{c}\text { Sublay } \\
(n=87) \\
\text { Underlay } \\
(n=4)\end{array}$ \\
\hline
\end{tabular}

$\mathrm{CRC}=$ Colorectal carcinoma, $\mathrm{IBD}=$ Inflammatory bowel disease, $\mathrm{Div}=$ Diverticular disease, N.S. = Not Specified, N.A. = Not Applicable, PP = polypropylene, NCC PDM = non-crosslinked collagen, porcine dermal matrix. ${ }^{*}$ The numbers of patients per group with IBD, diverticulitis or other cause for ileostomy were not further specified in the study of Liu et al.

\section{Hernia rates}

Three studies were included in the meta-analysis. ${ }^{19-21}$ The risk of incisional hernia in case of prophylactic mesh placement was significantly lower in comparison to no mesh placement (OR $0.10,95 \% \mathrm{Cl} 0.04$ to $0.27, p<0.001, \mathrm{I}^{2}=0 \%, 95 \% \mathrm{Cl} 0 \%$ to $91.40 \%$ ). Figure 8.3 shows the corresponding forest plot.

The results of the leave-one-out sensitivity analyses were comparable, indicating that the results of this meta-analysis are not based on one single study (supplementary Figure 8.1).

Warren et. al. described ileostomies separately from colostomies and this was the only included study also reporting on colostomies. ${ }^{21}$ Data regarding the incidence of incisional hernia at the former ileostomy site were pooled in a subgroup analysis (see Figure 8.4). The odds ratio was $0.13\left(95 \% \mathrm{Cl} 0.04\right.$ to $0.37, p<0.001, \mathrm{I}^{2}=0 \%$ ) in favour of preventive mesh placement. Regarding surgical site infections, no significant differences were found comparing preventive mesh placement with no mesh placement (OR 1.06, 95\% Cl 0.61 to $1.84, p=0.84, \mathrm{I}^{2}=0 \%$ ) (see Figure 8.5). 
Figure 8.3 Forest plot of incidence of incisional hernias after stoma reversal.

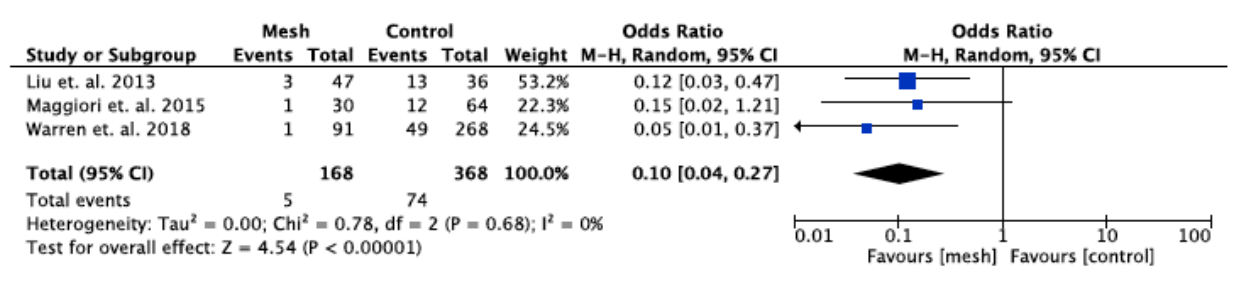

Figure 8.4 Forest plot of incidence of incisional hernias after ileostomy reversal.

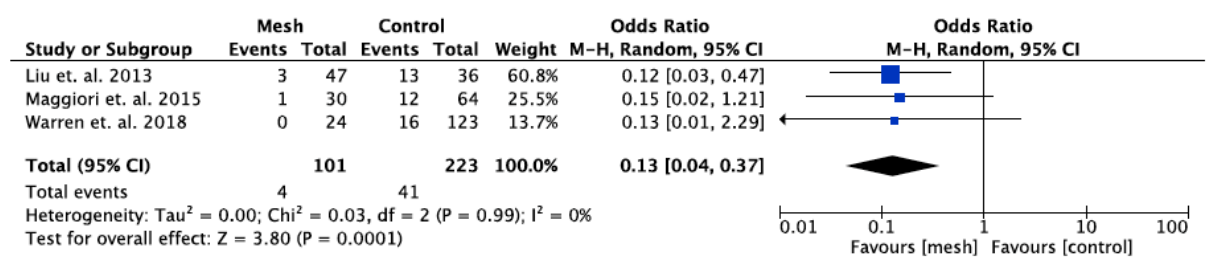

Figure 8.5 Forest plot of incidence of surgical site infections after stoma reversal.

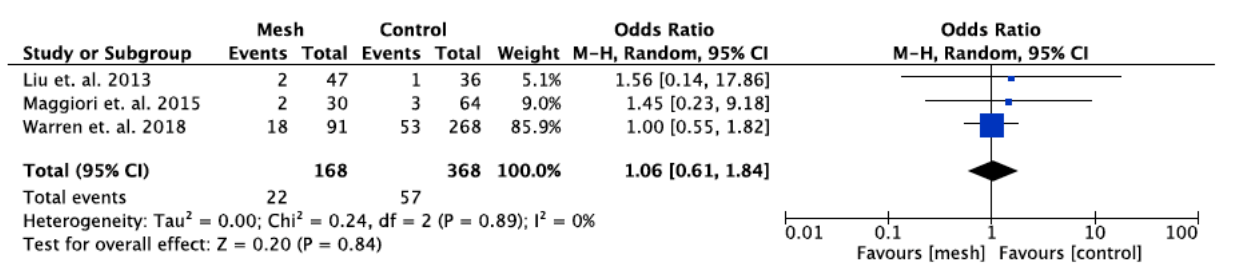

\section{Discussion}

The current review and meta-analysis shows that hernia rates after stoma reversal can decrease significantly, when a prophylactic mesh is used. Although surgeons are reluctant to use synthetic materials in fear of mesh infection, no differences in risk of infection could be detected.

Studies with as primary outcome the incidence of hernias at the former stoma site, reported incidences from $13-18 \%{ }^{22,23}$ This high percentage is comprehensible when the stoma site is considered to be a hernia that currently is primarily closed using suture technique instead of mesh repair. Suture repair of hernias is nowadays obsolete due to the increased recurrence rates compared to mesh repair. ${ }^{24}$ The necessity to reinforce former stoma sites with a mesh is underlined in the current study, although the numbers of included patients are small and the follow-up lengths are relatively short. Furthermore, only limited data regarding secondary outcomes are available. However, evidence in favour of prophylactic meshes to prevent midline incisional 
hernias and parastomal hernias is rising. ${ }^{10,11,14}$ Thus, it seems advisable to use prophylactic meshes in patients at risk for developing incisional hernias, although studies regarding quality of life and patient reported outcomes measures (PROMs) are needed to evaluate the overall benefits of prophylactic mesh placement after stoma reversal.

Risk factors for incisional hernias are an increased age, obesity and connective tissue disorders. Other risk factors might be malnutrition, elevated intra-abdominal pressure and comorbidities that influence a normal wound healing. ${ }^{25}$ Surgery related risk factors are a larger aperture size and peri-stomal complications, such as prolapse, obstruction or retraction. ${ }^{25,26} \mathrm{~A}$ recent meta-analysis has also shown an increased risk of incisional hernias after closure of colostomies compared to ileostomies. ${ }^{27}$

Next the timing of mesh placement is of interest. In the included studies, meshes were placed during stoma reversal. However, in one pilot study that was not included in the analysis, meshes were placed at the time of temporary stoma formation. ${ }^{28} \mathrm{An}$ advantage of this technique is that there is a good ingrowth of the mesh at the time of stoma reversal and in case the stoma will not be reversed the mesh serves as a prophylaxis for parastomal hernia formation. No reversal of temporary stomata occurs in up to $26 \%$ of all temporary stomata. Therefore, prophylactic mesh placement during stoma formation can have an extra benefit, namely to prevent both the occurrence of parastomal hernia and prolapse. ${ }^{15,29}$ On the other hand, mesh placement at the time of stoma creation might lead to problems when the stoma has to be dissected free from surrounding tissue during stoma reversal. ${ }^{28}$

Restraint of prophylactic mesh placement is required in an emergency setting. Operations in an emergency setting are thought to be more often complicated by contamination of the intra-abdominal cavity. This might lead to an increase in early postoperative complications, like wound infections. A meta-analysis looking at the risk factors for mesh related infections after hernia repair has shown that emergency hernia repair is a risk factor for mesh related infections and therefore caution is warranted regarding prophylactic mesh placement in these situations. ${ }^{30}$

Some strengths and limitations of the current study need to be addressed. The major strength of this study is its systematic approach and that it is the first metaanalysis published on the effect of prophylactic mesh placement during stoma reversal. It presents a good overview of the available literature.

On the other hand, data of high-quality studies are lacking, since no randomized controlled trials on this subject are available. Besides, we did not include grey literature or experts opinions.

Only three studies, whereof two retrospective studies and one prospective, casematched study, were included. This may have led to selection bias. Secondly, the quality of included articles was moderate, mainly due to the design of the studies, namely non-randomized prospective or retrospective trials. Furthermore, adequate blinding was always lacking. Thirdly, there was a considerable heterogeneity between the included studies. For example, meshes were placed in different layers of the 
abdominal wall. This might influence the development of hernias, although all included studies showed a lower risk of hernia formation when a prophylactic mesh was placed. In addition, a meta-analysis could not detect significant differences in recurrence rates after parastomal hernia repair with meshes placed in the different layers. ${ }^{31}$

Next, both biological and synthetic meshes were used and within these groups also the materials differed. Currently, there is no evidence available that shows superiority of synthetic meshes or biologic meshes regarding hernia recurrence rates and the use in contaminated fields. ${ }^{32,33}$ Also, in the current study no differences in surgical site infections (SSI) were seen between the included studies using synthetic or biologic meshes. Regarding the synthetic meshes, in all studies low-weight meshes have been used, which probably decrease the risk on mesh infections. ${ }^{34}$

Furthermore, the number of SSI did not differ between mesh and control groups. However, hernia occurrence instead of infection rates were reported as primary outcomes of the included studies. Therefore, it is uncertain whether the numbers of surgical site infections are accurate and thus conclusions should be drawn carefully.

Lastly, differences in follow-up time make it also more difficult to compare the studies included in this meta-analysis. Follow-up lengths varied between 10 and 26 months. Although it is known that $75 \%$ of the hernias are present after two years, the prevalence of incisional hernias increases with a longer follow-up period. ${ }^{35}$ Therefore, follow-up lengths in the included studies might be too short to draw hard conclusions regarding recurrence rates, although mesh related infections most likely occur during the early follow-up period.

\section{Conclusion}

All selected studies showed a reduced risk in hernia formation at the site of stoma reversal when a prophylactic mesh was used. In addition, the reported lack of any mesh related infection seems to justify the routine use of a prophylactic mesh during stoma reversal. 


\section{References}

1. Bhangu A, Nepogodiev D, Futaba K. Systematic review and meta-analysis of the incidence of incisional hernia at the site of stoma closure. World J Surg. 2012;36(5):973-83.

2. Feddern $\mathrm{ML}$, Emmertsen $\mathrm{KJ}$, Laurberg S. Life with a stoma after curative resection for rectal cancer. A population-based, cross-sectional study. Colorectal Dis. 2015.

3. Tan WS, Tang CL, Shi L, Eu KW. Meta-analysis of defunctioning stomas in low anterior resection for rectal cancer. Br J Surg. 2009;96(5):462-72.

4. Shabbir J, Britton DC. Stoma complications: a literature overview. Colorectal Dis. 2010;12(10):958-64.

5. Guenaga KF, Lustosa SA, Saad SS, Saconato H, Matos D. lleostomy or colostomy for temporary decompression of colorectal anastomosis. Cochrane Database Syst Rev. 2007(1):CD004647.

6. Carne PW, Robertson GM, Frizelle FA. Parastomal hernia. Br J Surg. 2003;90(7):784-93.

7. Nguyen MT, Phatak UR, Li LT, Hicks SC, Moffett JM, Arita NA, et al. Review of stoma site and midline incisional hernias after stoma reversal. J Surg Res. 2014;190(2):504-9.

8. Koltun L, Benyamin N, Sayfan J. Abdominal stoma fashioned by a used circular stapler. Dig Surg. 2000; 17(2):118-9.

9. von Smitten K, Husa A, Kyllonen L. Long-term results of sigmoidostomy in patients with anorectal malignancy. Acta Chir Scand. 1986;152:211-3.

10. Jairam AP, Timmermans L, Eker HH, Pierik R, van Klaveren D, Steyerberg EW, et al. Prevention of incisional hernia with prophylactic onlay and sublay mesh reinforcement versus primary suture only in midline laparotomies (PRIMA): 2-year follow-up of a multicentre, double-blind, randomised controlled trial. Lancet (London, England). 2017;390(10094):567-76.

11. Muysoms FE, Detry O, Vierendeels T, Huyghe M, Miserez M, Ruppert M, et al. Prevention of Incisional Hernias by Prophylactic Mesh-augmented Reinforcement of Midline Laparotomies for Abdominal Aortic Aneurysm Treatment: A Randomized Controlled Trial. Ann Surg. 2016;263(4):638-45.

12. Chapman SJ, Wood B, Drake TM, Young N, Jayne DG. Systematic Review and Meta-analysis of Prophylactic Mesh During Primary Stoma Formation to Prevent Parastomal Hernia. Dis Colon Rectum. 2017;60(1):107-15.

13. Cross AJ, Buchwald PL, Frizelle FA, Eglinton TW. Meta-analysis of prophylactic mesh to prevent parastomal hernia. Br J Surg. 2017;104(3):179-86.

14. Lopez-Cano M, Brandsma HT, Bury K, Hansson B, Kyle-Leinhase I, Alamino JG, et al. Prophylactic mesh to prevent parastomal hernia after end colostomy: a meta-analysis and trial sequential analysis. Hernia. 2017;21(2):177-89.

15. Sier MF, van Gelder L, Ubbink DT, Bemelman WA, Oostenbroek RJ. Factors affecting timing of closure and non-reversal of temporary ileostomies. Int J Colorectal Dis. 2015;30(9):1185-92.

16. Moher D, Liberati A, Tetzlaff J, Altman DG. Preferred reporting items for systematic reviews and metaanalyses: the PRISMA statement. Int J Surg. 2010;8(5):336-41.

17. Slim K, Nini E, Forestier D, Kwiatkowski F, Panis Y, Chipponi J. Methodological index for non-randomized studies (minors): development and validation of a new instrument. ANZ J Surg. 2003;73(9):712-6.

18. Review Manager (RevMan) [Computer program]. Version 5.3. Copenhagen: The Nordic Cochrane Centre, The Cochrane Collaboration. 2014.

19. Liu DS, Banham E, Yellapu S. Prophylactic mesh reinforcement reduces stomal site incisional hernia after ileostomy closure. World J Surg. 2013;37(9):2039-45.

20. Maggiori L, Moszkowicz D, Zappa M, Mongin C, Panis Y. Bioprosthetic mesh reinforcement during temporary stoma closure decreases the rate of incisional hernia: A blinded, case-matched study in 94 patients with rectal cancer. Surgery. 2015;158(6):1651-7.

21. Warren JA, Beffa LR, Carbonell AM, Cull J, Sinopoli B, Ewing JA, et al. Prophylactic placement of permanent synthetic mesh at the time of ostomy closure prevents formation of incisional hernias. Surgery. 2018;163(4):839-46.

22. De Haes F, Bullen NL, Antoniou GA, Smart NJ, Antoniou SA. Systematic review and meta-analysis of incisional hernia post-reversal of ileostomy. Hernia. 2020;24(1):9-21..

23. Lambrichts DPV, de Smet GHJ, van der Bogt RD, Kroese LF, Menon AG, Jeekel J, et al. Incidence, risk factors and prevention of stoma site incisional hernias: a systematic review and meta-analysis. Colorectal Dis. 2018;20(10):0288-0303. 
24. Mathes $T$, Walgenbach $M$, Siegel R. Suture Versus Mesh Repair in Primary and Incisional Ventral Hernias: A Systematic Review and Meta-Analysis. World J Surg. 2016;40(4):826-35.

25. Hotouras A, Murphy J, Thaha M, Chan CL. The persistent challenge of parastomal herniation: a review of the literature and future developments. Colorectal Dis. 2013;15(5):e202-14.

26. Ripoche J, Basurko C, Fabbro-Perray P, Prudhomme M. Parastomal hernia. A study of the French federation of ostomy patients. J Visc Surg. 2011;148(6):e435-41.

27. Geng HZ, Nasier D, Liu B, Gao H, Xu YK. Meta-analysis of elective surgical complications related to defunctioning loop ileostomy compared with loop colostomy after low anterior resection for rectal carcinoma. Ann R Coll Surg Engl. 2015:1-8.

28. van Barneveld KW, Vogels RR, Beets GL, Breukink SO, Greve JW, Bouvy ND, et al. Prophylactic intraperitoneal mesh placement to prevent incisional hernia after stoma reversal: a feasibility study. Surg Endosc. 2014;28(5):1522-7.

29. Bailey CM, Wheeler JM, Birks M, Farouk R. The incidence and causes of permanent stoma after anterior resection. Colorectal Dis. 2003;5(4):331-4.

30. Mavros MN, Athanasiou S, Alexiou VG, Mitsikostas PK, Peppas G, Falagas ME. Risk factors for meshrelated infections after hernia repair surgery: a meta-analysis of cohort studies. World J Surg. 2011;35(11):2389-98.

31. Hansson BM, Slater NJ, van der Velden AS, Groenewoud HM, Buyne OR, de Hingh IH, et al. Surgical techniques for parastomal hernia repair: a systematic review of the literature. Ann Surg. 2012;255(4): 685-95.

32. Kockerling F, Alam NN, Antoniou SA, Daniels IR, Famiglietti F, Fortelny RH, et al. What is the evidence for the use of biologic or biosynthetic meshes in abdominal wall reconstruction? Hernia. 2018;22(2):249-69.

33. Atema JJ, de Vries FE, Boermeester MA. Systematic review and meta-analysis of the repair of potentially contaminated and contaminated abdominal wall defects. Am J Surg. 2016;212(5):982-95 e1.

34. Tam KW, Wei PL, Kuo LJ, Wu CH. Systematic review of the use of a mesh to prevent parastomal hernia. World J Surg. 2010;34(11):2723-9.

35. Hoer J, Lawong G, Klinge U, Schumpelick V. [Factors influencing the development of incisional hernia. A retrospective study of 2,983 laparotomy patients over a period of 10 years]. Chirurg. 2002;73(5):474-80. 


\section{Supplementary material}

Figure S8.1 Forest plot of leave-one-out analysis of incidence of incisional hernias after stoma reversal.

\begin{tabular}{|c|c|c|c|c|c|c|c|c|}
\hline Study or Subgroup & \multicolumn{2}{|c|}{ Mesh } & \multicolumn{2}{|c|}{ Control } & Weight & Odds Ratio & \multicolumn{2}{|c|}{$\begin{array}{c}\text { Odds Ratio } \\
\text { M-H, Random, } 95 \% \mathrm{Cl}\end{array}$} \\
\hline Liu et. al. 2013 & 3 & 47 & 13 & 36 & $70.5 \%$ & $0.12[0.03,0.47]$ & & \\
\hline Maggiori et. al. 2015 & 1 & 30 & 12 & 64 & $29.5 \%$ & $0.15[0.02,1.21]$ & & \\
\hline Warren et. al. 2018 & 1 & 91 & 49 & 268 & $0.0 \%$ & $0.05[0.01,0.37]$ & & \\
\hline Total $(95 \% \mathrm{Cl})$ & & 77 & & 100 & $100.0 \%$ & $0.13[0.04,0.40]$ & & \\
\hline Total events & 4 & & 25 & & & & & \\
\hline $\begin{array}{l}\text { Heterogeneity. } \mathrm{Tau}^{2}= \\
\text { Test for overall effect: }\end{array}$ & $\begin{array}{l}0.00 ; \mathrm{Chi} \\
z=3.54\end{array}$ & $\begin{array}{l}2=0.0 \\
(P=0 .\end{array}$ & $\begin{array}{l}3, \mathrm{df}=1 \\
0004 \mathrm{j}\end{array}$ & $1(P=$ & $861 ; 1^{2}$ & & $\begin{array}{l}0.01 \quad 0.1 \\
\text { Favours [mesh] }\end{array}$ & $\begin{array}{|lrr|}1 & 10 & 100 \\
\text { Favours [control] }\end{array}$ \\
\hline
\end{tabular}

\begin{tabular}{|c|c|c|c|c|c|c|c|c|}
\hline Study or Subgroup & \multicolumn{2}{|c|}{ Mesh } & \multicolumn{2}{|c|}{ Control } & Weight & Odds Ratio & \multicolumn{2}{|c|}{$\begin{array}{c}\text { Odds Ratio } \\
\text { M-H, Random, } 95 \% \mathrm{CI}\end{array}$} \\
\hline Liu et. al. 2013 & 3 & 47 & 13 & 36 & $68.5 \%$ & $0.12[0.03,0.47]$ & & \\
\hline Maggiori et. al. 2015 & 1 & 30 & 12 & 64 & $0.0 \%$ & $0.15[0.02,1.21]$ & & \\
\hline warren et. al. 2018 & 1 & 91 & 49 & 268 & $31.5 \%$ & $0.05[0.01,0.37]$ & & \\
\hline Total $(95 \% \mathrm{Cl})$ & & 138 & & 304 & $100.0 \%$ & $0.09[0.03,0.28]$ & & \\
\hline Total events & 4 & & 62 & & & & & \\
\hline $\begin{array}{l}\text { Heterogeneity. Tau }{ }^{2}= \\
\text { Test for overall effect }\end{array}$ & $\begin{array}{l}0.00 ; \text { Chi } \\
=4.19\end{array}$ & $\begin{array}{l}=0.6 \\
P<0 .\end{array}$ & $\begin{array}{l}4, \mathrm{df}= \\
0001 \mathrm{j}\end{array}$ & $1(P=C$ & $0.43 \mathrm{l} ; \mathrm{I}^{2}=$ & & $\begin{array}{l}0.01 \quad 0.1 \\
\text { Favours [mesh] }\end{array}$ & $\begin{array}{|ccc|}1 & 10 & 100 \\
\text { Favours [control] }\end{array}$ \\
\hline
\end{tabular}

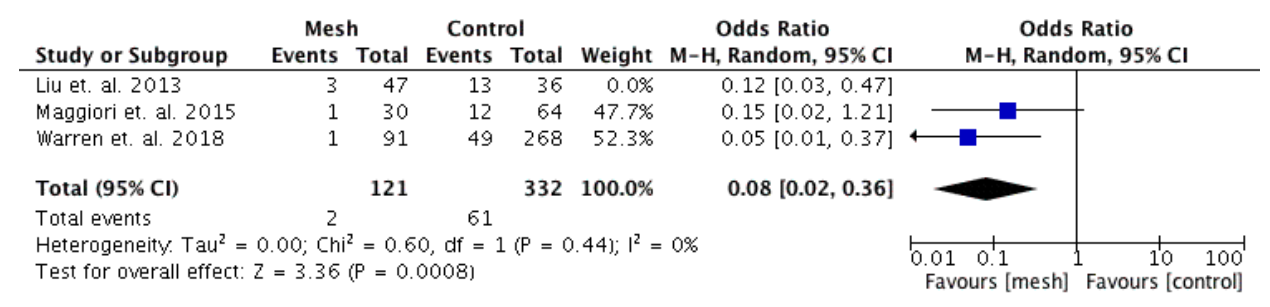






\section{PART IV}

Discussion 



\section{Chapter 9}

General discussion and future perspectives 



\section{General discussion}

Frequently occurring long-term complications after abdominal surgery include abdominal wall hernias and adhesion formation. In this thesis we addressed the prevention of incisional hernias and the placement of intra-abdominal meshes in case of incisional hernia. Special attention was paid to the formation of intra-abdominal adhesions to meshes.

\section{Clinical problem and awareness of adhesions}

Adhesions develop frequently after intra-abdominal surgery, with reported prevalences of more than $90 \%$ after laparotomy and $40 \%$ after laparoscopy. ${ }^{1,2}$ Within 5 years after surgery, $4.3 \%$ of the patients after open and $1.7 \%$ after laparoscopic surgery are readmitted due to complications that can directly be related to adhesions. Readmissions that were possibly related to adhesions show percentages as high as $18.2 \%$ and $16.0 \%$, respectively. ${ }^{3}$ Presenting symptoms are chronic abdominal pain, small bowel obstruction and female infertility. ${ }^{4}$

Although the burden of adhesions is high, a study performed in 2010 has shown that the awareness of adhesions among the surgical profession is limited. ${ }^{5}$ After training through lectures during congresses and surgical meetings, the knowledge and awareness regarding adhesions was re-evaluated in $2016 .{ }^{6}$ Although more respondents believed that laparoscopic surgery and meticulous surgical techniques can decrease the burden of adhesions, knowledge and behaviour toward adhesions still required improvement.

The apparent mismatch between the burden of adhesions and the awareness regarding this topic might be due to the fact that quite often the surgeon who performed the primary surgery is not involved in the treatment of his or her complications years later. This is especially true when complications occur due to both hernia and adhesion formation, since it can take many years before formed adhesions become clinically symptomatic. For instance, only $5 \%$ of patients will be readmitted most probably due to postoperative adhesions in the first five years after initial laparotomy. ${ }^{7}$ This number increases to $30 \%, 10$ years after surgery. ${ }^{8}$ During this period, surgeons may switch hospitals or retire. It is also possible that the connection between the primary surgery and readmission is not established due to the time period. In addition, the clinical relevance of adhesions is not always clear, since it might be hard to link complications such as chronic abdominal pain or female infertility directly to adhesion formation. ${ }^{9}$ Besides, adhesion-related complications are often not even treated by a surgeon. It is clear that female infertility is treated by a gynecologist, while chronic abdominal pain mostly is treated by a general practitioner or gastroenterologist.

As a consequence of the limited knowledge regarding adhesions, the information about adhesions that is provided to patients during the informed consent process is also limited or even completely absent. It is remarkable that two out of three surgeons 
do not mention adhesion formations as a long-term complication during the informed consent process of a laparoscopic procedure. Even though the number of adhesions is decreased in laparoscopic procedures compared to laparotomy, still 38\% of the patients develop adhesions to the abdominal wall. ${ }^{2}$ This decrease in adhesion formation is not associated with a decrease in time needed for adhesiolysis or a decrease in the risk of serosal injury during adhesiolysis compared to adhesion formation after open surgery. ${ }^{2}$ Thus, mentioning adhesions during the informed consent process is important in both open and laparoscopic procedures. Luckily, the number of surgeons mentioning adhesions during the informed consent slightly increased between 2010 and 2016.

Another topic in the performed survey involved the use of adhesion barriers. Literature shows a decrease in adhesion formation when an adhesion barrier has been used at the time of operation. ${ }^{10}$ Several of these anti-adhesive barriers are available, but the use of these barriers is limited since one out of three surgeons believe that antiadhesive barriers are not effective. Perhaps, the reason for this is the fact that it still remains a matter of debate whether a reduction in the extent of adhesions also leads to a decrease in adhesion-related complications. For instance, some surgeons believe that a single adhesion can lead to a higher risk of small bowel obstruction compared to the presence of multiple adhesions. ${ }^{9}$

\section{Characteristics of an ideal surgical mesh}

The implantation of meshes for hernia repair or other foreign bodies is always followed by an immune response of the body. During the foreign body reaction, macrophages and giant cells are activated in order to phagocytize the foreign body. ${ }^{11,12}$ If the mesh shows adequate biocompatibility, the mesh will nicely integrate in the surrounding tissue and a new balance is found. ${ }^{12}$

Important mesh-characteristics that determine biocompatibility include mesh material, mesh weight, pore size, tensile strength and elasticity. ${ }^{13}$ Lightweight meshes consist of less mesh material, due to the use of thinner filaments and larger pore sizes. Larger pores provide tissue ingrowth and decrease the risk on bridging granulomas. ${ }^{13}$ Next, larger pore size is associated with a decrease in adhesion formation. ${ }^{14}$ Also mesh material is an important mesh characteristic. Nowadays, synthetic meshes such as polypropylene, polyester and polytetrafluorethylene (PTFE) and biological meshes, often made from human, porcine or bovine dermis or pericardium are available for hernia repair. Different materials lead to different amount of scar formation and subsequently to differences in shrinkage of the mesh. ${ }^{15}$ The amount of scar formation plays also a role in the elasticity of meshes. Together with an appropriate tensile strength, elasticity is needed to resist forces to which the abdominal wall is exposed to. $^{13}$

To meet aforementioned criteria, an elastic mesh that retains pore shape, even under mechanical strain, was developed. ${ }^{16}$ The material we used was thermoplastic polyurethane (TPU). Our animal studies showed that this new mesh keeps its effective 
porosity for at least eight weeks by retaining its elastic properties. ${ }^{16,17}$ Next, compared to polypropylene meshes, the amount of adhesions was lower after seven and 21 days. At eight weeks, the amount of adhesions was comparable with polyvinylidenefluoride (PVDF) meshes. ${ }^{17,18}$ Since PVDF meshes show pore collapse, while TPU meshes keep an effective porosity, this was an unexpected finding.

A frequently occurring complication of incisional hernia repair is chronic abdominal pain. ${ }^{19,20}$ This can be caused by adhesion formation to the mesh, although scar plate formation, due to mesh placement, can also lead to chronic pain. ${ }^{4,21}$ Scar plate formation is the result of bridging of multiple single granulomas that merge together. This can lead to encapsulation, rather than ingrowth of the mesh and subsequently lead to decreased flexibility. ${ }^{22}$ Flexibility is an important mesh characteristic, since meshes are placed in a resilient environment. Therefore, it is thought that elastic meshes can reduce chronic postoperative pain, since it imitates the function of the original abdominal wall. ${ }^{23}$ However, if meshes become too elastic, it might lead to an increased risk of hernia recurrence or decreased functional outcomes, such as bulging. ${ }^{13}$

Another cause of abdominal pain after hernia repair is mesh folding, which can occur when a mesh is not or inadequately fixated. ${ }^{24}$ Also, mesh placement under pneumoperitoneum can cause mesh folding, since pneumoperitoneum leads to extension of the abdominal wall and it is not possible to position non-elastic meshes under traction, in contrast to elastic meshes. After termination of the pneumoperitoneum, it is shown that non-elastic meshes show folding, while this is not the case for elastic meshes. ${ }^{18,25}$ Thus, with the increased flexibility of meshes and decrease in mesh folding, it is likely that chronic abdominal pain can be decreased if elastic meshes are used. Since it is hard to assess this outcome in animal studies, clinical studies are necessary.

\section{Translatability and scoring systems}

Animal research is often performed to foresee biocompatibility and behaviour of medications and prostheses in human subjects. With the introduction of the European legislation on animal research called the "Directive on Animal-based Experiments" and a socially increased interest in animal welfare, the necessity of animal research is becoming a serious topic of debate.

A review showed that important factors regarding design and methods are often lacking in publications of animal research. ${ }^{26}$ Next, it was shown that only one-third of highly cited animal papers reported outcomes that could be repeated in clinical trials. ${ }^{27}$ These factors make it hard to compare animal studies and translate them to a human situation. In hernia research, a wide variance in animal models and scoring systems when performing animal studies has been detected. ${ }^{28,29}$ Clearly, more standardization is needed.

A first step was taken by determining that rats and humans show comparable results regarding adhesion formation and general inflammatory response to implanted 
meshes. ${ }^{30}$ However, in rats a higher number of granulocytes was seen, which might be explained by differences in follow-up time between rats and humans. As a consequence, it could be that the inflammatory response in rats is still in the acute phase, while in humans already the chronic phase has started.

It might be hard to detect the ideal follow-up time in rats. It is shown that during adulthood one human year is comparable with 11.8 rat days. ${ }^{31}$ However, time of wound healing in rats and humans is comparable. ${ }^{32}$ Therefore, differences in life expectancy between humans and rats might not be of interest and perhaps the same follow-up time should be chosen. To investigate this, more studies are necessary.

Next to a suitable animal species, appropriate scoring systems are needed to measure adhesion formation to meshes. During the last decades, several adhesion scores have been developed and subsequently adjusted. ${ }^{33-36}$ To create more uniformity in order to increase study comparability, we set out to develop a consensus-based mesh-tissue adhesion score (META scoring system), starting from existing adhesion scores. ${ }^{37}$ It may seem remarkable to propose yet another adhesion score, but it was thought that this adhesion score could be widely adapted. One of the reasons for this is the fact that consensus was sought from the experts that have been most active in performing relevant animal studies and reporting on their outcomes. Then, when widely adapted, comparisons between studies and meshes would be possible, leading to improved efficiency and easier to interpret data. Finally, when compared to the application of such scoring in patients, correlations between scoring in a clinical and experimental setting could be established. The resulting translatability will then improve both the usefulness of experimental research and clinical care for patients.

The META scoring system exists of four variables; the percentage of mesh surface covered with adhesions, the tenacity and thickness of adhesions and the extent of organ involvement. Together, these variables should give a good impression of adhesion formation to meshes and the possible relationship to related complications in patients. The question remains if all four variables are needed in one scoring system and whether they can be combined to one aggregated score. By measuring and always reporting these factors separately, future evaluations can determine which variables overlap and if these variables need to be adjusted or even have to be removed from the scoring system. In addition, the first need should be to further establish the validation of the scoring of these variables.

\section{Prevention of abdominal wall hernia}

Incisional hernia is a frequently occurring complication of abdominal surgery, with reported incidences up to $10-20 \% .^{38,39}$ Recently, several techniques to prevent incisional hernias have been described. Firstly, the small steps and small bites technique reduced the incidence of reported hernias significantly. ${ }^{39}$ Guidelines from the European Hernia Society (EHS) on closing midline incisions recommend a suture to wound length ratio of $4: 1$, using a continuous running suture and wound closure in one layer. ${ }^{40}$ Regarding suture materials, only weak recommendations could be provided. ${ }^{40}$ 
In literature, no differences in the incidence of incisional hernias using non-absorbable compared to slowly-absorbable sutures were seen. ${ }^{41}$ Nevertheless, a weak recommendation in favour of slowly-absorbable sutures is provided based on an increased risk of suture sinus development and prolonged abdominal pain when nonabsorbable sutures are used. ${ }^{41}$ However, it is hard to draw firm conclusions, since suture technique and suture materials were often not investigated separately.

In order to better understand the effect of suture materials on abdominal wall healing, a study in rats was performed, using non-absorbable, slowly-absorbable and rapidly-absorbable sutures. Results of this study show an increased clec10a expression after 7 days in the polydioxanone suture (PDS ${ }^{\circledR}$ ) group, compared to the Prolene ${ }^{\circledR}$ group. Clec10a is a marker for subtype M2 macrophages, which are associated with extracellular matrix remodelling and differentiation of fibroblasts into myofibroblasts. ${ }^{42,43}$ These cells are involved in collagen production in wounds. Increased presence of these type of macrophages might facilitate wound closure. ${ }^{43}$ Since an increased number of M2 macrophages is seen in the early postoperative phase in the PDS ${ }^{\circledR}$ group, this might suggest that in this group abdominal wall regeneration starts earlier. Perhaps, this can cause a decreased risk on early wound dehiscence, although in clinical studies no difference in wound dehiscence have been between slowly-absorbable and non-absorbable sutures. ${ }^{41}$ No differences between the PDS $^{\circledR}$ group and Prolene ${ }^{\circledR}$ group were seen after 21 days, which is in accordance with clinical outcomes. It might be that 21 days of follow-up was too short to detect differences, since it takes approximately six weeks before the abdominal wall regains $50 \%$ of its original strength ${ }^{44}$ and therefore a longer follow-up time could have led to differences between the study groups. Furthermore, in the three groups only one brand of each material has been used, which might have influenced the results. Other brands might use a combination of other materials or have other suppliers for the same materials used in their sutures., which subsequently can lead to other results. Another possibility is that tensile strength of the different sutures plays an important role, as absorbable sutures lose their tensile strength earlier compared to non-absorbable sutures. ${ }^{45}$

Next to new suture techniques to decrease the incidence of incisional hernias, also the placement of prophylactic meshes has recently been explored. These studies show promising results in preventing both incisional hernias after laparotomy as well as preventing parastomal hernias. ${ }^{46,47}$ However, regarding prophylactic mesh placement after reversal of temporary stomata less information is available. Therefore, a systematic review and meta-analysis was performed by our research group. Results from this meta-analysis showed a significant decrease in hernia formation after stoma reversal when a prophylactic mesh was placed. It should be noticed, that the quality of the evidence is moderate, since no randomized-controlled trials could be included.

Aforementioned results are to be expected when the former stoma site is regarded to be an abdominal wall hernia. Closure of abdominal wall hernias using a mesh has shown to be superior compared to primary closure. ${ }^{48}$ However, surgeons are reluctant to place meshes in a clean-contaminated or potentially contaminated area in 
view of potential mesh infections. However, available literature does not underline this idea. In fact, no differences in surgical site infections (SSI) could be detected in case of mesh placement in a clean-contaminated or even a contaminated field. Yet, in contaminated fields the incidence of hernia development was increased when a biological mesh was used compared to a synthetic mesh. ${ }^{49}$ Besides, it is thought that after biological meshes have been degraded, the formed scar tissue is not as strong as the original abdominal wall tissue and therefore forms a risk factor for hernia development. ${ }^{50}$ Since follow-up times in hernia research are relatively short, this could not be confirmed yet. To further prove this idea, studies that compare biological and synthetical meshes with follow-up times of more than two years are necessary.

\section{Future perspectives}

\section{Improving adhesion awareness}

Although the burden of adhesions has widely been explored and every surgeon will treat multiple patients for adhesion related complications during his career, it is remarkable that knowledge about adhesions is relatively limited. Subsequently, patients are not adequately informed pre-operatively and also adhesion preventive measures are not utilized optimally. ${ }^{6}$ To change this, both knowledge and attitude need to be improved.

Guidelines could be helpful to improve knowledge and attitude regarding adhesions and their related complications. Unfortunately, there are only few guidelines regarding this topic available. In 2012, an expert-panel of European gynecologists published a field guideline to prevent adhesions after gynecological surgery and this guideline was updated in 2016..$^{51,52}$ Furthermore, a guideline for diagnosis and treatment of small bowel obstruction due to adhesions has been published, but more relevant guidelines regarding adhesions are not available. ${ }^{53}$ It can thus be recommended to create more guidelines to change daily practice.

However, even with the presence of guidelines, it seems difficult to change practice. Mentioned causes for this are lack of time and lack of patient compliance, although the latter is of little relevance in relation to this subject. Also, it has been suggested that more education, promoting of guidelines, increased availability and keeping guidelines straightforward, would lead to improved implementation of guidelines. $^{54}$ Therefore, education of surgeons, gynecologists, urologists, anesthesiologists and gastroenterologists during trainings and congresses should be provided with information on chronic abdominal pain and small bowel obstruction on a regular base. Since adhesion-related complications such as chronic abdominal pain transcends the field of general surgery, it is important that not only surgeons will be educated, but also other specialists.

To further improve the knowledge about adhesions among medical doctors, this topic should be implemented in the medical curriculum, so future doctors will be 
reached in an early stage of their career, which should make it easier to implement the knowledge in daily practice.

Next, accurate diagnostic tools to detect adhesions can be helpful, since proving an actual relation between presence of adhesions and some complications, such as chronic abdominal pain or infertility, is difficult. Before the availability of cine MRI, intra-abdominal adhesions could only be detected during laparoscopy or laparotomy. Although transabdominal ultrasonography showed to have an accuracy of $83 \%$, sensitivity was only $43 \%$. Furthermore, ultrasonography is not possible to perform in all patients, for example due to gas or obesity. ${ }^{55}$ Therefore, cine MRI was introduced. It has shown promising results, regarding detecting adhesions non-invasively and it might be possible to find a correlation between adhesions and abdominal pain, when locations of both correspond. ${ }^{55,56}$ Other tools to improve knowledge about the burden of adhesions include national and international databases. In these databases much information, including patient characteristics and data on adhesion-related complications, can be collected. This way, many data are prospectively gathered, which can be helpful to detect risk factors and might subsequently lead to changes in future detection- and treatment-strategies. Studies which are now conducted like pain pad and pain trac with Dr. ten Broek as a principal investigator will hopefully in the near future also give more insight in which patients are prone to develop adhesions.

With an improved knowledge, change of attitude might partly occur automatically. Important steps in change of attitude, includes minimizing intraabdominal injury during surgery, usage of anti-adhesive barriers and avoidance of intraabdominal meshes and other foreign bodies. When for technical or patient-related reasons, only an intra-abdominal placed mesh is possible, these meshes should be covered with an anti-adhesive layer and fixated with resolvable tackers.

\section{Scoring mesh related adhesions}

Uniformity is of great importance in order to compare study outcomes and to increase translatability, leading to an improved clinical relevance. Despite the formation of guidelines in the past to create uniformity in both clinical and animal research, a wide variation in study design and reported outcome measures between studies in hernia and adhesion research currently still exists. ${ }^{29,57,58}$ To decrease this interstudy variation, it is important that study designs are comparable. The American and European Hernia Societies should take the lead to develop study models for both clinical and experimental research. These models should include guidelines on the preferable animal model, follow-up time and adhesion score in animal research.

With the view to decrease interstudy variation, the META scoring system has been developed. ${ }^{37}$ For this score to succeed, validation of this score should be performed on the short term. This way, the META scoring system is distinctive from other mesh adhesion scores, since nowadays no validated adhesion scores exist. Furthermore, a broad support of the META scoring system is vital in order to implement it in mesh tissue adhesion research. Since this score has been developed in cooperation with 
international experts, it is likely that this score will be introduced and used at the departments of these experts. The score should be further brought to attention at congresses in order to reach all medical doctors and researchers involved in the field of hernia research. Preferably, the American and European Hernia Societies would also endorse such large and coordinated consensus study outcomes that set a firm base for all future animal and eventually also clinical studies. Ways to do so could be in the form of publication of the scoring system once it has been validated on their websites or even include it as a "soft" requirement for the studies published in their related scientific journals.

On the long term, data using the META scoring system should be collected and analyzed. It is important to determine the clinical relevance of the included variables. Therefore, it might be helpful to address supplemental variables and their scoring next to the ones in the META scoring system, for instance on microscopic outcomes. Also, it is important to use the scores in both clinical and experimental settings to gather as much as significant information as possible. With this information, it could eventually be concluded that some variables need to be adjusted in order to meet clinical relevance. Next, it might be necessary to assign weight factors to the different variables. For example, it could turn out that percentage of mesh covered with adhesions is of less importance than organ involvement. Already during the consensus meeting, held in 2016 during the 38th International Congress of the European Hernia Society (EHS) in Rotterdam, the Netherlands, the experts concluded that an adhesion reduction of at least $50 \%$ is relevant. In literature, it is even thought that only complete prevention of adhesions is important, since one filmy adhesion also can cause complications. ${ }^{59}$ However, tenacity and thickness of adhesions are important factors regarding perioperative morbidity. ${ }^{60}$ On the other hand, for research purposes it is important that variables have a more extensive description in order to make studies comparable.

As the META scoring addresses the physical appearance of adhesions, the recently developed CLAS-score is of great interest. ${ }^{61}$ This score measures the morbidity of intraabdominal adhesions by assessing the clinical outcomes of adhesion-related complications. Combining the META scoring system and CLAS-score in clinical studies can be helpful to detect a correlation between intra-operative macroscopic characteristics and clinical outcomes.

\section{Prevention of abdominal wall hernias and adhesions}

The last decades, several improvements in surgical techniques have been implemented to optimize ventral hernia repair in order to reduce recurrence rates and complication risks. Laparoscopic ventral hernia repair with an intraperitoneally placed mesh is associated with comparable recurrence rates compared to open hernia repair, but leads to a decreased risk on postoperative wound infections. ${ }^{62,63}$ On the other hand, it is demonstrated that adhesions form to intraabdominal placed meshes ${ }^{64}$, subsequently increasing the risk on adhesive small-bowel obstruction. To reduce this risk, meshes can 
be placed extraperitoneally. Recently, endoscopic retromuscular ventral hernia repair studies, with and without robotic assistance, have been reported with promising results. ${ }^{65-67}$ Using this technique the mesh is placed endoscopically in the retromuscular layer of the abdominal wall; this way combining advantages of both open and laparoscopic hernia repair. Since this procedure is still in its learning phase, it is important that surgeons will be educated and trained in the upcoming future, in order to enable more widespread use of this technique. Recently published studies have demonstrated that robotic hernia repair in the learning phase seems safe. ${ }^{68,69}$ However, another study regarding extraperitoneal inguinal hernia repair has shown that up to 250 procedures should be performed, before surgeons have gone through the learningcurve. ${ }^{70}$ Furthermore, robotic retromuscular hernia repair should be further explored to investigate the advantages and disadvantages. ${ }^{66}$

Other techniques to reduce adhesion formation include minimalization of peritoneal trauma during surgery and the use of adhesion barriers. ${ }^{53}$ Intraoperative peritoneal trauma can be decreased by laparoscopy, although it is shown that adhesions still develop after laparoscopic procedures. ${ }^{71}$ Therefore, other options to decrease peritoneal trauma, such as minimizing the use of foreign material and minimizing thermal injury, should also be considered. ${ }^{72}$ Furthermore, it is suggested that pneumoperitoneum during laparoscopy plays a role in adhesion development. Involving factors seem to be type of gas, temperature, gas humidity and insufflation pressure. ${ }^{73,74}$ Regarding the latter, no clinical trials comparing the potential benefits on adhesion formation of low-pressure compared with normal-pressure pneumoperitoneum have been performed yet. ${ }^{75}$ However, low pneumoperitoneum pressure and insufflation of warmed and humidified gas have shown beneficial outcomes concerning postoperative pain compared to higher pressure and insufflation of cold and dry gas. ${ }^{74}$ Thus, it could be of interest to investigate the ideal insufflation pressure during laparoscopy.

Next to prevention of adhesions, prevention of abdominal wall hernias should have a high priority in the upcoming years. With the introduction of the small step and small bites technique, hernia recurrence rates can be reduced from $21 \%$ to $13 \%{ }^{39}$ Furthermore, it is shown that prophylactic mesh placement can reduce the risk on development of incisional hernia, parastomal hernia and hernia after stoma reversal. ${ }^{47,76,77}$ However, prophylactic mesh placement is not yet common practice. According the European Hernia Society guidelines a prophylactic mesh is suggested in high risk patients, which include patients with a history of abdominal aneurysm or obesity. ${ }^{40}$ In 2016, a risk model to predict patients at high risk to develop incisional hernia was developed. ${ }^{78}$ This model can be helpful in detecting patients who benefit most from a prophylactic mesh.

Another promising tool to detect patients with an increased risk on incisional hernia might be the eNose. With this eNose, volatile organic compounds in exhaled breath can be measured and patterns can be recognized. In a recent published proof- 
of-concept study, it has been shown that patients with recurrent hernia could be distinguished from healthy controls using the eNose. ${ }^{79}$

With the possibility to detect patients at risk to develop an incisional hernia, surgeons should be persuaded to use prophylactic meshes in these patients. Nowadays, surgeons are reluctant to use prophylactic meshes, in fear of mesh infections, while these meshes should often directly be placed after a gastrointestinal procedure. However, it is demonstrated that meshes can be placed safely in a contaminated area, without increased risk of mesh infection. ${ }^{80}$

An important topic of discussion is the question which surgeon should close the abdomen after laparotomy. For example, can it be expected that a vascular surgeon, who only have to close the abdomen after an open abdominal aorta aneurysm operation, has the expertise to close the abdomen according the most recent guidelines? Regarding recent literature, it appears that the number of hernia repairs during general surgery training is inadequate to overcome the learning curve. ${ }^{70}$ Therefore, fellowships in hernia repair and specialized hernia surgeons are needed. ${ }^{81,82}$ From this point of view, it might be interesting to form specialized hernia teams, who are not only involved in hernia repair, but also in hernia prevention and thus members of this team should close the abdominal wall.

Besides the use of prophylactic meshes, also recommendations regarding mesh types should be provided. Evidence is rising that hernia repair using biologic meshes is associated with higher recurrence rates compared to repair with synthetic meshes, without benefits of decreased complication rates when used in a contaminated field. Furthermore, biological meshes are expensive. ${ }^{49,83,84}$ Therefore, it is concluded that the routine use of biological meshes cannot be recommended. ${ }^{85}$

Finally, concerning appropriate care and shared decision making, it can be questioned if all procedures would and should be performed, when patients are correctly informed. Risk stratification systems can be helpful to calculate risks for each single patient. ${ }^{86}$ 


\section{References}

1. Menzies D, Ellis H. Intestinal obstruction from adhesions--how big is the problem? Ann R Coll Surg Engl. 1990;72(1):60-3.

2. Stommel MWJ, Ten Broek RPG, Strik C, Slooter GD, Verhoef C, Grunhagen DJ, et al. Multicenter Observational Study of Adhesion Formation After Open-and Laparoscopic Surgery for Colorectal Cancer. Ann Surg. 2018;267(4):743-8.

3. Krielen P, Stommel MWJ, Pargmae P, Bouvy ND, Bakkum EA, Ellis $H$, et al. Adhesion-related readmissions after open and laparoscopic surgery: a retrospective cohort study (SCAR update). Lancet. 2020;395(10217):33-41.

4. ten Broek RP, Issa Y, van Santbrink EJ, Bouvy ND, Kruitwagen RF, Jeekel J, et al. Burden of adhesions in abdominal and pelvic surgery: systematic review and met-analysis. BMJ. 2013;347:f5588.

5. Schreinemacher MH, ten Broek RP, Bakkum EA, van Goor H, Bouvy ND. Adhesion awareness: a national survey of surgeons. World J Surg. 2010;34(12):2805-12.

6. van Steensel S, van den Hil LCL, Schreinemacher MHF, Ten Broek RPG, van Goor H, Bouvy ND. Adhesion awareness in 2016: An update of the national survey of surgeons. PLoS One. 2018;13(8):e0202418.

7. Parker MC, Wilson MS, Menzies D, Sunderland G, Clark DN, Knight AD, et al. The SCAR-3 study: 5-year adhesion-related readmission risk following lower abdominal surgical procedures. Colorectal Dis. 2005; 7(6):551-8.

8. Ellis H, Moran BJ, Thompson JN, Parker MC, Wilson MS, Menzies D, et al. Adhesion-related hospital readmissions after abdominal and pelvic surgery: a retrospective cohort study. Lancet. 1999;353(9163): 1476-80.

9. ten Broek RP, Bakkum EA, Laarhoven CJ, van Goor H. Epidemiology and Prevention of Postsurgical Adhesions Revisited. Ann Surg. 2016;263(1):12-9.

10. Robb WB, Mariette C. Strategies in the prevention of the formation of postoperative adhesions in digestive surgery: a systematic review of the literature. Dis Colon Rectum. 2014;57(10):1228-40.

11. Anderson JM, Rodriguez A, Chang DT. Foreign body reaction to biomaterials. Semin Immunol. 2008;20(2):86-100.

12. Bryan N, Battersby C, Smart N, Hunt J. A review of biocompatibility in hernia repair; considerations in vitro and in vivo for selecting the most appropriate repair material. Hernia. 2015;19(2):169-78.

13. Bilsel Y, Abci I. The search for ideal hernia repair; mesh materials and types. Int J Surg. 2012;10(6): 317-21.

14. Conze J, Rosch R, Klinge U, Weiss C, Anurov M, Titkowa S, et al. Polypropylene in the intra-abdominal position: influence of pore size and surface area. Hernia. 2004;8(4):365-72.

15. Elango S, Perumalsamy S, Ramachandran K, Vadodaria K. Mesh materials and hernia repair. Biomedicine (Taipei). 2017;7(3):16.

16. Lambertz A, Vogels RR, Binnebosel M, Schob DS, Kossel K, Klinge U, et al. Elastic mesh with thermoplastic polyurethane filaments preserves effective porosity of textile implants. J Biomed Mater Res A. 2015;103(8):2654-60.

17. Lambertz A, van den Hil LCL, Schob DS, Binnebosel M, Kroh A, Klinge $U$, et al. Analysis of adhesion formation of a new elastic thermoplastic polyurethane (TPU) mesh in comparison to polypropylene (PP) meshes in IPOM position. J Mech Behav Biomed Mater. 2016;53:366-72.

18. Lambertz A, van den Hil LCL, Ciritsis A, Eickhoff R, Kraemer NA, Bouvy ND, et al. MRI Evaluation of an Elastic TPU Mesh under Pneumoperitoneum in IPOM Position in a Porcine Model. J Invest Surg. 2018; 31(3):185-91.

19. Gronnier C, Wattier JM, Favre H, Piessen G, Mariette C. Risk factors for chronic pain after open ventral hernia repair by underlay mesh placement. World J Surg. 2012;36(7):1548-54.

20. Burger JW, Luijendijk RW, Hop WC, Halm JA, Verdaasdonk EG, Jeekel J. Long-term follow-up of a randomized controlled trial of suture versus mesh repair of incisional hernia. Ann Surg. 2004;240(4): 578-83; discussion 83-5.

21. Schumpelick $V$, Klinge $U$, Rosch $R$, Junge K. Light weight meshes in incisional hernia repair. J Minim Access Surg. 2006;2(3):117-23.

22. Brown CN, Finch JG. Which mesh for hernia repair? Ann R Coll Surg Engl. 2010;92(4):272-8.

23. Klinge $U$, Klosterhalfen B. Mesh implants for hernia repair: an update. Expert Rev Med Devices. 2018;15(10):735-46. 
24. Amid PK. Radiologic images of meshoma: a new phenomenon causing chronic pain after prosthetic repair of abdominal wall hernias. Arch Surg. 2004;139(12):1297-8.

25. Otto J, Kuehnert N, Kraemer NA, Ciritsis A, Hansen NL, Kuhl C, et al. First in vivo visualization of MRIvisible IPOM in a rabbit model. J Biomed Mater Res B Appl Biomater. 2014;102(6):1165-9.

26. Kilkenny C, Parsons N, Kadyszewski E, Festing MF, Cuthill IC, Fry D, et al. Survey of the quality of experimental design, statistical analysis and reporting of research using animals. PLoS One. 2009;4(11): e7824.

27. Hackam DG, Redelmeier DA. Translation of research evidence from animals to humans. JAMA. 2006;296(14):1731-2.

28. Schreinemacher $M$, Henatsch D, van Barneveld K, Bouvy N. The need for standardised animal models and scoring systems in assessing mesh biocompatibility. Hernia. 2010;14(3):335-6.

29. Vogels RRM, Kaufmann R, van den Hil LCL, van Steensel S, Schreinemacher MHF, Lange JF, et al. Critical overview of all available animal models for abdominal wall hernia research. Hernia. 2017;21(5):667-75.

30. van den Hil LCL, Vogels RRM, van Barneveld KWY, Gijbels MJJ, Peutz-Kootstra CJ, Cleutjens JPM, et al. Comparability of histological outcomes in rats and humans in a hernia model. J Surg Res. 2018;229: 271-6.

31. Sengupta P. The Laboratory Rat: Relating Its Age With Human's. Int J Prev Med. 2013;4(6):624-30.

32. Vidinsky B, Gal P, Toporcer T, Longauer F, Lenhardt L, Bobrov N, et al. Histological study of the first seven days of skin wound healing in rats. Acta Vet Brno. 2006;75(2):197-+.

33. de Oliveira N, Paschoa AF, Crespo CC, Massumoto CM, Adam C. [Use of the combination of a nitrofurazone derivative with polyethylene glycols in the prevention of the formation of peritoneal adhesions - experimental study]. Arq Gastroenterol. 1981;18(2):54-9.

34. Garrard CL, Clements RH, Nanney L, Davidson JM, Richards WO. Adhesion formation is reduced after laparoscopic surgery. Surg Endosc-Ultras. 1999;13(1):10-3.

35. Diamond MP, Linsky CB, Cunningham T, Constantine B, diZerega GS, DeCherney AH. A model for sidewall adhesions in the rabbit: reduction by an absorbable barrier. Microsurgery. 1987;8(4):197-200.

36. Zuhlke HV, Lorenz EM, Straub EM, Savvas V. [Pathophysiology and classification of adhesions]. Langenbecks Archiv fur Chirurgie Supplement II, Verhandlungen der Deutschen Gesellschaft fur Chirurgie Deutsche Gesellschaft fur Chirurgie Kongress. 1990:1009-16.

37. van den Hil LCL, Mommers EHH, Bosmans J, Morales-Conde S, Gomez-Gil V, LeBlanc K, et al. META Score: An International Consensus Scoring System on Mesh-Tissue Adhesions. World J Surg. 2020; 44(9):2935-2943.

38. Hoer J, Lawong G, Klinge U, Schumpelick V. [Factors influencing the development of incisional hernia. A retrospective study of 2,983 laparotomy patients over a period of 10 years]. Chirurg. 2002;73(5): 474-80.

39. Deerenberg EB, Harlaar JJ, Steyerberg EW, Lont HE, van Doorn HC, Heisterkamp J, et al. Small bites versus large bites for closure of abdominal midline incisions (STITCH): a double-blind, multicentre, randomised controlled trial. Lancet. 2015;386(10000):1254-60.

40. Muysoms FE, Antoniou SA, Bury K, Campanelli G, Conze J, Cuccurullo D, et al. European Hernia Society guidelines on the closure of abdominal wall incisions. Hernia. 2015;19(1):1-24.

41. Sajid MS, Parampalli U, Baig MK, McFall MR. A systematic review on the effectiveness of slowlyabsorbable versus non-absorbable sutures for abdominal fascial closure following laparotomy. Int J Surg. 2011;9(8):615-25.

42. Martinez FO, Gordon S. The M1 and M2 paradigm of macrophage activation: time for reassessment. F1000Prime Rep. 2014;6:13.

43. Hesketh M, Sahin KB, West ZE, Murray RZ. Macrophage Phenotypes Regulate Scar Formation and Chronic Wound Healing. Int J Mol Sci. 2017;18(7).

44. Carlson MA, Chakkalakal D. Tensile properties of the murine ventral vertical midline incision. PLoS One. 2011;6(9):e24212.

45. Ducheyne P. Comprehensive biomaterials. Amsterdam ; Boston: Elsevier; 2011.

46. Borab ZM, Shakir S, Lanni MA, Tecce MG, MacDonald J, Hope WW, et al. Does prophylactic mesh placement in elective, midline laparotomy reduce the incidence of incisional hernia? A systematic review and meta-analysis. Surgery. 2017;161(4):1149-63.

47. Cross AJ, Buchwald PL, Frizelle FA, Eglinton TW. Meta-analysis of prophylactic mesh to prevent parastomal hernia. Br J Surg. 2017;104(3):179-86. 
48. Mathes $T$, Walgenbach $M$, Siegel R. Suture Versus Mesh Repair in Primary and Incisional Ventral Hernias: A Systematic Review and Meta-Analysis. World J Surg. 2016;40(4):826-35.

49. Lee L, Mata J, Landry T, Khwaja KA, Vassiliou MC, Fried GM, et al. A systematic review of synthetic and biologic materials for abdominal wall reinforcement in contaminated fields. Surg Endosc. 2014;28(9): 2531-46.

50. Baylon K, Rodriguez-Camarillo P, Elias-Zuniga A, Diaz-Elizondo JA, Gilkerson R, Lozano K. Past, Present and Future of Surgical Meshes: A Review. Membranes (Basel). 2017;7(3).

51. De Wilde RL, Brolmann H, Koninckx PR, Lundorff P, Lower AM, Wattiez A, et al. Prevention of adhesions in gynaecological surgery: the 2012 European field guideline. Gynecol Surg. 2012;9(4):365-8.

52. De Wilde RL, Alvarez J, Brölmann H, Campo R, Cheong Y, al. e. Prevention of Adhesions in Gynecological Surgery: The 2016 Experts Recommendations on Adhesion Prophylaxis. Gynecol Obstet (Sunnyvale). 2017(7):428.

53. Ten Broek RPG, Krielen P, Di Saverio S, Coccolini F, Biffl WL, Ansaloni L, et al. Bologna guidelines for diagnosis and management of adhesive small bowel obstruction (ASBO): 2017 update of the evidencebased guidelines from the world society of emergency surgery ASBO working group. World J Emerg Surg. 2018;13:24.

54. Hobbs FD, Erhardt L. Acceptance of guideline recommendations and perceived implementation of coronary heart disease prevention among primary care physicians in five European countries: the Reassessing European Attitudes about Cardiovascular Treatment (REACT) survey. Fam Pract. 2002; 19(6):596-604.

55. Zinther NB, Fedder J, Friis-Andersen H. Noninvasive detection and mapping of intraabdominal adhesions: a review of the current literature. Surg Endosc. 2010;24(11):2681-6.

56. van den Beukel BAW, Stommel MWJ, van Leuven S, Strik C, MA IJ, Joosten F, et al. A Shared Decision Approach to Chronic Abdominal Pain Based on Cine-MRI: A Prospective Cohort Study. Am J Gastroenterol. 2018;113(8):1229-37.

57. Kilkenny C, Browne WJ, Cuthill IC, Emerson M, Altman DG. Improving bioscience research reporting: the ARRIVE guidelines for reporting animal research. PLoS Biol. 2010;8(6):e1000412.

58. Schulz KF, Altman DG, Moher D, Group C. CONSORT 2010 statement: updated guidelines for reporting parallel group randomised trials. BMJ. 2010;340:c332.

59. Diamond MP, Wexner SD, diZereg GS, Korell M, Zmora O, Van Goor H, et al. Adhesion prevention and reduction: current status and future recommendations of a multinational interdisciplinary consensus conference. Surg Innov. 2010;17(3):183-8.

60. ten Broek RP, Strik C, Issa Y, Bleichrodt RP, van Goor H. Adhesiolysis-related morbidity in abdominal surgery. Ann Surg. 2013;258(1):98-106.

61. Lier EJ, van den Beukel BAW, Gawria L, van der Wees PJ, van den Hil L, Bouvy ND, et al. Clinical adhesion score (CLAS): development of a novel clinical score for adhesion-related complications in abdominal and pelvic surgery. Surg Endosc. 2020.

62. Zhang $\mathrm{Y}$, Zhou H, Chai $\mathrm{Y}, \mathrm{Cao} \mathrm{C}$, Jin $\mathrm{K}, \mathrm{Hu}$ Z. Laparoscopic versus open incisional and ventral hernia repair: a systematic review and meta-analysis. World J Surg. 2014;38(9):2233-40.

63. Al Chalabi H, Larkin J, Mehigan B, McCormick P. A systematic review of laparoscopic versus open abdominal incisional hernia repair, with meta-analysis of randomized controlled trials. Int J Surg. 2015;20:65-74.

64. Jenkins ED, Yom V, Melman L, Brunt LM, Eagon JC, Frisella MM, et al. Prospective evaluation of adhesion characteristics to intraperitoneal mesh and adhesiolysis-related complications during laparoscopic re-exploration after prior ventral hernia repair. Surg Endosc. 2010;24(12):3002-7.

65. Penchev D, Kotashev G, Mutafchiyski V. Endoscopic enhanced-view totally extraperitoneal retromuscular approach for ventral hernia repair. Surg Endosc. 2019;33(11):3749-56.

66. Santos DA, Limmer AR, Gibson HM, Ledet CR. The current state of robotic retromuscular repairs-a qualitative review of the literature. Surg Endosc. 2020.

67. Kumar N, Palanisamy NV, Parthasarathi R, Sabnis SC, Nayak SK, Palanivelu C. A comparative prospective study of short-term outcomes of extended view totally extraperitoneal (e-TEP) repair versus laparoscopic intraperitoneal on lay mesh (IPOM) plus repair for ventral hernia. Surg Endosc. 2020.

68. Halpern DK, Howell RS, Boinpally H, Magadan-Alvarez C, Petrone P, Brathwaite CEM. Ascending the Learning Curve of Robotic Abdominal Wall Reconstruction. JSLS. 2019;23(1). 
69. Muysoms F, Van Cleven S, Pletinckx P, Ballecer C, Ramaswamy A. Robotic transabdominal retromuscular umbilical prosthetic hernia repair (TARUP): observational study on the operative time during the learning curve. Hernia. 2018;22(6):1101-11.

70. Kockerling F. What Is the Influence of Simulation-Based Training Courses, the Learning Curve, Supervision, and Surgeon Volume on the Outcome in Hernia Repair?-A Systematic Review. Front Surg. 2018;5:57.

71. Yamada T, Okabayashi K, Hasegawa H, Tsuruta M, Yoo JH, Seishima R, et al. Meta-analysis of the risk of small bowel obstruction following open or laparoscopic colorectal surgery. Br J Surg. 2016;103(5): 493-503.

72. Beyene RT, Kavalukas SL, Barbul A. Intra-abdominal adhesions: Anatomy, physiology, pathophysiology, and treatment. Curr Probl Surg. 2015;52(7):271-319.

73. Molinas CR, Binda MM, Manavella GD, Koninckx PR. Adhesion formation after laparoscopic surgery: what do we know about the role of the peritoneal environment? Facts Views Vis Obgyn. 2010;2(3): 149-60.

74. Binda MM. Humidification during laparoscopic surgery: overview of the clinical benefits of using humidified gas during laparoscopic surgery. Arch Gynecol Obstet. 2015;292(5):955-71.

75. Ozdemir-van Brunschot DMD, van Laarhoven KCJHM, Scheffer GJ, Pouwels S, Wever KE, Warle MC. What is the evidence for the use of low-pressure pneumoperitoneum? A systematic review. Surg Endosc. 2016;30(5):2049-65.

76. Jairam AP, Lopez-Cano M, Garcia-Alamino JM, Pereira JA, Timmermans L, Jeekel J, et al. Prevention of incisional hernia after midline laparotomy with prophylactic mesh reinforcement: a meta-analysis and trial sequential analysis. BJS Open. 2020;4(3):357-68.

77. van den Hil LCL, van Steensel S, Schreinemacher MHF, Bouvy ND. Prophylactic mesh placement to avoid incisional hernias after stoma reversal: a systematic review and meta-analysis. Hernia. 2019;23(4):73341.

78. Fischer JP, Basta MN, Mirzabeigi MN, Bauder AR, Fox JP, Drebin JA, et al. A Risk Model and Cost Analysis of Incisional Hernia After Elective, Abdominal Surgery Based Upon 12,373 Cases: The Case for Targeted Prophylactic Intervention. Ann Surg. 2016;263(5):1010-7.

79. Mommers EHH, van Kooten L, Nienhuijs SW, de Vries Reilingh TS, Lubbers T, Mees BME, et al. Can Electric Nose Breath Analysis Identify Abdominal Wall Hernia Recurrence and Aortic Aneurysms? A Proof-of-Concept Study. Surg Innov. 2020:1553350620917898.

80. Birolini C, de Miranda JS, Tanaka EY, Utiyama EM, Rasslan S, Birolini D. The use of synthetic mesh in contaminated and infected abdominal wall repairs: challenging the dogma-A long-term prospective clinical trial. Hernia. 2020;24(2):307-23.

81. Kockerling F, Sheen AJ, Berrevoet F, Campanelli G, Cuccurullo D, Fortelny R, et al. Accreditation and certification requirements for hernia centers and surgeons: the ACCESS project. Hernia. 2019;23(2): 185-203.

82. Kockerling F, Sheen AJ, Berrevoet F, Campanelli G, Cuccurullo D, Fortelny R, et al. The reality of general surgery training and increased complexity of abdominal wall hernia surgery. Hernia. 2019;23(6): 1081-91.

83. Heniford BT, Ross SW, Wormer BA, Walters AL, Lincourt AE, Colavita PD, et al. Preperitoneal Ventral Hernia Repair: A Decade Long Prospective Observational Study With Analysis of 1023 Patient Outcomes. Ann Surg. 2020;271(2):364-74.

84. Huntington CR, Cox TC, Blair L, Schell S, Randolph D, Prasad T, et al. Biologic mesh in ventral hernia repair: Outcomes, recurrence, and charge analysis. Surgery. 2016;160(6):1517-27.

85. Kockerling F, Alam NN, Antoniou SA, Daniels IR, Famiglietti F, Fortelny RH, et al. What is the evidence for the use of biologic or biosynthetic meshes in abdominal wall reconstruction? Hernia. 2018;22(2):249-69.

86. Fligor JE, Lanier ST, Dumanian GA. Current Risk Stratification Systems Are Not Generalizable across Surgical Technique in Midline Ventral Hernia Repair. Plast Reconstr Surg Glob Open. 2017;5(3):e1206. 




\section{PART V}

Appendices 

Summary 



\section{Summary}

Abdominal surgery is related to the risk to develop incisional hernia and adhesions. These complications often require readmissions and new surgical interventions, such as hernia repair with mesh and adhesiolysis.

This thesis explores the problem of adhesions in a clinical setting and the scoring of adhesions in both experimental and clinical settings, then evaluates the effect of different sutures in abdominal wall healing and the behavior of an elastic mesh in an experimental setting, and eventually an animal model in hernia research is explored and a strategy to prevent hernias after stoma reversal is being developed.

\section{Part 1: Awareness of adhesions and scoring systems}

Firstly, we aimed to assess the awareness of the problem of adhesions in both Dutch surgeons and surgical residents and aimed to develop a new adhesion scoring system.

In Chapter 2, we performed an Adhesion Awareness survey, six years after the first adhesion awareness survey was published, to assess the awareness of Dutch surgeons with regard to post-operative adhesions and related complications. The Adhesion Awareness study 2010 was updated and surgeons and surgical trainees in the Netherlands were invited to participate. With a response rate of $32.6 \%$, the response rate was comparable with the Adhesion Awareness study 2010 (34.4\%). Although the rate of respondents that acknowledge the clinical relevance of adhesions was similar in the surveys performed in 2010 and 2016, more surgeons mentioned adhesion-related complications in the informed consent process in 2016. However, still one third of the surgeons never mentioned adhesions at all during informed consent. The awareness of the occurrence of bowel lesions during adhesiolysis increased significantly over the mentioned time-period. It could be concluded that overall adhesion awareness did not increase over six years. Thus, in the future, attention should be drawn to this problem to close the gap between the major impact of adhesions as complication of abdominal surgery and the limited awareness regarding the clinical problem of adhesions.

Next to this limited adhesion awareness, there is a lack of consensus on how to score mesh tissue adhesions in both experimental and clinical settings, leading to an overwhelming amount of adhesion scores, subsequently causing incomparable scientific results. In Chapter 3, it was aimed to develop an adhesion score together with experts in the field, in order to improve support of this new adhesion score. A literature search was performed to select the expert panel and the Delphi-method was used to reach consensus. The panel was queried on seven items in two questionnaire-based rounds and one consensus meeting. In total, two third of the experts, who accepted the invitation to participate, completed both questionnaires. Of those experts, $56 \%$ were able to participate in the consensus meeting. The final proposal of the META adhesion scoring system was sent to and approved by all experts that completed the second round. The amount of mesh surface covered with adhesions, tenacity and thickness of adhesions and organ involvement should be the minimal set of variables described in 
future mesh tissue adhesion research. It was concluded that interstudy comparability and objectivity can be increased using the META scoring system. Eventually, it might be possible to link the items in this score to clinically relevant outcomes.

\section{Part 2: Abdominal wall closure and hernia repair; experimental findings}

After determining the burden of adhesions and creating a new adhesion score, the second part of this thesis studied the foreign body reaction on different suture materials and the properties of an elastic mesh in experimental settings.

For a better understanding of the process of fascia healing, in order to support the choice of suture material in abdominal wall closure, in Chapter 4 the foreign body reaction on a non-absorbable (Prolene ${ }^{\circledR}$ ), slow-absorbable (PDS ${ }^{\circledR}$ ) and fast-absorbable $\left(\right.$ Vicryl $\left.^{\circledR}\right)$ suture was studied in a rat model, with follow-up times of 7 and 21 days. A semi-quantitatively score was used to measure microscopic foreign body reaction. Evaluation of fibroblast activity and vascularization took place using qPCR macrophage polarization. All animals completed the follow-up time without the occurrence of complications. After 21 days, a significantly higher presence of macrophages has been shown in the Vicryl ${ }^{\circledR}$ group, compared to both Prolene ${ }^{\circledR}$ and PDS ${ }^{\circledR}$. Furthermore, more foreign body giant cells were detected in the Vicryl ${ }^{\circledR}$ group compared to Prolene ${ }^{\circledR}$ at 7 days follow-up and PDS ${ }^{\circledR}$ at 21 days follow-up. A significantly higher expression of clec10A was shown in PDS ${ }^{\circledR}$ compared to Prolene ${ }^{\circledR}$ after 7 days. These results show a beneficial macrophage response in $\mathrm{PDS}^{\circledR}$ and therefore supports carefully the use of a slow-absorbable suture in abdominal wall closure.

In Chapter 5, adhesion formation of a new elastic thermoplastic polyurethane (TPU) mesh was compared with a polypropylene mesh after 7 and 21 days follow-up in a rabbit model. Meshes were implanted laparoscopically in intraperitoneal onlay mesh (IPOM) position. After completing the follow-up time, a laparotomy was performed, the extent of adhesions was measured using the Diamond adhesion score, mesh elongation was measured and the abdominal walls with the meshes were explanted to assess histological outcomes. In this study, the elastic TPU mesh performed better than the polypropylene mesh, with significantly better adhesion scores and an increased mesh expansion under a force of $3 \mathrm{~N}$. The number of macrophages, proliferating cells and apoptotic cells was comparable in both groups. It could be concluded that the TPU mesh preserved its elastic properties during the follow-up time and that it reduces adhesion formation in comparison with a polypropylene mesh.

A TPU mesh was also the object of investigation in Chapter 6, in which it was evaluated if TPU containing meshes in comparison with polyvinylidenefluoride (PVDF) meshes with similar structure retained an Effective Porosity under mechanical strain. Meshes were placed laparoscopically in IPOM position in a porcine model for 8 weeks. At this time-point, MRI of the abdomen with and without pneumoperitoneum was performed to assess the visibility and elasticity of the mesh. Finally, a laparotomy was performed to assess adhesion formation to the mesh and the abdominal wall, including the mesh, was explanted for immunohistochemical evaluation. It was shown that the 
position of the mesh could precisely be detected and measured with and without pneumoperitoneum, with a significant difference in increase of mesh surface under pneumoperitoneum in favor of TPU meshes. Although no differences in adhesion formation could be seen, the number of leukocytes was decreased and the Collagen I/III ratio increased in the TPU group compared to the PVDF group. This has led to the conclusion that TPU meshes preserve their elastic properties and have better biocompatibility than PVDF meshes.

\section{Part 3: A human model for adhesion assessment and hernia prevention}

In the last part of this thesis, we explored the rat as animal model in hernia research and the utility of prophylactic meshes around stomata.

Chapter $\mathbf{7}$ focused on the comparability of adhesion formation and foreign body reaction in rats and humans in hernia research. Rats are often used in experimental hernia research, although the correlation with clinical findings in humans has never been shown. To explore this, a fixed type of mesh was implanted in both rats and humans and after a follow-up of 12 weeks and 6 months respectively, adhesion formation was assessed and samples of the mesh were collected for immunohistochemical evaluation. After termination of the follow-up period, no differences in adhesion formation were detected. Furthermore, general inflammation scores were comparable between rats and humans, although a significant higher number of granulocytes and giant cells was present in rats, while the presence of fibrosis was higher in humans. It was concluded that adhesion formation and foreign body reaction in rats and humans are comparable and therefore it is recommended to use rats in experimental research that includes the investigation of meshes for incisional hernia.

Finally, the effectiveness of a prophylactic mesh to avoid incisional hernias after stoma reversal was evaluated in Chapter 8. A literature search and meta-analysis were performed and as primary outcome measure the incidence of incisional hernia formation after stoma reversal was chosen. Also, mesh-related complications were assessed. Eventually, 3 studies including 536 patients were included. During follow-up, ranging from 10 to 21 months, a significant lower risk on development of an incisional hernia was seen in the prophylactic mesh group, without an increased risk on surgical site infections. Thus, the use of a prophylactic mesh seems to decrease the risk on incisional hernia after stoma reversal and therefore, it should be considered to perform mesh reinforcement after stoma reversal. 
Appendices 
Nederlandse samenvatting 



\section{Nederlandse samenvatting}

Buikoperaties kunnen leiden tot littekenbreuken en adhesies. Om deze complicaties te kunnen behandelen, zijn vaak heropnames en nieuwe operaties noodzakelijk.

In dit proefschrift hebben we eerst geprobeerd het probleem omtrent adhesies bij patiënten te schetsen en hebben we een nieuwe score ontwikkeld om adhesies in zowel klinische als preklinische studies te beschrijven. Daarna hebben we in preklinische studies gekeken naar het effect van verschillende hechtmaterialen op de genezing van de buikwand en naar het gedrag van een nieuwe elastische mat. Tenslotte hebben we onderzocht of een diermodel vergelijkbaar is met de humane situatie in herniaonderzoek en hebben we een strategie ontwikkeld om littekenbreuken ter plaatse van een eerder stoma te voorkomen.

\section{Deel 1: Kennis omtrent adhesies en scoringsmodellen}

Ten eerste hebben we geprobeerd een beeld te krijgen over de bestaande kennis van adhesies onder Nederlandse chirurgen. Daarnaast hebben we getracht een nieuwe score te ontwikkelen, waarmee adhesies systematisch beschreven kunnen worden.

In hoofdstuk 2 hebben we een studie verricht naar het bewustzijn van Nederlandse chirurgen met betrekking tot postoperatieve adhesies en gerelateerde complicaties. Deze studie is verricht 6 jaar na de originele 'Adhesion Awareness Survey'. De vragenlijst uit 2010 werd geüpdatet en chirurgen en chirurgen in opleiding werden uitgenodigd om deel te nemen aan het onderzoek. De response ratio was met $32.6 \%$ vergelijkbaar met de ratio in 2010 (34.4\%). Ondanks het feit dat het percentage respondenten dat de klinische relevantie van adhesies erkent gelijk was in de uitgevoerde enquêtes in 2010 en 2016, steeg het percentage chirurgen (in opleiding) dat complicaties die door adhesies veroorzaakt worden met patiënten bespreekt. Eén op de drie chirurgen bespreekt het ontwikkelen van postoperatieve adhesies echter nooit. Meer chirurgen zijn zich ervan bewust dat letsels aan de darm kunnen optreden tijdens het losmaken van adhesies tijdens een operatie. Over het algemeen kan geconcludeerd worden dat het bewustzijn omtrent adhesies in 6 jaar tijd gelijk is gebleven. Daarom moet in de toekomst aandacht gevraagd worden voor dit probleem, om zo het gat tussen de enorme impact van adhesies na buikchirurgie en het beperkte bewustzijn hieromtrent te dichten.

Naast het beperkte bewustzijn omtrent adhesies, ontbreekt het ook aan consensus over hoe adhesies aan matten, in zowel experimenteel als klinisch onderzoek, gescoord dienen te worden. Als gevolg hiervan zijn er vele scores om adhesies te rapporteren in omloop, waardoor het haast onmogelijk is studies met elkaar te vergelijken. In hoofdstuk 3 is er, met medewerking van experts op het gebied van adhesies aan matten, getracht een nieuwe adhesiescore te ontwikkelen. Door deze samenwerking is de verwachting dat deze nieuwe score beter ondersteund wordt. Middels een literatuurstudie werd het expertpanel geselecteerd en gebruik makend van de Delphi-methode kreeg het expertpanel, in twee opeenvolgende vragenlijsten en 
een consensusmeeting, vragen met betrekking tot zeven items voorgelegd. In totaal voltooide twee derde van de experts die de uitnodiging voor deelname accepteerden beide vragenlijsten. Hiervan kon $56 \%$ aan de consensusmeeting deelnemen. Het uiteindelijke voorstel van de META adhesie score werd naar alle experts gestuurd die beide vragenlijsten voltooiden. Zij keurden allen de score goed. Er werd geconcludeerd dat zowel het percentage van de mat dat bedekt wordt met adhesies, de dikte en sterkte van adhesies als de betrokkenheid van organen als minimale set van variabelen gebruikt moet worden om in toekomstig onderzoek adhesies aan matten te beschrijven. Tevens werd de conclusie getrokken dat de objectiviteit en vergelijkbaarheid tussen studies vergroot kan worden door gebruik te maken van de META adhesie score. Ten slotte zou het mogelijk kunnen zijn om bovengenoemde variabelen aan klinisch relevante uitkomsten te koppelen.

\section{Deel 2: Sluiten van de buikwand en littekenbreukherstel; bevindingen in experimentele studies}

Het tweede deel van dit proefschrift richt zich op de reacties van de buikwand op verschillende hechtmaterialen en de eigenschappen van een nieuw ontwikkelde elastische mat in experimentele studies.

Om het genezingsproces van de fascie beter te begrijpen en zo de keus van hechtmateriaal te ondersteunen, werd in hoofdstuk 4 de vreemd lichaam reactie op een niet-oplosbare (Prolene ${ }^{\circledR}$ ), langzaam-oplosbare $\left(\right.$ PDS $\left.^{\circledR}\right)$ en snel oplosbare $\left(\right.$ Vicryl $^{\circledR}$ ) hechting onderzocht in een rattenmodel. De follow-up tijd bedroeg 7 en 21 dagen. Er werd een semi-kwantitatieve score gebruikt om de microscopische vreemd lichaam reactie te beschrijven en de fibroblastactiviteit en vascularisatie werden geëvalueerd met behulp van een genexpressie-analyse. Alle ratten behaalde het eindpunt van de follow-up tijd zonder complicaties. Na 21 dagen waren er in de Vicryl ${ }^{\circledR}$-groep significant meer macrofagen aanwezig ten opzichte van de Prolene ${ }^{\circledR}$ - en PDS ${ }^{\circledR}$-groep. Bovendien werden er meer reuscellen gezien in de Vicryl ${ }^{\circledR}$-groep vergeleken met de Prolene ${ }^{\circledR}{ }_{-}$ groep na 7 dagen en ten opzichte van de PDS ${ }^{\circledR}$-groep na 21 dagen follow-up.

In de PDS $^{\circledR}$-groep werd een significant hogere expressie van clec10A gezien ten opzichte van Prolene ${ }^{\circledR}$ na 7 dagen. Bovengenoemde resultaten laten een betere respons van macrofagen in de $\mathrm{PDS}^{\circledR}$-groep zien en daarom kan voorzichtig geconcludeerd worden dat een langzaam-oplosbare hechting gebruikt zou moeten worden bij het sluiten van de buikwand.

In hoofdstuk 5 werd de vorming van adhesies aan een nieuwe, elastische mat, gemaakt van thermoplastisch polyurethaan (TPU), vergeleken met de vorming van adhesies aan een mat van polypropyleen in een konijnenmodel, waarbij een follow-up tijd van 7 en 21 dagen werd gehanteerd. De matten werden laparoscopisch geïmplanteerd in een intraperitoneale onlay positie van de mat (IPOM). Aan het einde van de follow-up tijd werd een laparotomie uitgevoerd, waarbij de uitgebreidheid van de adhesievorming werd beschreven met behulp van de Diamond-score. Bovendien werd de rek van de mat gemeten en werd de buikwand samen met de mat verwijderd 
om histologische eindpunten te meten. In deze studie lieten de TPU-matten betere uitkomsten zien dan de matten van polypropyleen; ook was de adhesiescore significant beter in de TPU-groep en de matten vertoonden een betere rek onder een kracht van $3 \mathrm{~N}$. De hoeveelheid macrofagen, proliferatieve cellen en cellen in apoptose waren vergelijkbaar in de groepen. Er kon geconcludeerd worden dat TPU-matten betere elastische eigenschappen behielden tijdens de follow-up tijd en dat er minder adhesies vormden aan TPU-matten ten opzichte van een mat van polypropyleen.

In hoofdstuk 6 waren TPU-matten ook het onderzoeksobject. Hier werden matten van polyvinylideenfluoride (PVDF) vergeleken met matten die zowel PVDF als ook TPU bevatten, waarbij de matten een vergelijkbare structuur hadden. Gekeken werd of de effectieve poreusheid van beide matten behouden blijft onder mechanische rek. De matten werden wederom laparoscopisch in IPOM positie geïmplanteerd, ditmaal in een varkensmodel met een follow-up tijd van 8 weken. Na 8 weken werden er twee MRI's van het abdomen gemaakt; één met en één zonder pneumoperitoneum. Zo werd gekeken hoe goed de matten zichtbaar waren en werd de elasticiteit gemeten. Tenslotte werd een laparotomie verricht om de adhesievorming te bepalen en werd de buikwand met mat verwijderd om immunohistochemisch te kunnen onderzoeken. De positie van de mat kon nauwkeurig aangetoond en gemeten worden, zowel zonder als met pneumoperitoneum. De TPU-matten toonden hierbij een significante toename van matoppervlak onder pneumoperitoneum. Er konden geen verschillen in adhesiescores vastgesteld worden tussen beide groepen. Het aantal leukocyten was significant lager, terwijl de collageen type I/III ratio juist groter was in de TPU-groep vergeleken met de PVDF-groep. Op basis van deze gegevens werd geconcludeerd dat TPU-matten hun elastische eigenschappen behouden en een betere biocompatibiliteit hebben dan PVDF-matten.

\section{Deel 3: Een humaan model voor adhesiebeoordeling en herniapreventie}

In het laatste deel van dit proefschrift onderzochten we of een rattenmodel geschikt is voor onderzoek naar nieuwe matten en wat het nut is van een profylactische mat rondom stomata.

Hoofdstuk 7 richtte zich op de overeenkomsten tussen ratten en mensen met betrekking tot adhesievorming en vreemd lichaam reactie in onderzoek naar littekenbreuken. Ratten worden vaak ingezet in onderzoek naar littekenbreuken, ondanks dat de correlatie met klinische uitkomsten nooit is aangetoond. Om dit te onderzoeken werd een specifiek type mat geïmplanteerd in zowel ratten als mensen en, na een follow-up tijd van respectievelijk 12 weken en 6 maanden, werd de adhesievorming gescoord en werden monsters van de mat genomen voor immunohistochemisch onderzoek. Na het behalen van de follow-up tijd konden geen verschillen in adhesievorming gedetecteerd worden. Bovendien was de mate van de vreemd lichaam reactie vergelijkbaar tussen ratten en mensen, hoewel er een significant grotere hoeveelheid granulocyten en reuscellen aanwezig was in ratten. 
Daarentegen was er in mensen meer fibrose aanwezig. Er kon geconcludeerd worden dat de adhesievorming en vreemd lichaam reactie in ratten en mensen vergelijkbaar is. Daarom werd het aanbevolen om in toekomstig experimenteel onderzoek naar littekenbreuken waarbij matten gebruikt worden, gebruik te maken van ratten als diermodel.

Tot slot werd in hoofdstuk 8 de effectiviteit van een profylactische mat om littekenbreuken ter hoogte van een opgeheven stoma te voorkomen, onderzocht. Een literatuurstudie en meta-analyse werden verricht, waarbij het vóórkomen van littekenbreuken ter hoogte van een voormalig stoma als primaire uitkomstmaat werd gekozen. Bovendien werden complicaties die aan het gebruik van een mat gerelateerd konden worden, geregistreerd. In totaal werden er 3 studies met 356 patiënten geïncludeerd in deze meta-analyse. Tijdens de follow-up tijd, die varieerde van 10 tot 21 maanden, werd er een significant lager risico op het ontwikkelen van een littekenbreuk gedetecteerd in de groep met een profylactische mat. Het risico op wondinfecties was niet verhoogd. Het gebruik van een profylactische mat lijkt daarom het risico op een littekenbreuk na het opheffen van een stoma te verkleinen en daarom moet het overwogen worden om een profylactische mat te gebruiken bij het opheffen van een stoma.

In hoofdstuk 9 volgt een discussie over de voorgaande hoofdstukken. Zo kan het zijn dat de kennis omtrent adhesies in 6 jaar niet toegenomen is, doordat het moeilijk is om complicaties, zoals pijn en infertiliteit, direct aan adhesies te relateren. Verder zouden flexibele matten tot minder chronische pijn kunnen leiden en moet er nog onderzocht worden wat de ideale follow-up tijd is in onderzoek naar littekenbreuken waarbij ratten gebruikt worden. Tevens wordt ter discussie gesteld of alle variabelen in de META adhesie score even belangrijk zijn. Daarnaast schetsen we in dit hoofdstuk een toekomstbeeld om de uitkomsten van de studies in dit proefschrift te implementeren. Zo is het maken van richtlijnen belangrijk om zowel de kennis van verklevingen onder chirurgen te vergroten als ook om meer uniformiteit in onderzoek naar littekenbreuken te vergroten. Ook zullen nieuwe operatietechnieken nodig zijn om de kans op adhesies en littekenbreuken te verkleinen.

Tot slot wordt in hoofdstuk $\mathbf{1 0}$ het nut van dit proefschrift voor de maatschappij beschreven. Met een geschat aantal van 8500 operaties per jaar aan littekenbreuken is dit onderwerp een relevant maatschappelijk probleem. Ook adhesies vormen een relevant probleem, gezien het feit dat $35 \%$ van de patiënten binnen 10 jaar na de index-operatie heropgenomen wordt met adhesie-gerelateerde complicaties. Dit proefschrift heeft een brede doelgroep. Zo moeten zowel chirurgen, gynaecologen, urologen, maag-darm-lever-artsen en huisartsen het probleem van adhesies herkennen en erkennen om zo patiënten goed voor te kunnen lichten. Tevens zouden patiënten zelf informatie over operaties en de risico's moeten inwinnen. Hier kunnen patiëntenverenigingen een belangrijke rol bij spelen. Innovatief in dit proefschrift is dat er nieuwe hulpmiddelen ontwikkeld zijn om onderzoek naar littekenbreuken te 
verbeteren. Bovendien is aangetoond dat een profylactische mat veilig gebruikt kan worden om littekenbreuk na het opheffen van een stoma te voorkomen. 
Appendices 
Valorisation 



\section{Valorisation}

With an increased age of our population an improved treatment for chronic diseases such as adhesions and incisional hernia is mandatory. Subsequently, healthcare costs rise with the increased life expectancy. Therefore, not only functionality of newly developed devices and interventions, but also related costs are nowadays important aims in medical research. Furthermore, quality of life and patient related outcome measurements are crucial to consider when new treatment options are introduced. In the current chapter, the social and economic impact of the research conducted in this thesis, is discussed.

\section{Relevance}

Hernias can be congenital, develop spontaneously or are acquired. Congenital and spontaneously developed hernias are the so-called primary abdominal wall hernias, while acquired hernias develop after abdominal surgery.

Acquired hernias include incisional hernia, parastomal hernia and hernia after stoma reversal. Incidences up to $20 \%, 30-50 \%$ and $30 \%$ respectively are reported and the risk to develop them increases with higher BMI. Surgical repair of these hernias is required in $27-44 \%$.

In the Netherlands, it is postulated that 8500 incisional hernia repairs take place yearly. With increasing numbers of intra-abdominal procedures, the number of hernia repair is probably also increasing. Although surgical hernia repair is seen as a low-risk procedure, complications such as hernia recurrence, chronic abdominal pain, mesh infection and adhesion formation in combination with the frequency of the procedure can have a significant impact on health care costs and morbidity.

Postoperative adhesions are frequent complications of intra-abdominal surgery and are related to chronic abdominal pain, bowel obstruction and female infertility. Since this leads to a readmission rate of $35 \%$ within 10 years after the index-operation, this will affect the health care system and quality of life of the operated patients significantly.

Furthermore, intra-abdominal placed meshes for hernia repair trigger adhesions to form between meshes and viscera, which may lead to severe complications such as fistula formation between intestines and the mesh. Therefore, prevention of such complications is important for both patients and society.

\section{Target groups}

Results of the studies in this thesis could be of interest to a wide audience. First of all, medical professionals, in particular surgeons, gynecologists and urologists should acknowledge and recognize adhesion-related complications and inform patients preoperatively about the risks of adhesion formation after abdominal surgery. Furthermore, these professionals form the corner stone in prevention of adhesions and 
incisional hernias, by using anti-adhesive barriers, prophylactic meshes or closing the abdominal wall according the small steps small bites technique. Besides, gastroenterologists and general practitioners should be aware of the possible complications of adhesions, since these specialists may also treat patients with chronic abdominal pain, small bowel obstruction or infertility.

Next, patients should take their responsibility in obtaining information about surgical interventions and possible risks. Patients' associations can play an important role in providing this information and can act as a negotiator with medical professionals, policy makers and health insurance companies in order to change current practice.

Furthermore, health insurance companies are an important target group. It might be that the costs of anti-adhesive barriers and prophylactic meshes are a limiting factor in the widespread use, although these products have proven their cost-effectiveness. Health care companies can provide funding or plan together with hospitals and medical professionals to increase the use of these products.

Lastly, companies and researchers that are involved in the development of meshes can profit from the information described in this thesis. Since it is shown that the rat is a good animal model in hernia research, it should be considered to use rats in future mesh research to minimize the use of animals for research goals. Furthermore, an additional decrease in animal research can be reached using the META scoring system described in this thesis, as it makes it easier to compare studies.

\section{Activities and products}

Despite activities from the Dutch Adhesion Group and several research groups in the past, the in 2016 repeated adhesion awareness survey showed that the burden of adhesions is still an underestimated problem. To draw attention to this problem, new studies with recent numbers on adhesion-related readmission rates, new adhesion scores and cost-effectiveness studies have been performed. In combination with the Bologna guidelines for the diagnosis and treatment of adhesive small bowel obstruction, this will hopefully lead to an increased awareness and subsequently change of daily practice.

Regarding the newly developed elastic thermoplastic polyurethane (TPU) mesh, results presented in this thesis are promising. The elasticity of this mesh should imitate the function of the abdominal wall and therefore should lead to less complaints. To further explore possible applications of this mesh, studies that investigate the utilization of this elastic mesh as inlay mesh in large abdominal wall defects and the performance of this meshes when used as a parastomal mesh have been performed in pigs. These studies have also shown promising results and thus, additional studies in humans should be designed to conduct randomized clinical trials using this mesh. 


\section{Innovation}

Several innovative developments have been addressed in this thesis. The first important innovation covers the development of tools to improve hernia research. Secondly, prophylactic measures to prevent hernias are an important topic of this thesis.

Regarding the performance of hernia research, especially in animals, hardly no guidelines exist. Since there are general concerns about the quality, reproducibility and translatability of animal research, guidelines such as the PREPARE and ARRIVE guidelines have been developed to improve animal research. Nevertheless, in the field of hernia research, it has been shown that many different animal models have been used, subsequently decreasing the reproducibility of these studies. Furthermore, several adhesion scoring systems are available. To improve hernia research, we decided to approach these problems. We showed that rats are a good animal model in hernia research, with comparable outcomes as in humans. Next, we were able to unite a group of experts in the field to develop a new mesh tissue adhesion score. Both subjects can help to improve hernia research by increasing reproducibility and translatability.

In the last years, research with the topic of hernia prevention has been increased. For example, it has been shown that abdominal wall closure with the small steps and small bites technique leads to a decrease in hernia formation. However, it remains unclear if a slow-absorbable or non-absorbable suture should be used. Therefore, we investigated the inflammatory response on both types of sutures, as well as on fastabsorbable sutures. Based on macrophage response, a slow-absorbable suture seems favorable in abdominal wall closure.

Next, prevention of hernia formation using prophylactic meshes has been widely explored. Unfortunately, data on prophylactic mesh placement to prevent incisional hernia after stoma reversal are limited. We decided to perform a systematic review and meta-analysis to give a clear overview. This study showed the effectiveness of a prophylactic mesh, although no information about cost-effectiveness and quality of life exists.

\section{Schedule and implementation}

The research described in this thesis provides the opportunity for interesting follow-up studies.

Regarding the META scoring system, it is important that this scoring system will be validated on the short term, since currently, no validated adhesion score exists. This can be an explanation of the quantity of used adhesion scores. For the validation of the META scoring system, limited additional experimental testing is required. During this process, it might be necessary to add small adjustments to the score in order to clarify the score. As soon as the META scoring system is validated, it should be used as standard mesh tissue adhesion score in both experimental and clinical research. With 
the gathered information, the META scoring system could in the future be modified to use as scoring system for post-operative adhesions in general.

Another important finding is that histological outcomes in rats and humans in a hernia model are comparable. Therefore, the rat should be the animal model used in future hernia research. Both abovementioned findings can lead to increased reproducibility and translatability and thus to a decrease in required animal research. Therefore, guidelines in the field of hernia and adhesion research are necessary. These guidelines should include factors as preferred animal type, adhesion models and scoring systems. It seems logical to develop these guidelines in cooperation with the National Centre for the Replacement, Refinement and Reduction of Animals in Research (NC3Rs), the organization that is also involved in the development of the ARRIVE guidelines. The European and American Hernia Societies can also play a role in developing and spreading the guidelines.

Furthermore, it is shown that prophylactic mesh placement after stoma reversal is promising. However, sample sizes in these studies are relatively small and the quality of life and cost effectiveness are not described yet. To examine this, several study groups are including patients in randomized clinical trials. Outcomes of these studies will be published in the upcoming years. Due to the high number of treated patients with stoma reversal and the high risk on hernia development, even small improvements can have a significant impact on societal health care.

Lastly, clinical trials to investigate the effectiveness of the newly developed elastic TPU mesh in human should be designed to measure the effectiveness and quality of life in patients who receive this mesh. 


Dankwoord 



\section{Dankwoord}

En dan, na al die jaren, ligt mijn proefschrift eindelijk voor me en mag ik beginnen aan het (waarschijnlijk) meest gelezen hoofdstuk van dit proefschrift. Zonder de hulp van vele leuke en lieve collega's, vrienden en familie was het me waarschijnlijk niet gelukt dit traject tot een goed einde te brengen. Daarom wil ik via deze weg iedereen bedanken die op welke manier dan ook heeft bijgedragen aan de totstandkoming van dit proefschrift.

Geachte professor Bouvy, beste Nicole, jouw geduld en vertrouwen zijn eindeloos. Ook jij moet je toch wel eens afgevraagd hebben of dit proefschrift er ooit zou komen. Toch heb ik nooit het gevoel gehad dat je het vertrouwen verloor. Je reageert altijd weer enthousiast en hebt me de ruimte gegeven om me te ontplooien en dit traject op mijn eigen tempo af te maken. Door jouw brede interesse op zowel medisch als ook persoonlijk vlak is de samenwerking met jou altijd fijn geweest. Dank je wel, dat je me de kans hebt gegeven om samen dit traject aan te gaan. Ik merk iedere dag weer hoe waardevol deze ervaring is!

Beste Marc, mijn copromotor, jouw enthousiasme voor onderzoek is onevenaarbaar. Je had altijd 1001 ideeën die je met veel energie aan mij hebt geprobeerd over te dragen. Helaas niet altijd met succes... Ik kijk met plezier terug op de discussies die we gevoerd hebben en het voelde als een succesje als ik je zo nu en dan van mijn visie kon overtuigen. Jouw kritische blik heeft me enorm geholpen, al was ik niet altijd even blij als ik mijn artikel na jouw revisies helemaal rood terugkreeg. Maar eerlijk is eerlijk, het resultaat werd er meestal beter door. Ik vind het dan ook erg jammer dat je de chirurgie vaarwel gezegd hebt en de kalksteengroeven ingedoken bent. Hopelijk kunnen ze daar jouw enthousiasme net zo waarderen.

Ook wil ik graag de leden van mijn promotiecommissie bedanken. Allereerst professor Stassen, hartelijk dank dat $u$ de beoordelingscommissie wilde voorzitten. Professor Olde Damink, beste Steven, bedankt dat je voor professor Stassen wilt waarnemen tijdens mijn verdediging en dank voor de leuke en leerzame tijd op het lab. Beste doctor lbelings, dank $u$ wel voor uw deelname aan mijn promotiecommissie, maar bovenal dank voor de leuke en leerzame tijd in Tilburg. Ik heb altijd met veel plezier met u samengewerkt en heb veel van u kunnen leren! Professor Lange, ook $u$ wil ik hartelijk bedanken, in het bijzonder voor de hulp aan de META-score. Ik had graag intensiever met u samengewerkt, hopelijk dient zich die mogelijkheid in de toekomst nog eens aan.

Professor van der Hulst, professor Masclee en doctor Melenhorst, wij hebben tijdens mijn promotietraject helaas niet samen kunnen werken. Des te meer waardeer ik het dat jullie de tijd en moeite genomen hebben om aan mijn promotiecommissie deel te nemen. 
Dank aan alle collega's op het lab in Maastricht, ik voelde me er snel thuis!

Charlotte, dank je wel dat je me aan Nicole hebt voorgesteld en een goed woordje voor me hebt gedaan.

Anne-Claire, jij hebt me op weg geholpen toen ik begon in Maastricht. In het begin liep dat misschien niet altijd even makkelijk, maar je enthousiasme en behulpzaamheid hebben me enorm geholpen. Ook jouw onuitputtelijke hoeveelheid energie en uitspraken had ik niet willen missen!

Dank aan de andere collega's uit Team Bouvy: Ruben, jij bent de voorganger die voor verschillende projecten de eerste stappen al gemaakt had. Hierdoor heb ik een soepele start kunnen maken met mijn promotie. Audrey, dank je wel voor de hulp met opereren, kleuringen en ideeën voor onderzoek. Het was altijd leuk met jou op het lab! Sebastiaan, je begon als mijn student en hebt me daarna op rap tempo ingehaald. Onze samenwerking heeft tot enkele mooie, gezamenlijke publicaties geleid. Het was altijd fijn samenwerken met je. Elwin, jij hebt op sneltreinvaart je promotie afgerond. Je kritische blik en motivatie om steeds voortgang te boeken, hebben me enorm geholpen bij onze Delphi-studie. Hong, we didn't work that long together, but it is admirable that you moved all by yourself to the other side of the world to start and finish your PhD at MUMC+.

David, Martine, Jules, Anne-Claire, Jacqueline, Audrey en Cathelijne, jullie wil ik bedanken voor alle leuke fietstochten die we gemaakt hebben in Zuid-Limburg. Ik mis de mooie heuvels met de bijbehorende ijsjes of biertjes.

Dennis, Bas en David, vaak leek het of jullie dachten dat kamer G4.246 de koffiekamer was, in plaats van een kamer waar ook gewerkt moest worden. Uren hebben jullie op deze kamer doorgebracht en vaak niet tegelijk.

Mijn werkdagen waren dan ook niet altijd even productief, maar zonder deze koffiemomenten was mijn tijd op UNS40 lang niet zo leuk geweest.

Bas, je weet hoe erg ik me op dit moment verheugd heb. Dat ik je gewoon kan bedanken, zonder dat je tegen begint te sputteren... Dus lieve Bas, dank je wel dat je deze dummy de beginselen van histologische kleuringen hebt weten bij te brengen. Dank je wel voor je hulp in het lab, omdat die kleuringen vaak toch niet helemaal lukten. Dank je wel voor alle koffie. Dank je wel, dat ik mee mocht doen aan coach van het jaar. Dank je wel voor je subtiliteit (lk weet nu dat je voor bepaalde kleding een Cup $D$ nodig hebt en dat sommige collega's meer moeten squatten). Maar bovenal dank je wel, dat je hier als mijn paranimf naast me wil staan. Ik had me geen betere paranimf kunnen wensen (met Claire natuurlijk op gelijke hoogte). 
En dan heel veel dank voor mijn andere paranimf en oud-roomie. Lieve Claire, toen ik net op het lab begon en je eigenlijk nog niet goed kende, dacht ik dat je veel te verfijnd en keurig voor me was. Het tegendeel bleek meer dan waar. Hoe vaak jij stress gehad hebt, omdat je weer eens te laat was met het kopen van een jurk voor een bruiloft. Het broekpak bleek ook niet zo'n succes. Door jou kwam ik erachter dat toch niet iedereen op het lab zo'n diehard onderzoeker was als ik dacht. Maar weet je, iedereen heeft zijn eigen kwaliteiten. Zo zijn wij een topteam bij 30 seconds. Of het nou Jon Bon Jovi of Bryan Adams is, jij weet wie ik bedoel. Ik ben blij dat ik met jou dit promotietraject doorlopen heb en dat je nu mijn paranimf bent.

Mijn lieve roomies wil ik ook bedanken. Luuk, een beetje mannelijkheid konden we op onze kamer wel gebruiken. Je hebt je kranig geweerd tussen de vrouwen. Cathelijne (geeeeeeeek), na het vertrek van Luuk, konden we ons geen betere nieuwe roomie wensen. Ook al ligt je frequentie soms buiten het bereik van het menselijk gehoor, we hebben nog genoeg kunnen lachen om de verhalen die we wel konden verstaan. Frans, ik weet eigenlijk niet welke tijd je beter beviel; de tijd dat wij je secretaresses waren of de tijd dat je zelf gedegradeerd werd en bij ons op de kamer terechtkwam. Ik vrees dat als je op die eerste kamer had kunnen blijven, je promotie wel klaar was geweest, maar ik hoop dat het 't waard was. Ik kijk uit naar het moment dat je ideeënbus geopend gaat worden.

De andere collega's op het lab, in willekeurige volgorde en in de hoop dat ik niemand vergeet; Annemarie, Mo, Hans, Frank, Zita, Kaatje, Sander, Inca, Dirk, Kirsten, Kevin, Joyce-Manyi, Lori, Junfang, Rutger, Milou, Givan, Rianne B., Miriam, Kiran, Jasper, Tim, Dennis J., Ralph, Evelien, Kim, Selwyn, Irene Fleur, Victor, Martijn, Robert, Briete, Thiemo, Yvonne, Martine U., Marissa, Romy, Rob, Mirjam, Rianne. Hartelijk dank!

Marion, dank je wel voor de uren achter de microscoop en de lessen die je me hebt bijgebracht. Een goede patholoog zal ik nooit worden, maar ik weet nu iets beter waar ik op moet letten als ik achter de microscoop zit.

Meine Kollegen der Universitätskliniken Aachen; sehr geehrter Professor Klink, lieber Christian, vielen Dank, dass ich in deinem Forschungsteam arbeiten dürfte. Ich habe während meiner Arbeitszeit in Aachen viel gelernt. Es hat mich gefreut zu hören, dass du Chefarzt in Speyer geworden bist. Ich hoffe, wir werden uns in der Zukunft treffen. Andreas, es hat Spaß gemacht mit dir operieren und Manuskripten schreiben zu können.

Ellen, Ilka, Anne und Katharina, vielen Dank für die Zusammenarbeit und die Hilfe im Labor! 
Graag wil ik ook alle studenten en coauteurs hartelijk bedanken voor de fijne samenwerking.

Ik wil verder nog mijn collega's uit het Maxima Medisch Centrum bedanken. Als ANIOS zonder enige ervaring werd ik door jullie goed opgevangen en kon ik de ervaring opdoen om te ontplooien tot de arts die ik nu ben. Gerrit, jij zei me dat ik te lief ben, maar dat ik dat vooral ook niet moet veranderen. Ik ben blij dat ik naar je geluisterd heb. Het heeft me misschien niet de opleidingsplaats in Nederland opgeleverd, maar de Duitsers zijn gek op die lieve Nederlandse arts.

Lieve collega's uit het Elisabeth-Tweesteden Ziekenhuis, wat heb ik met veel plezier met jullie samengewerkt. De vrijdagmiddagborrels mis ik nog regelmatig, maar misschien kunnen we dat binnenkort weer eens organiseren. Dank jullie wel voor het vertrouwen dat jullie me gegeven hebben. Ik hoop dat we elkaar in de toekomst weer tegen zullen komen.

Liebe Kollegen der Allgemein- und Viszeralchirurgie der Kliniken Maria Hilf, vielen Dank für die tolle Zusammenarbeit. Professor Kania, ich danke Ihnen, dass Sie es sich getraut haben eine niederländische Ärztin ein zu stellen. Professor Kirschniak, ich freue mich darauf, Forschung nach Hernien in unserer Klinik fortsetzen zu können. Frau Gürtler und Denise, vielen Dank für alle Unterstützung beim Papierkram. Frau Grünewald, Bolle, Caro, Isis, Anne, Jens, Tim, Janine, Peter, Vinush, Sabrina, Andrea, Anahita, Dorothee, Johanna, Kate, Sara, Steffi und Thomas, ich habe mich vom Anfang an wohl gefühlt in unserem Team. Das Vorgehen bei manchen Krankheiten ist in Deutschland manchmal etwas anders als ich es gewohnt war, aber ich habe schon gelernt, dass alle Wegen nach Rom führen.

En dan zijn er nog een aantal lieve vrienden, die ik wil bedanken. Zonder de ontspanning met jullie, was mijn promotietijd een stuk minder leuk geweest!

Lieve Annette en Viviënne, we leerden elkaar tijdens het eerste jaar van onze studie kennen en door jullie is mijn studententijd een onvergetelijke tijd geworden. Dinertjes na tentamens, Geneeskundefeestjes, stappen of carnaval, we hebben veel plezier gehad! We zien en spreken elkaar nu wat minder vaak, maar als we elkaar zien, is het altijd leuk. Margot, jij voegde je iets later bij ons, maar met jouw hoeveelheid energie was je een goede aanvulling op ons. Dank je wel voor alle keren dat ik kon blijven slapen als ik weer even in Rotterdam moest zijn.

Lieve Dirk en Lisan, ook wij leerden elkaar in het eerste studiejaar kennen en de discussies met jullie zijn onvergetelijk. Tijdens onze studietijd over van alles en nog wat, tegenwoordig tijdens een spelletjesavond over de te volgen strategieën. Ik ben blij dat 
jullie na de studie ook naar het zuiden getrokken zijn, dat maakt het afspreken wat makkelijker!

Lieve Denise, Elke en Jolien, mijn vriendinnetjes in Eindhoven. Denise, jou ken ik natuurlijk al bijna mijn hele leven en wat ben ik blij met jou. We hebben aan een half woord genoeg en door jou heb ik Elke en Jolien leren kennen. Met z'n vieren uit eten of op stap. Het afgelopen jaar hebben we elkaar maar weinig kunnen zien, hopelijk komt daar snel verandering in!

Ruud, Judith, Sander, Patty, Eric, Sanne, Bram, Maaike, Niels, Liane, Peter en Manon, wintersportvakanties, vriendenweekenden of borrelavonden, ze zijn altijd gezellig. Maar ook in moeilijke tijden staan jullie klaar. Ik prijs me gelukkig met zo'n lieve vriendengroep.

Clim, Ellen en Lieke, het is fijn om jullie in de buurt te hebben. Manon, dank je wel voor al die keren dat je me op sleeptouw hebt genomen. Jullie hebben er voor gezorgd dat ik me thuis voel in Venlo!

Pieter, dank je wel voor de hulp bij het ontwerpen en drukken van mijn proefschrift.

Lieve Bèr en Annelies, je schoonfamilie heb je niet voor het uitkiezen en het is altijd maar afwachten of dat klikt. Ik had het niet veel beter kunnen treffen. Dank jullie wel dat jullie altijd voor me klaarstaan!

Oma, wat fijn dat u deze dag nog mee kan maken. Ik hoop dat we nog vele jaren van u kunnen genieten.

Bas, als kind wilde ik altijd al een grote broer. Door jou heb ik er nu een! Ik hoop dat we snel de première van Shahnameh kunnen bijwonen.

Tamara, bedankt dat je mijn grote zus bent en ik altijd bij je terecht kan, of het nou om serieuze zaken of zoiets als een concert van de Backstreet Boys gaat. Ik hoop dat de Disney-avondjes snel weer mogelijk zijn. Reinout, Veerle en Hannah, jullie enthousiasme maakt me altijd blij. Verlies dat niet!

Lieve Evelien, sissie, vroeger mochten we dan vrijwel altijd ruzie hebben, dat is inmiddels gelukkig wel anders. Samen lachen, samen huilen, samen huilen van het lachen, met jou kan ik het allemaal. Een klein berichtje is vaak al meer dan genoeg om te laten weten dat je aan me denkt. Dennis, jij past perfect bij Evelien. Fijn dat jullie samen zo'n topteam zijn!

Ewoud, broeder, vroeger speelden we regelmatig samen met lego of k'nex. Tegenwoordig gaan we allebei meer onze eigen weg, maar ik ben blij dat jij mijn broertje bent. 
Lieve papa en mama, ik was het vroeger niet altijd eens met jullie regels, maar ik geloof dat ik vrij aardig terechtgekomen ben. Jullie hebben altijd in mij geloofd, me gesteund en geleerd om niet te snel tevreden te zijn. Als je iets echt wil, dan is er altijd wel een manier om je doel te bereiken. Dank jullie wel. En pap, sorry als ik het met mama te vaak over mijn werk heb. Ik zal proberen er op te letten.

Liefste Tobias, jij bent de reden dat dit boekje er nu eindelijk ligt. Met jou veilig in mijn buik, mocht ik niet in het ziekenhuis werken en had ik ineens tijd om dit proefschrift tot een goed einde te brengen. Dank je wel, lieverd. Papa en mama missen je ontzettend!

Lieve Tommie, jou kan ik niet genoeg bedanken. Dat jij er altijd in bent blijven geloven dat ik mijn promotie zou afmaken en dat het uiteindelijk met mijn opleiding tot chirurg goed zou komen, onderstreept jouw oneindige vertrouwen in mij. Door jou heb ik de gok durven nemen om mijn carrière in Duitsland voort te zetten. Dank je wel dat je mij alle ruimte geeft om mijn dromen achterna te jagen. Ik weet dat wij samen alles aankunnen. Jij maakt me iedere dag aan het lachen, met je soms goede, maar regelmatig ook minder goede (woord-)grappen. Nu dit proefschrift af is en ik in ieder geval op papier de slimste in huis ben, heb ik weer tijd om naar al je grappen te luisteren. Ik houd van je! 


Curriculum Vitae 



\section{Curriculum Vitae}

Leontine Charlotte Louise van den Hil was born on the 26th of February 1989 in 's-Gravendeel, the Netherlands. She spent her younger years in Heeze and graduated in 2007 from 'Scholengemeenschap Augustinianum' in Eindhoven. In the same year, Leontine started her study medicine at the Erasmus University Rotterdam. During her scientific internship under the supervision of Prof. dr. Vincent Jaddoe, her interest for scientific research was aroused. During her study, Leontine was fascinated by the field of general surgery and after graduation in 2014, she started this PhD project at Maastricht University Medical Center under supervision of Prof. dr. med. Nicole Bouvy and dr. Marc Schreinemacher. This PhD project was combined with a research project at the Universitätsklinikum Aachen, under supervision of dr. med. Christian Klink. In 2016, Leontine continued her career as a resident not in training (ANIOS) at the department of general surgery at the Maxima Medical Center in Veldhoven, followed by a job as resident not in training at the department of general surgery at the Elisabeth-Tweesteden Hospital in Tilburg. In 2020 she started her surgical residency in Maria Hilf Kliniken Mönchengladbach (Germany) under supervision of Prof. dr. Ulrich Kania and Prof. dr. med. Andreas Kirschniak. 
Appendices 
List of publications 



\section{List of publications}

1. Taal HR, van den Hil LC, Hofman A, van der Heijden AJ, Jaddoe VW. Genetic variants associated with adult blood pressure and kidney function do not affect fetal kidney volume. The Generation R Study. Early Hum Dev. 2012;88(9):711-6.

2. van den Hil LC, Rob Taal H, de Jonge LL, Heppe DH, Steegers EA, Hofman A, et al. Maternal first-trimester dietary intake and childhood blood pressure: the Generation R Study. Br J Nutr. 2013;110(8):1454-64.

3. Lambertz A, van den Hil LCL, Schob DS, Binnebosel M, Kroh A, Klinge $U$, et al. Analysis of adhesion formation of a new elastic thermoplastic polyurethane (TPU) mesh in comparison to polypropylene (PP) meshes in IPOM position. J Mech Behav Biomed Mater. 2016;53:366-72.

4. Vogels RRM, Kaufmann R, van den Hil LCL, van Steensel S, Schreinemacher MHF, Lange JF, et al. Critical overview of all available animal models for abdominal wall hernia research. Hernia. 2017;21(5):667-75.

5. Lambertz A, van den Hil LCL, Ciritsis A, Eickhoff R, Kraemer NA, Bouvy ND, et al. MRI Evaluation of an Elastic TPU Mesh under Pneumoperitoneum in IPOM Position in a Porcine Model. J Invest Surg. 2018;31(3):185-91.

6. van den Hil LCL, Vogels RRM, van Barneveld KWY, Gijbels MJJ, Peutz-Kootstra CJ, Cleutjens JPM, et al. Comparability of histological outcomes in rats and humans in a hernia model. J Surg Res. 2018;229:271-6.

7. van Steensel S, van den Hil LCL, Schreinemacher MHF, Ten Broek RPG, van Goor H, Bouvy ND. Adhesion awareness in 2016: An update of the national survey of surgeons. PLoS One. 2018;13(8):e0202418.

8. van den Hil LCL, van Steensel S, Schreinemacher MHF, Bouvy ND. Prophylactic mesh placement to avoid incisional hernias after stoma reversal: a systematic review and meta-analysis. Hernia. 2019;23(4):733-41.

9. van Steensel S, Bloemen A, van den Hil LCL, van den Bos J, Kleinrensink GJ, Bouvy ND. Pitfalls and clinical recommendations for the primary lumbar hernia based on a systematic review of the literature. Hernia. 2019;23(1):107-17.

10. van den Hil LCL, Mommers EHH, Bosmans J, Morales-Conde S, Gomez-Gil V, LeBlanc K, et al. META Score: An International Consensus Scoring System on MeshTissue Adhesions. World J Surg. 2020;44(9):2935-43.

11. van Steensel S, van den Hil LCL, Bloemen A, Gijbels MJ, Breukink SO, Melenhorst J, et al. Prevention of incisional hernia using different suture materials for closing the abdominal wall: a comparison of PDS, Vicryl and Prolene in a rat model. Hernia. 2020;24(1):67-78.

12. Lier EJ, van den Beukel BAW, Gawria L, van der Wees PJ, van den Hil L, Bouvy ND, et al. Clinical adhesion score (CLAS): development of a novel clinical score for adhesion-related complications in abdominal and pelvic surgery. Surg Endosc. 2021;35(5):2159-68. 
Appendices 